

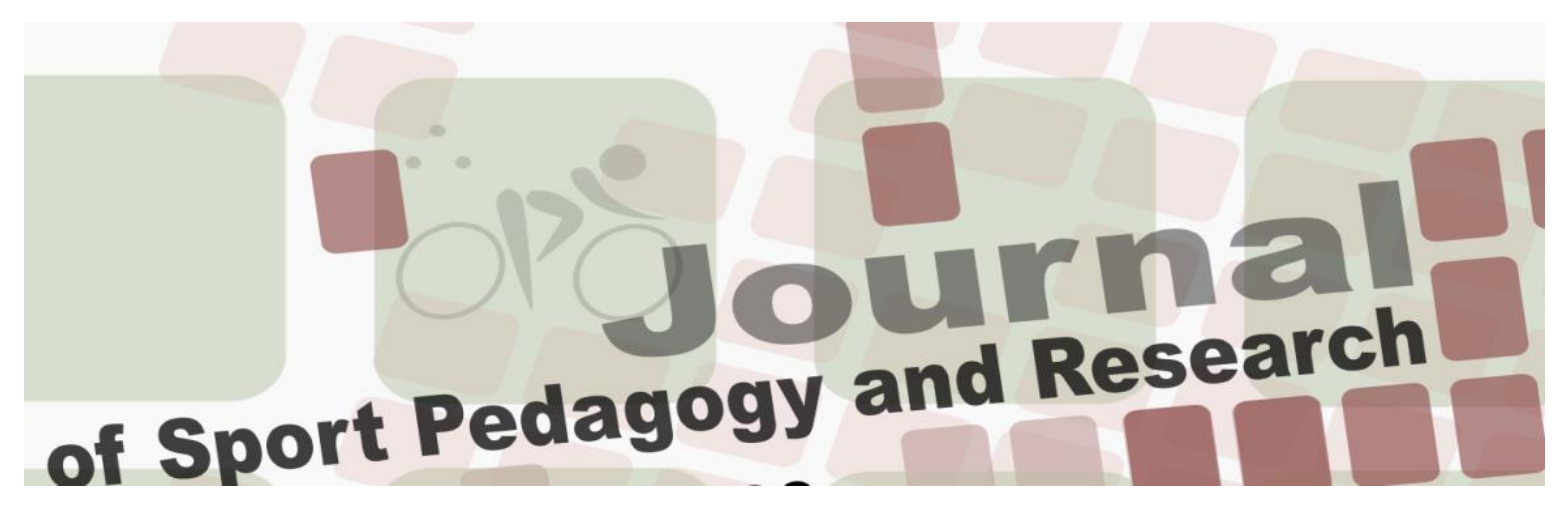

Diretor Editorial - Rui Resende (ISMAI)

Diretor Editorial Adjunto

- Hugo Sarmento (FCDEF-UC/CIDAF)

- Adilson Marques (FMH-UL)

- Paula Batista (FADE-UP)

Secretária Direção - Liliana Fontes

\section{Conselho Editorial}

Ágata Aranha (UTAD-Portugal), Alcides Scaglia (UNICAMP-Brasil), Antonino Pereira (ESEV-IPV-Portugal), Carlos Zuluaga (Universidad de Caldas-Colômbia), Cecília Borges (Universidad Montreal-Canadá), Gelcemar Farias (UDESC-Brasil), Hélder Lopes (UMAPortugal), José Rodrigues (ESDRM-IPSantarém-Portugal), Juarez Nascimento (UFSCBrasil), Larissa Benites (UDESC-Brasil), Larissa Galati (UNICAMP-Brasil), Miguel Saavedra (UDC-Espanha), Nuno Pimenta (IPMAIA-Brasil), Ricardo Lima (IPVCPortugal), Roberto Hernández (Universidad Autonoma-Chile), Rui Gomes (Universidade do Minho-Portugal), Samuel Neto (UNESP-Brasil), Sérgio Ibanez (UNEX-Portugal), Vitor Ferreira (FMH-UL-Portugal).

\section{Edição}

Sociedade Científica de Pedagogia do Desporto (SCPD)

Capa - Mariana Moreira

ISSN 1647-9696 
O JSPR congratula-se pela sua terceira edição no corrente ano. Iniciou com o número especial de Desporto de Natureza e com o número especial como os resumos submetidos ao XIII Congresso Internacional de Avaliação Formativa em Educação - Boas práticas de avaliação formativa em todas as etapas educativas e que decorreu entre os dias 24 e 26 de junho na Universidade de Coimbra, Faculdade de Ciências do desporto e Educação Física. Aguarda-se com expetativa o $9^{\circ}$ congresso da Sociedade Científica de Pedagogia denominado ao tema Inovação e Tecnologia no Desporto e que irá decorrer nos dias 15 e 16 de Outubro na Escola Superior de Educação e Ciências Sociais, do Politécnico de Leiria.

JSPR welcomes its third edition this year. It started with the special issue of Nature Sport and with the special issue with the abstracts submitted to the XIII International Congress of Formative Evaluation in Education - Good practices of formative evaluation in all educational stages that took place between 24 and 26 June at the University of Coimbra, Faculty of Sports Sciences and Physical Education. The 9th congress of the Scientific Society of Pedagogy called innovation and technology in sport is expected to take place on October 15 and 16 at the Higher School of Education and Social Sciences, of the Polytechnic of Leiria.

JSPR da la bienvenida a su tercera edición de este año. Comenzó con el número especial de Nature Sport y con el número especial como los resúmenes presentados al XIII Congreso Internacional de Evaluación Formativa en Educación - Buenas prácticas de evaluación formativa en todas las etapas educativas y que tuvo lugar entre el 24 y el 26 de junio en la Universidad de Coímbra, Facultad de Ciencias del Deporte y Educación Física. Está previsto que el $9^{\circ}$ congreso de la Sociedad Científica de Pedagogía denominado innovación y tecnología en el deporte tenga lugar los 15 y 16 de octubre en la Escuela Superior de Educación y Ciencias Sociales, del Politécnico de Leiria.

\author{
Rui Resende \\ Hugo Sarmento \\ Adilson Marques \\ Paula Batista
}




\title{
Conteúdos de aprendizagem do judô: da prática tradicional às novas abordagens pedagógicas
}

\author{
Carolina Cirino $^{1}$, Marcos Paulo Vaz de Campos Pereira ${ }^{2}$ \\ ${ }^{1}$ Universidade Estadual de Campinas - Brasil \\ ${ }^{2}$ Universidade do Estado de Santa Catarina - Brasil
}

\begin{abstract}
Palavras-chave Esportes de Combate; Pedagogia do Esporte; Ensino

\section{RESUMO:}

O judô é uma luta de origem japonesa que foi idealizado para fins educacionais, entretanto, o processo de esportivização ocasionou mudanças em sua prática pedagógica. Dessa forma, este estudo descritivo-reflexivo de caráter bibliográfico tem por objetivo apresentar novas abordagens pedagógicas para o ensino do judô a partir da contextualização da modalidade sob os aspectos históricos, filosóficos, educacionais, esportivos e técnicos. Esta revisão promove uma reflexão acerca da sistematização do judô, reunindo os conteúdos de aprendizagem como os aspectos históricos e filosóficos, a etiqueta do judô, as regras, os fundamentos técnicos, o vocabulário e os métodos de instrução. Além disso, destaca a problemática do ensino tradicional e aponta novas abordagens pedagógicas, sugerindo elementos norteadores que resgatem o significado da idealização do judô.
\end{abstract}

\footnotetext{
Keywords Combat Sports; Sport Pedagogy; Teaching

Judo Learning Contents: from traditional practice to new pedagogical approaches

\section{ABSTRACT:}

Judo is a fight of Japanese origin that was idealized for educational purposes, however, the sporting process has brought about changes in its pedagogical practice. Thus, this descriptive-reflective study of a bibliographic character aims to present new pedagogical approaches to the teaching of judo from the contextualization of the modality under the historical, philosophical, educational, sports and technical aspects. This review promotes a reflection on the systematization of judo, bringing together learning contents such as historical and philosophical aspects, judo etiquette, rules, technical foundations, vocabulary, and instructional methods. In addition, it highlights the issue of traditional teaching and points out new pedagogical approaches, suggesting guiding elements that recover the meaning of the idealization of judo.
} 


\section{Conteúdos de aprendizagem do judô: da prática tradicional às novas abordagens pedagógicas}

O judô, uma luta criada por Jigoro Kano em 1882 a partir de formas antigas de combate japonês, tornouse uma modalidade difundida por todo o mundo, integrando o grupo de esportes olímpicos desde 1964 (International Judo Federation, 2021). A luta de judô é caracterizada pelo combate em pé com o objetivo de projetar o oponente e no solo com a possibilidade de finalização por meio de estrangulamentos, chaves de articulações e imobilizações (Martins et al. 2019; Olívio Junior \& Drigo 2019).

Jigoro Kano idealizou o judô para fins educacionais (Avelar \& Figueiredo, 2009; Mesquita, 2014), mas assim como outras modalidades, também sofreu um processo de esportivização. Além de mudanças nos conhecimentos técnicos, nas formas de ensino e na relação entre professores e alunos, este processo ocasionou modificações nos objetivos que levam à prática desta modalidade, primando pelo resultado esportivo (Brousse, 2001; Paes, 2010). Assim, a prática do judô está disseminada principalmente em clubes, academias e associações.

O foco na conquista de resultados e títulos pode conduzir o ensino das lutas, bem como no judô, apenas para a valorização da execução correta dos gestos técnicos e sequência de movimentos (Martins et al. 2019; Rufino, 2012). À vista disso, a negligência de determinados aspectos no processo de ensino pode levar ao conhecimento restrito ou até mesmo ao desconhecimento da história e dos princípios filosóficos da modalidade como aponta o estudo de Silva e Santos (2005) ao analisar o conhecimento destes aspectos e a aplicação da filosofia do judô durante a prática e no cotidiano.

Em uma investigação sobre perfil dos treinadores de judô foi observado que em relação às áreas de conhecimento para sua atuação profissional, os treinadores ressaltaram como mais importante, os conhecimentos técnicos do judô, seguidos dos demais conhecimentos específicos da modalidade e depois os conhecimentos referentes à área de Pedagogia do Esporte, apontando que os conhecimentos transmitidos essencialmente pela relação mestre e aluno continuam sendo os balizadores para a atuação desses treinadores (Cavazani et al, 2013). Entretanto, a Pedagogia do Esporte possui papel fundamental na atuação do profissional de judô, pois tem por finalidade "estudar a intervenção do processo ensinoaprendizagem-treinamento, bem como a organização, sistematização, aplicação e avaliação das práticas esportivas nos mais diversos cenários de manifestação (Galatti et al, 2014).

Perante este retrato, torna-se necessário uma reflexão em torno do trato pedagógico das aulas de judô, na intenção de resgatar os princípios que estruturaram a criação desta modalidade, visto que Jigoro kano idealizou o judô para ser aplicado como uma prática de educação física relacionada ao treinamento intelectual, à educação moral, à interação social e à vida cotidiana do cidadão (Jennings, 2017; Lopes et al., 2016; Mesquita, 2014; Kusnierz, Cynarski, \& Gorner, 2017).

Dessa forma, este estudo descritivo-reflexivo de caráter bibliográfico tem por objetivo apresentar novas abordagens pedagógicas para o ensino do judô a partir da contextualização da modalidade sob os aspectos históricos, filosóficos, educacionais, esportivos e técnicos.

\section{A Essência do Judô}

A partir da segunda metade do século XIX, o Japão passou por uma profunda transformação política social influenciada pela introdução do modelo ocidental de civilização, denominada Era Meiji (1867-1911) (Calleja, 1982). Neste período de modernização, os japoneses não se preocuparam em conservar suas tradições, tendo a desvalorização das artes marciais como uma de suas consequências (Carr, 1993). Nos períodos anteriores a Era Meiji, no Japão Feudal, os guerreiros praticavam o jujutsu que representada por dois caracteres chineses significa a "arte suave" (ju - suavidade e jutsu - arte, prática) (Kano, 1994). O Jujutsu se caracterizava pelos diferentes estilos de luta, em combates corpo a corpo, utilizando as próprias mãos (Mesquita, 2014; Virgílio, 1994). Tradicionalmente, estes estilos de luta primavam pelo combate, a disciplina e a moral, onde o verdadeiro espírito do jujutsu era lutar até a morte (Calleja, 1982). Com o intuito de desenvolver a moral e o autocontrole, Jigoro kano abandona o espírito do jujutsu pelo conceito de "Do" (caminho, princípio), que valorizava a beleza do movimento com o mínimo de força, uma vez que já não existia mais a necessidade de desenvolvimento técnico da luta em razão do período de paz no Japão (Carr, 1993). Partindo desta transformação moral e filosófica, nasce o Judô Kodokan que significa "o caminho da suavidade" (Kano, 1994). Jigoro Kano utilizou este termo para diferenciar o seu estilo de outra escola que também utilizava o termo judô (Calleja, 1982). Este novo modo de lutar teve como grande objetivo contribuir para a educação integral do ser humano (Santos, 2014). Assim, durante seu processo de desenvolvimento, o judô teria sua base estruturada especialmente nos princípios do ju (suavidade), "Do" (caminho), jita kyoei (prosperidade e benefício mútuo) e Seiryoku Zen’yo (máxima eficiência com o mínimo esforço) (Santos, 2014).

Os ideogramas que formam a palavra judô tiveram suas raízes no Taoísmo em que "ju” representava o conceito de ceder para vencer ou vencer a brutalidade gentilmente (Santos, 2014) e o conceito de "Do" pode ser entendido como o próprio caminho da vida (Kano, 1994), possibilitando ao ser humano a autoanálise da consciência (Mesquita, 2014). O princípio Jita Kyoei foi influenciado pelos conceitos do Confucionismo de benevolência, respeito e benefício aos outros, onde 
"Jita Kyo" exprimi a cooperação com outros e "ei" define-se como êxito, fundamentando a máxima "prosperidade e benefício mútuo" (Santos, 2014). Também influenciado pelo Confucionismo, o princípio Seiryoku Zen'yo é definido por Jigoro Kano como o princípio básico do judô, em que o significado do melhor uso da energia pessoal em todos os aspectos da vida, busca a aplicação nos treinamentos intelectual, moral e marcial do judô (Souza, Cardias, \& Franchini, 2007). Dessa forma, por meio destes princípios, Jigoro Kano buscou desenvolver uma nova forma de lutar que promovesse ao praticante de judô a compreensão do seu desenvolvimento diante da sociedade (Mesquita, 2014).

Jigoro kano, no desejo de promover o autoconhecimento, idealizou o judô ao perceber que os praticantes de lutas só conheciam seu próprio estilo e que não compreendiam o funcionamento das técnicas de combate, passando a estudar diversos estilos de luta com a finalidade de entender o princípio da eficiência das técnicas utilizadas no combate, para posteriormente, selecionar e classificar as melhores. Juntamente, com a classificação das melhores técnicas, Jigoro Kano estruturou a base técnica do judô em quedas (ukemis), posturas (shisei), deslocamentos (shintai), pegadas (kumikatas), desequilíbrios (kuzushi), preparação da técnica (tsukuri) e projeção (kake) (Kano, 1994; Mesquita, 2014). A luta de judô tem por objetivo de combate arremessar o oponente com velocidade e controle, podendo imobilizá-lo, estrangulá-lo ou aplicar uma chave de articulação (Brousse \& Matsumoto, 1999).

Assim o ápice da luta é a projeção do oponente, no entanto, para a segurança dos praticantes absorvendo o impacto dos golpes, o primeiro fundamento a ser ensinado no judô são as quedas (Kano, 1994). No combate, as posturas são importantes para se posicionar diante do oponente no momento da projeção ou para se defender durante o ataque. Os deslocamentos favorecem o desequilíbrio e o uso correto das técnicas de projeção. Este fundamento explora a força do adversário, aplicando o princípio da máxima eficiência com a mínima força. As pegadas são as formas de segurar no kimono (judogui) do oponente e foi um dos fundamentos técnicos que mais se modificou ao longo da evolução do judô, demonstrando que para dominar o combate, o judoca deve prevalecer a sua pegada. Em conjunto com os deslocamentos e a pegada, o desequilíbrio promove o uso inteligente da força, deixando o oponente vulnerável no momento do ataque (Mesquita, 2014).

A preparação para a técnica ocorre depois do desequilíbrio, onde o judoca se posiciona para a projeção (Kano, 1994), induzindo o oponente a uma emboscada para ter sucesso na projeção da técnica (Mesquita, 2014). As técnicas de projeção (nagewaza), que cumprem o objetivo do combate da luta em pé foram divididas em técnicas em pé (tachi- waza) e em técnicas de sacrifício (sutemi-waza) em que o judoca sacrifica a sua posição, projetando-se antes para arremessar o oponente (Kano, 1994). As técnicas em pé foram classificadas de acordo com as principais alavancas de pernas (ashi-waza), braços (te-waza) e quadril (koshi-waza). As técnicas de sacrifício foram classificadas de acordo com a direção da projeção, pela frente (ma-sutemi-waza) e lateralmente (Yoko-sutemi-waza) (Mesquita, 2014). Além das técnicas de projeção, Jigoro Kano classificou as técnicas de solo (katame-waza) em imobilização (osae-komi-waza), estrangulamento (shime-waza) e chaves de articulação (kansetsuwaza) (Kano, 1994).

A partir destes estudos, constituiu normas para o aprendizado e também criou regras para um combate, fundamentando-se no espírito de ippon-shobu (luta pelo ponto completo), em que o objetivo principal não seria a vitória e sim a prática da atividade física para a educação integral do ser humano (Calleja, 1982).

Portanto, para a prática do judô como atividade física, Jigoro kano sistematizou o método de educação física baseado em exercícios individuais, utilizando socos e chutes, e como defesa pessoal realizado em duplas Seiryoku Zenyo Kokumin Taiku, ou a Educação Física Nacional de Máxima Eficiência. Este método buscava promover o desenvolvimento da força e da saúde; ser interessante e ter utilidade (Kano, 1994). Com o objetivo de proporcionar o desenvolvimento físico, intelectual e moral Jigoro Kano apresentou quatro métodos de ensino (Oimatsu, 1984): (1) kata (formas); (2) Randori (prática livre); (3) Mondo (perguntas e respostas); (4) kogi (leituras).

Para Jigoro Kano (1994) o kata e o randori são os dois aspetos principais do treinamento de judô que busca o desenvolvimento do corpo e o treinamento das formas de ataque e defesa. O kata significa forma e é um sistema de movimentos pré-estabelecidos que ensina os fundamentos de ataque e defesa, onde cada parceiro sabe o movimento que o outro vai fazer. A Kodokan reconhece oito formas de kata (Federação Paulista de Judô, 2019): nage no kata (formas de arremesso); katame no kata (formas de domínio no solo); kime no kata (formas de decisão); kodokan goshin jutsu (defesa pessoal do kodokan); ju no kata (formas suaves ou flexíveis); itsutsu no kata (as cinco formas); koshiki no kata (formas antigas); seryoku zen'yo kokumin taiiku no kata (formas da educação física nacional baseado no princípio da máxima eficiência). O kata tem sido muito utilizado como requisito para a promoção para a graduação de faixas pretas (Souza, Cardias, \& Franchini, 2007).

O randori é a prática livre entre uma dupla de parceiros representando uma luta real. Para o máximo benefício da prática do randori é fundamental que ambos os praticantes tomem cuidado para não machucar um ao outro, prevalecendo a etiqueta do judô (Kano, 1994). No entanto, atualmente, o randori é utilizado como método de treinamento com o 
objetivo voltado para a competição na maioria dos locais de prática do judô. Além destes aspectos, Jigoro kano propôs os métodos Mondo e Kogi onde a ênfase do ensino seria nos estudos e reflexões sobre o judô. O método mondo refere-se a perguntas e respostas sobre a técnica, a etiqueta no dojô e a vida social, promovendo a reflexão sobre os ensinamentos do judô em todos os aspectos. Kogi inclui um estudo mais profundo do judô envolvendo história, fundamentos, treinamento por meio de leituras e aulas (Souza et al., 2007). Portanto, o ensino do judô vai além do domínio dos fundamentos técnicos, exigindo a reflexão dos princípios que estruturaram este método educacional que, por sua vez, retratam sua essência compreendida na sua evolução histórica.

\section{Conteúdos de Aprendizagem do Judô}

Para atender os propósitos de Jigoro Kano de contribuir para a educação integral do ser humano (Santos, 2014), respeitando a essência do judô e ressignificando sua prática pedagógica, torna-se necessária a organização dos conteúdos de forma que resgate os princípios do judô e favoreça a compreensão da luta.

Os conteúdos do judô estão intimamente vinculados ao sistema de graduação por faixas de diferentes cores, uma vez que as faixas representam o nível de prática da modalidade. De acordo com a Confederação Brasileira de Judô (2019), o sistema de graduação é dividido em três níveis: (1) Dangai: subdividido em nível básico (da faixa branca à faixa amarela/laranja) e nível intermediário (da faixa laranja à faixa marrom); (2) Yudansha: refere-se ao nível graduado (faixas pretas do $1^{\circ}$ ao $5^{\circ}$ grau); (3) Kodansha: refere-se à graduação superior (da faixa vermelha e branca $-6^{\circ}$ ao $8^{\circ}$ grau e faixa vermelha $9^{\circ}$ e $10^{\circ}$ graus). A responsabilidade de outorga de faixas e graus está dividida respeitando os níveis de graduação. Para o nível Dangai as faixas são outorgadas sob a responsabilidade do professor pelas Associações ou entidades similares reconhecidas pelas federações.

No nível graduado, os graus são outorgados após exame teórico e prático realizado pela Comissão Estadual de Graduação. Para a graduação superior, o $6^{\circ}$ grau é conferido pela $\mathrm{CBJ}$, já o $7^{\circ}$ grau é homologado pela Confederação Panamericana de Judô e a partir do $8^{\circ}$ até o $10^{\circ}$ grau a homologação é de responsabilidade da Federação Internacional de Judô (Confederação Brasileira de Judô, 2019). Entretanto, os conteúdos serão organizados para o nível de graduação entre as faixas branca e marrom, uma vez que este estudo é direcionado principalmente para a prática pedagógica dos professores de Associações, clubes e academias.

Segundo Zabala (1998, p. 30), conteúdo é “tudo quanto se tem que aprender para alcançar determinados objetivos". Os conteúdos vinculados ao sistema de graduação propostos pela Confederação Brasileira de Judô (2019) referem-se aos aspectos históricos e filosóficos que fundamentam os princípios da modalidade e as técnicas sistematizadas por Jigoro Kano que foram revisadas em 1908 e 1920 e atualizadas com poucas modificações em 1982 e 1997. Contudo, entende-se que os conteúdos de aprendizagem do judô devem ser abordados sob os Aspectos Históricos e Filosóficos, Etiqueta, Regras, Fundamentos Técnicos, Vocabulário e Métodos de Instrução (Figura 1).

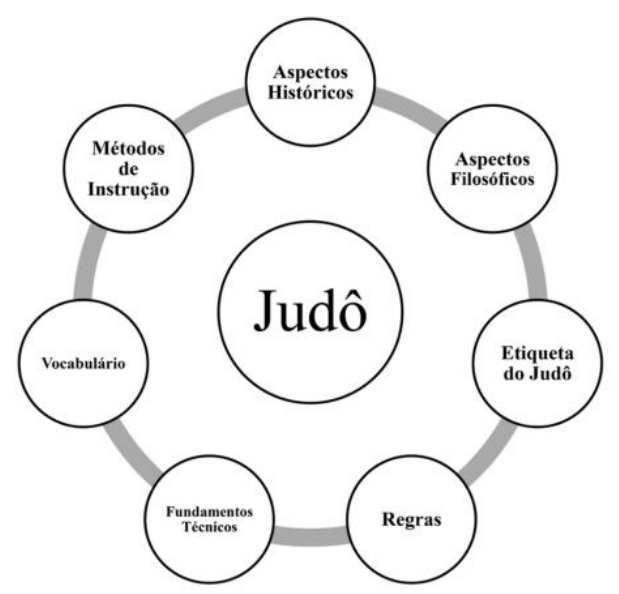

Figura 1. Conteúdos de Aprendizagem do Judô

Todos os conteúdos inerentes do judô são interligados e dependentes, portanto, quando um conteúdo é negligenciado, seu entendimento e sua prática tornam-se superficiais, prejudicando o desenvolvimento do praticante. A abordagem dos aspectos históricos e filosóficos permite a compreensão da essência do judô, ou seja, dos alicerces que norteiam esta luta independente do objetivo e do ambiente que seja praticado. Em relação à etiqueta, as saudações, cumprimentos e condutas particulares da prática cotidiana do judô dão significado aos princípios filosóficos. Para o praticante compreender o combate é necessário que ele aprenda as regras e os fundamentos técnicos que possibilitam a vivência na prática de todo o significado do judô. $\mathrm{O}$ aprendizado do vocabulário também é fundamental para assimilar o que está sendo ensinado e torna a língua do judô universal. Além disso, os métodos de instrução criados por Jigoro Kano levam a prática do judô à sua totalidade, tornando o judoca conhecedor e crítico da sua prática. Os conteúdos de aprendizagem organizados referemse ao nível básico e intermediário, de acordo com a proposta da Confederação Brasileira de Judô (2019) e correspondem aos níveis entre a faixa branca e faixa marrom. Por esta razão, entende-se que a prática do judô ainda vai além dos conteúdos aqui abordados. Além de sistematizar as técnicas e os métodos de instrução para o ensino do judô, Jigoro Kano estabeleceu três níveis a serem alcançados sob os aspectos marciais, do cultivo intelectual/mental e moral pessoal, e da energia em benefício da 
sociedade. O nível denominado inferior refere-se aos aspectos marciais da defesa pessoal, onde Jigoro Kano pensava na integração com outros caminhos marciais, relembrando a importância do treinamento como defesa pessoal contra as armas, e se possível desde criança, com implementos de materiais alternativos, por questões de segurança. No nível intermediário, além dos aspectos educacionais físicos, os aspectos intelectuais, a educação moral e as questões pessoais da vida diária são integradas à prática para consciência dos princípios do judô.

No nível superior é a aplicação do princípio seiryoku zen'yo nas dimensões física, pessoal e social, ou seja, o bom uso da energia cultivada nos aspectos marciais, psicofísicos e sociais, aplicada para o aprimoramento da humanidade. Estes níveis determinados por Jigoro Kano muitas vezes são esquecidos ou mesmo desconhecidos pelos praticantes (Souza et al., 2007). Com isso, surge a reflexão sobre os conteúdos abordados nas aulas de judô, apontando o contexto pedagógico atual da modalidade. Os conteúdos de aprendizagem estão caracterizados no Quadro 1. 
Quadro 1. Conteúdos de Aprendizagem do Judô

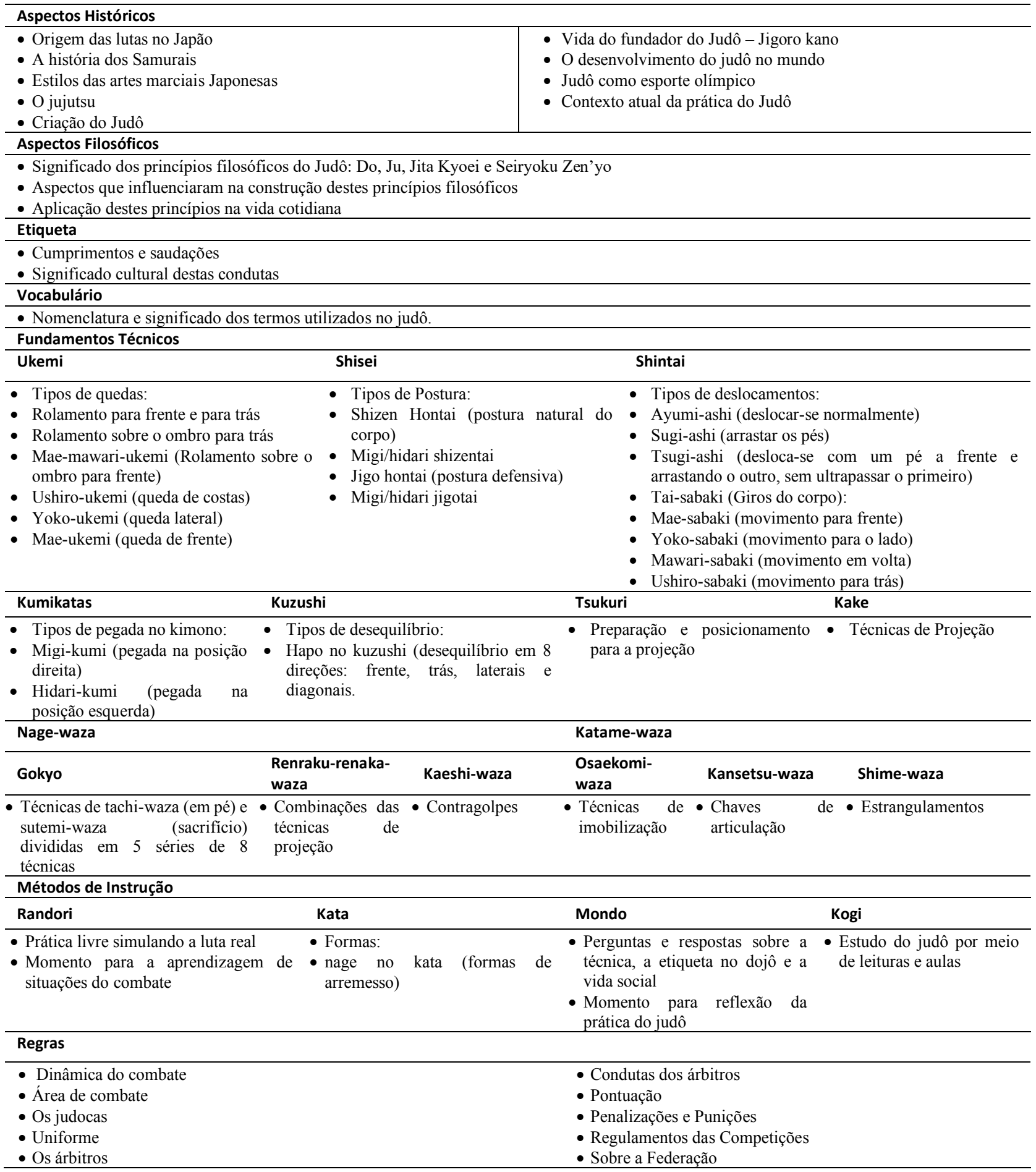




\section{A Prática Tradicional do Judô}

O judô foi criado como método educacional (Mesquita, 2014), pelo qual os praticantes deveriam aplicar os princípios aprendidos durante a prática do judô em sua vida diária e em benefício da sociedade (Brousse \& Matsumoto, 1999; Kusnierz et al., 2017). No contexto atual, em que as atuais tendências em Pedagogia do Esporte têm como foco principal o indivíduo em interação com a prática, como sujeito ativo no processo de construção de seu conhecimento (Galatti et al, 2014; Leonardi et al., 2014; Scaglia, Reverdito, \& Galatti, 2014) encontramos consonância com as ideias de Jigoro kano, percebendo que o nascimento do judô contrapôs os aspectos tradicionais da época, em consequência da sua modernidade (Franchini \& Del'Vecchio, 2007). Embora Jigoro Kano tenha sistematizado seus conteúdos e os métodos de ensino do judô, ocorreram muitas mudanças metodológicas no seu ensino, devido o processo de esportivização após a criação da FIJ (Federação Internacional de Judô) em 1951 (Brousse, 2001). Esse processo de esportivização que ocorreu com as lutas passou a valorizar a conquista de resultados e títulos em competições em detrimento dos princípios éticos e filosóficos dessas práticas corporais (Paes, 2010). Este fato contradiz os objetivos de Jigoro Kano quando passou a difundir o judô como prática educacional, demonstrando que a vitória do combate não era o foco principal do ensino do judô e sim primeiramente a prática da atividade física (Calleja, 1982).

Podemos identificar estas mudanças no ensino nos estudos de Rufino (2012) quando observou as aulas de quatro modalidades de lutas, incluindo o judô. $\mathrm{O}$ primeiro ponto relevante deste estudo foi em relação aos rituais e cerimônias, que no judô referem-se as saudações e cumprimentos, ainda presentes nas aulas mesmo após o processo de esportivização, já que sua importância está atrelada à história das lutas, ou seja, fazem parte da essência destas práticas. Estas saudações nos momentos iniciais e finais das aulas, foram associadas pelo professor de judô como oportunidades de disciplinar os alunos. Na verdade, este momento poderia ser a oportunidade de refletir sobre os princípios filosóficos do judô, proporcionando principalmente o ensino do caminho "Do". Portanto, Rufino (2012) defende a permanência dos rituais e cerimônias nas aulas de lutas, mas devem ser ressignificados mediando o que é tradição e o que foi culturalmente adquirido, pois é necessário que os praticantes de lutas compreendam o propósito destes rituais tão distintos de suas realidades.

As lutas trazem consigo características específicas, partes integrantes de sua história que refletem suas tradições, sendo fundamentais para a prática pedagógica das aulas (Jennings, 2017). Em suas observações Rufino (2012) destacou a disciplina como parte das tradições, visto que foi um elemento muito evidenciado durante as aulas. Contudo, notouse que os professores, mesmo que de forma implícita, adotaram uma postura de superioridade, onde não houve desrespeito à hierarquia dos professores em relação aos alunos e quando ocorreu alguma desobediência, os alunos sofreram sanções. Ainda que a hierarquia faça parte da tradição da prática das lutas, esta não pode ser relacionada a castigos ou imposições, pois o aluno deve compreender que a hierarquia está associada ao nível de conhecimento e experiência do professor e que este deve ser o motivo pelo qual precisa ser respeitado.

Jigoro Kano ao idealizar o judô, criou os métodos de instrução Mondo e Kogi que possibilitavam a reflexão da prática pelos alunos (Souza et al., 2007), porém, nas observações realizadas por Rufino (2012) foram identificados apenas atitudes de conformidade, representando a passividade dos alunos perante as regras e imposições hierárquicas. Estas observações demonstram uma distorção das tradições por parte dos professores, uma vez que de acordo com Mesquita (2014) o judô foi idealizado para contribuir para a formação do ser humano.

Outro fator determinante observado por Rufino (2012) nas aulas de lutas foi o método de ensino tradicional focado somente na execução correta dos gestos técnicos por meio de sessões de repetição contínua e incessante. Além disso, as aulas foram ministradas de forma muito semelhante para adultos e crianças, ou seja, priorizando a repetição das técnicas estipuladas pelo professor, diferenciando somente durante as atividades realizadas de maneira lúdica no início e no final das aulas. Entretanto, a prática pedagógica que valoriza somente os gestos técnicos impede a compreensão adequada da lógica da luta, pois limita a aprendizagem dos aspectos táticos (Kozub \& Kozub, 2004; Kusnierz et al., 2017). Além disso, ao retomar a origem dos estudos de Jigoro Kano, pode-se verificar a preocupação com os lutadores, pois ao perceber a limitação da compreensão do funcionamento das técnicas, buscou entender a eficiência da execução das técnicas e idealizou métodos que facilitassem o aprendizado (Calleja, 1982). Assim, torna-se importante o resgate dos propósitos de Jigoro Kano ao idealizar o judô, a partir de uma ressignificação dos conteúdos em torno de atuais tendências em Pedagogia do Esporte que, primeiramente, preocupam-se com o praticante antes da execução da técnica (Galatti et al, 2014; Rufino, 2012; Scaglia et al., 2014).

Ao analisarmos o estudo de Silva, Tavares Junior, e Drigo (2008) que procurou identificar se o conhecimento produzido na área acadêmica está sendo aplicado na prática pedagógica do judô a partir da visão dos treinadores, pode-se compreender a problemática do ensino do judô, já que as aulas de judô ainda mantêm seu foco embasado no método tradicional de ensino das lutas. Neste estudo, participaram 17 treinadores de judô, onde 58.8\% não possuem formação universitária e dos que possuem 
formação universitária, apenas $29.4 \%$ são profissionais de Educação Física. Apesar dos treinadores considerarem os profissionais de educação como os mais importantes para a atuação na prática do judô, os pedagogos do esporte foram elencados apenas em $6^{\circ}$ lugar dentre todos os profissionais, ficando atrás de médicos, psicólogos, fisioterapeutas e fisiologistas (Silva, Tavares Junior, \& Drigo, 2008).

Esse desconhecimento da área da Pedagogia do Esporte e sua intervenção também se refletem na análise do grau de importância das áreas de conhecimento das ciências do esporte por treinadores de judô. Esses treinadores elegeram os conhecimentos específicos do judô, como história e fundamentos técnicos, sendo mais importantes que Pedagogia do Esporte e Treinamento Esportivo, demonstrando a tradição da modalidade pela valorização dos conhecimentos relacionados à graduação de faixa preta (Cavazani et al, 2013; Silva et al., 2008).

Com base nos tópicos abordados nas aulas de judô, torna-se evidente a necessidade de novas abordagens pedagógicas que ressignifiquem o ensino de judô, abordando os objetivos da criação do judô, com suas tradições e princípios, respeitando o processo de desenvolvimento do aluno na prática da modalidade.

\section{Novas Abordagens Pedagógicas para o Ensino do Judô}

Contrapondo o ensino tradicional, caracterizado pela reprodução de gestos sem significado e por métodos de treinamento pautados na repetição exaustiva e realizados da mesma forma para adultos e crianças (Paes, 2010; Rufino e Darido, 2012), as novas abordagens de ensino do judô devem ser fundamentadas nos referenciais teóricos da Pedagogia do Esporte, neste caso voltados para o ensino das lutas (Galatti et al, 2015), considerando três aspectos: i. o Técnico-tático, em que no judô refere-se aos fundamentos técnicos e a demanda física do combate; ii. O Socioeducativo baseado nos princípios éticos e filosóficos do judô; iii. E o Histórico-cultural que considera a origem e evolução do judô, englobando conteúdos como a etiqueta do judô, vocabulário, regras e métodos de instrução.

A partir desses referenciais teóricos da Pedagogia do Esporte, podemos ressignificar a prática do randori nas aulas de judô considerando os princípios condicionais das lutas que valoriza a percepção da dinâmica da luta e a elaboração de estratégias táticas durante o combate para as etapas de iniciação na modalidade (Gomes et al, 2010). Portanto, considerando estes princípios propostos por Gomes et al (2010), o ensino dos fundamentos do judô deve estar relacionado ao contato proposital com o oponente, à fusão ataque/defesa e à imprevisibilidade geradas pelas ações simultâneas, ao alvo móvel personificado no oponente e às regras que regem a dinâmica do combate. Entretanto, em um contexto mais específico, Olivio Junior \& Drigo (2015) dividem as ações da luta de judô em unidades funcionais que refletem as situações do combate para criar janelas de oportunidade para a aplicação de técnicas de projeção na tentativa de alcançar a pontuação no combate. Essa proposta também promove o aprendizado pela elaboração de estratégias de combate, facilitando a ampliação do repertório técnico a partir da tática (Olivio Junior \& Drigo, 2015).

O ensino dos fundamentos do judô pelas situações de combate, possibilitando a elaboração de estratégias táticas pode ser desenvolvido por meio de jogos, visto suas características sistêmicas que envolvem aleatoriedade, organização e interação como um fenômeno dinâmico e não-linear, com múltiplas conexões (Reverdito \& Scaglia, 2007). Ademais, o ensino do judô pelo jogo favorece a compreensão do combate não apenas por suas ações, mas por seus aspectos históricos e culturais, desenvolvendo a autonomia de seus praticantes e resgatando os princípios éticos e filosóficos do judô (Galatti et al, 2015).

Tendo em vista o sistema de graduação do judô por faixas relatado anteriormente e a complexidade do processo de aprendizagem das lutas, a avaliação do judô não deve ficar restrita à julgamentos pontuais de fundamentos técnicos, mas deve ser realizada de forma processual, oferecendo significado à prática a partir da indicação do progresso e das limitações dos alunos, buscando formas de contribuir para sua formação (Rufino, 2014). Dessa forma, a avaliação deve ser parte integrante do processo de ensinoaprendizagem, deixando claro que embora a evolução do aluno esteja condicionada ao sistema de graduação por faixas, o seu nível de conhecimento deve ser comparado a si próprio e não com a graduação de outros alunos (Rufino e Darido, 2012).

Respeitando o contexto cultural do judô e seus diversos cenários de prática, a sistematização de seus conteúdos de aprendizagem pode ser proposta de forma flexível e não linear como descrevem Pereira et al (2017), planejando o ensino em um modelo de rede complexa que valoriza os aspectos em comum a cada conteúdo, e consequentemente, facilita a ação didática do professor e o aprendizado do aluno. Por fim, para que o praticante possa compreender o significado da prática do judô, o professor deve ser o mediador do conhecimento para que o aluno conquiste sua autonomia (Galatti et al, 2014; Scaglia et al., 2014;).

\section{Reflexões Finais}

A contextualização do judô desde seus aspectos históricos, conteúdos de aprendizagem até sua prática tradicional, permite a compreensão dos aspectos culturais da modalidade que refletem as características de suas manifestações, levantando 
reflexões sobre a problemática do ensino tradicional, em que valoriza apenas o resultado esportivo e negligência os aspectos filosóficos e históricos.

Diante do contexto atual desse trato pedagógico, reunimos novas abordagens de ensino do judô para fundamentar as aulas dos professores de Associações, academias e clubes. Esta revisão não pretende impor propostas rígidas para o ensino, mas tem por finalidade sugerir elementos norteadores que resgatem o significado da idealização do judô, principalmente, a partir dos aspectos históricos e filosóficos que estruturam esta luta como método educacional.

\section{Referências}

Avelar, B., \& Figueiredo, A. (2009). La iniciación a los deportes de combate: Interpretación de la estructura del fenómeno lúdico luctatorio. Revista de Artes Marciales Asiáticas, 4(3), 4457. doi: 10.18002/rama.v4i3.177

Brousse M. (2001). Les origines du judo en France, de la fin du XIXe siècle aux années 1950: Histoire d'une culture sportive. Organisme de Soutenance, Université de Bordeaux.

Brousse M., \& Matsumoto, D. (1999). Judo: A sport and a way of life. International Judo Federation.

Calleja, C. (1982). Caderno técnico-didático: Judô. MEC.

Carr, K. (1993). Making way: War, philosophy, and sport in Japanese judo. Journal of Sport History, 20(2), 167-188.

Cavazani R., Cesana J., Silva L., Cressoni F., Tavares Junior A., Aranha A., \& Drigo A. (2013). O técnico de judô: Um estudo comparativo após 10 anos da regulamentação da educação física. Revista Brasileira de Ciência e Movimento, 21(3), 105-117. doi: $10.18511 / \mathrm{rbcm} . \mathrm{v} 21 \mathrm{i} 3.3679$

Confederação Brasileira de Judô. (2019). Regulamento para exame e outorga de faixas e graus. Brasil: Confederação Brasileira de Judô.

Federação Paulista de Judô. (2019). Manual técnico de Nage No Kata. São Paulo: Federação Paulista de Judô.

Franchini E., \& Del'Vecchio, F. (2007). Tradição e modernidade no judô: Histórico e implicações. In: Rubio K. (eds.). Ética e compromisso social nos estudos olímpicos (pp. 121-145). Editora PUC- RS.

Galatti, L., Reverdito, R., Scaglia, A., Paes, R., \& Seoane, A. (2014). Pedagogia do esporte: Tensão na ciência e o ensino dos jogos esportivos coletivos. Revista da Educação
Física, 25(1), 153-162. doi: 10.4025/reveducfis.v25i1.21088

Galatti, L.; Cirino, C. \& Scaglia, A. (2015). Reflexões metodológicas do ensino para o processo de iniciação esportiva das lutas. In: J. Nascimento, E. Souza, V. Ramos, \& J. Rocha, (Orgs.). Educação física e esporte: Convergindo para novos caminhos... (p. 489511). UDESC.

Gomes, M. S., Morato, M. P., Duarte, E., \& Almeida, J. J. (2010). Ensino das lutas: Dos princípios condicionais aos grupos situacionais. Movimento, 16(2), 207-227. doi: $10.22456 / 1982-8918.9743$

International Judo Federation. (2021). History. https://www.ijf.org/history

Jennings G. (2017). Martial arts pedagogies and practice: A report on the contributions to coaching knowledge. Revista de Artes Marciales Asiáticas, 12(2), 101-105. doi: http://dx.doi.org/10.18002/rama.v12i2.5152.

Kano, J. (1994). Kodokan Judô. Japão: Kodansha International.

Kozub F., \& Kozub M. (2004). Teaching combative sports through tactics. Journal of Physical Education, Recreation and Dance, 75(8), 1621.

Kusnierz C., Cynarski W. J., \& Gorner K. (2017). Social reception and understanding of combat sports and martial arts by both school students and adults. Ido Movement for Culture. Journal of Martial Arts Anthropology, 17(1), 30-37. doi:0.14589/ido.17.1.5

Leonardi T., Galatti, L., Paes, R., \& Seoane A. (2014). Pedagogia do esporte: Indicativos para o desenvolvimento integral do indivíduo. Revista Mackenzie de Educação Física e Esporte, 13, 1, 41-58.

Lopes, H., Vicente, A., Simões J., Vieira, M., \& Fernando, C. (2016). The pedagogical process in combat sports. Journal of Sport Pedagogy and Research, 2(3), 48-52.

Martins F. P., Souza L. S., Campos R. P., Bromley S. J., Takito M. Y., \& Franchini E. (2019), Techniques utilized at 2017 Judo World Championship and their classification: Comparisons between sexes, weight categories, winners and non-winners. Ido Movement for Culture. Journal of Martial Arts Anthropology, 19(1), 58-65. doi: 10.14589/ido.19.1.6.

Mesquita C. (2014). Judô...da reflexão à competição: O caminho suave. Galenus. 
Oimatsu S. (1984). The way of seiryoku zenyo - jita kyoei and its instructions. The Bulletin for the Scientific Study of Kodokan Judo, 6(1), 3-8.

Olívio-Junior, J. A., \& Drigo, A. J. (2015). Pedagogia complexa do Judô: Um manual para treinadores de equipes de base. Leme: Mundo Jurídico, 157.

Paes R. (2010). Desenvolvimento das aulas de lutas: Da compreensão teórica aos procedimentos práticos. In: Breda M., Galatti L., Scaglia A., \& Paes, R. (eds.), Pedagogia do Esporte aplicada às Lutas (49-72). Editora Phorte,

Pereira, M. P., Cirino, C., Correa, A. O., \& Farias, G. O. (2017). Lutas na escola: Sistematização do conteúdo por meio da rede dos jogos de lutas. Conexões, 15(3), 338-348.

Reverdito, R. S., \& Scaglia, A. J. (2007). A gestão do processo organizacional do jogo: Uma proposta metodológica para o ensino dos jogos coletivos. Motriz. 51-63.

Rufino L. (2012). Pedagogia das lutas: Caminhos e possibilidades. Paco Editorial.

Rufino, L. G. (2014). Lutas. In: F. J. González, S. C. Darido, A. A. Oliveira \& L. C. Silva (Orgs.) Lutas, capoeira e práticas corporais de aventura (p. 31-65). UEM.

Santos S. (2014). Orientações filosófico-educativas do Judô Kodokan na perspectiva da integração Oriente-Ocidente. Cadernos de educação, 13(26), 159-180.

Scaglia A., Reverdito R., \& Galatti L. (2014). A contribuição da pedagogia do esporte ao ensino do esporte na escola: Tensões e reflexões metodológicas. In: A. Marinho, J. Nascimento \& A. Oliveira (Eds.), Legados do Esporte Brasileiro (pp. 45-86). Editora UDESC.

Silva D., \& Santos S. (2005). Princípios filosóficos do judô aplicado à prática e ao cotidiano. EFDeportes, 10(1), 86-87.

Silva L., Tavares Junior A., \& Drigo A. (2008). Produção científica no judô: Da academia às academias. Conexões, 6(1), 665-677.

Souza G., Cardias F., \& Franchini E. (2007). Contribuições do Judô à educação olímpica e responsabilidade social. In: K. Rubio (Ed.). Educação olímpica e responsabilidade social (pp. 171-189). Casa do Psicólogo.

Virgilio, S. (1994). A arte do judô. Ed. Rígel.

Zabala, A. (1998). Os enfoques didáticos. In C. Coll, E. Martín, T. Mauri, M. Miras, J. Onrubia, I. Solé, \& A. Zabala (Eds.), O construtivismo em sala de aula (pp. 153-196). Ática. 


\title{
Perfil do Professor de Educação Física Inclusivo: Contributos para uma reflexão
}

\author{
Tadeu Celestino ${ }^{1}$, Antonino Pereira $^{2}$, Esperança Ribeiro $^{2}$ \\ ${ }^{1}$ Agrupamento de Escolas de Nelas, Invictus - Viseu, Escola Superior de Educação de Viseu. \\ ${ }^{2}$ Escola Superior de Educação de Viseu, Centro de Estudos em Educação e Inovação (CI\&DEI).
}

\begin{abstract}
Palavras-chave Educação Física Inclusiva, Ética Educativa, Formação, Desempenho Docente.

Docente.

\section{RESUMO:}

A complexidade do paradigma da educação inclusiva exige, cada vez mais, profissionais de educação física capazes de a um só tempo e no mesmo espaço, efetivar a promoção da inclusão, da participação e sucesso educativo de todos os alunos. Porém, a concretização deste desígnio requer que o perfil do professor de educação física transcenda a matriz científico pedagógica e aglutine, intencionalmente e equitativamente, dimensões da formação humana, do saber ser, do saber estar e agir. Deste modo, e em resposta à escassa evidência em torno do perfil do professor de educação física inclusivo, no presente artigo objetivamos catalisar a reflexão teórica em torno dos valores, das atitudes, das competências e práticas que podem constituir este perfil face aos processos de inclusão de alunos com necessidades educativas específicas no contexto da educação física. Neste sentido, na consecução de um perfil do professor de educação física inclusivo defendemos a formação e intervenção docente sob uma perspetiva bio-psico-socio-axiológica. Assim, o professor de educação física inclusivo deve pautar-se de uma intencionalidade no pensar, no agir, e ser, em consequência da catalisação integrada e permanente das dimensões: (a) éticas de ser professor de educação física, (b) da formação específica, e (c) da realização e do desempenho docente.

\footnotetext{
Keywords Inclusive Physical Education, Educational Ethics, Education, Teacher Practice.

The Profile of the Physical Education Teacher: Contribution to a reflection

\section{ABSTRACT:}

The complexity of the inclusive education paradigm increasingly requires from physical education professionals the ability to indorse, at the same time and in the same space, the promotion of inclusion, participation, and educational success for all students. However, the assertiveness of this answer requires a profile of the physical education teacher that transcends the scientific pedagogical matrix and brings together, intentionally, and equitably, dimensions of human education, knowing how to be, knowing how to be and act. Thus, and in reply to the scant evidence surrounding the profile of the inclusive physical education teacher, in this article we aim to catalyze the theoretical reflection around the values, attitudes, skills and practices that can establish this profile in facing the inclusion processes of students with specific educational needs in the context of physical education. In this sense, in achieving an inclusive physical education teacher profile, we defend teacher training and intervention we praise teaching achievement from a bio-psycho-socioaxiological perspective. Therefore, the inclusive physical education teacher must be guided by an intentionality in thinking, acting, and being, because of the integrated and permanent catalysis of the following dimensions: (a) ethics of being a physical education teacher, (b) specific training, and (c) teaching achievement and performance.
} 


\section{Perfil do Professor de Educação Física Inclusivo: Contributos para uma reflexão}

A educação inclusiva é um processo que visa aumentar a participação e diminuir a exclusão (Booth \& Ainscow, 2002), sob uma abordagem que incorpora valores particulares (Ainscow, et al., 2006) que possibilitam a aceitação e apoio da diversidade de todos os alunos. Assim, objetiva-se a eliminação da exclusão social, das consequentes atitudes e respostas ineficazes à diversidade de raça, classe social, etnia, religião género e habilidade (Ainscow, 2005). Deste modo, o princípio base subjacente a este entendimento é o de desenvolver e promover a aprendizagem conjunta entre todos os alunos, independentemente das suas capacidades, estatuto socioeconómico ou outras características (Rodrigues \& Rodrigues, 2017).

Reforçando esta perspetiva, a educação inclusiva é então conceptualmente compreendida como o compromisso de incluir os alunos com necessidades educativas específicas nas atividades escolares regulares, melhorando e adaptando as práticas às especificidades dos mesmos (Coates \& Vickerman 2008; De Boer, Pijl \& Minnaert, 2010), possibilitando-lhes, assim, não apenas ser integrados fisicamente, mas também incluídos socialmente (Mieghema, et al., 2020). Por outras palavras, a educação inclusiva configura-se um constructo multidimensional que na sua ação procura eliminar barreiras que se encontram subjacentes à aprendizagem e à participação do aluno, por meio de uma multiplicidade de estratégias, atividades, recursos, projetos e processos que vão ao encontro das necessidades de todos e cada uma das crianças e alunos (Inspeção-Geral da Educação e Ciência IGEC, 2016).Em suma, objetiva modificar as práticas educacionais tradicionais, removendo as barreiras e promovendo a aprendizagem de todos (Rodrigues, 2007) numa lógica de educação de qualidade para todos (IGEC, 2016).

Em resposta a este desiderato, muito recentemente, a publicação do Decreto-Lei n. ${ }^{\circ} 54 / 2018$, de 6 de julho, veio sublinhar a necessidade da escola, enquanto instituição, reconhecer a mais-valia da diversidade dos alunos, estimulando-a a encontrar formas lidar com essa diferença por meio da adequação de processos de ensino às especificidades e condições de cada um dos alunos, mobilizando, deste modo, todos os recursos ao seu dispor para promover a aprendizagem e o sucesso educativo. Por conseguinte, procura-se, assim, definitivamente alavancar a necessidade de se olhar para o processo inclusivo de forma mais assertiva em resposta " ... à diversidade das necessidades e potencialidades de Todos e de Cada Um dos Alunos" (Decreto-Lei n. ${ }^{\circ}$ 54/2018, de 6 de julho). Em suma, abandona-se definitivamente a linguagem das necessidades especiais para colocar a ênfase na diversidade dos alunos.
No mesmo sentido, o Despacho n. ${ }^{\circ}$ 6478/2017, um documento de referência para a organização de todo o sistema educativo e para o trabalho das escolas, já reforçava a perspetiva equitativa, inclusiva $\mathrm{e}$ agregadora de todos, sendo efetivamente a inclusão um dos princípios orientadores que constituem o Perfil dos Alunos à Saída da Escolaridade Obrigatória. Assim, ao longo do processo educativo perspetiva-se o desenvolvimento de um cidadão que, entre outros aspetos, realce a "valorização do respeito pela dignidade humana, pelo exercício da cidadania plena, pela solidariedade para com os outros, pela diversidade cultural e pelo debate democrático," assim como, "rejeite todas as formas de discriminação e de exclusão social." (Martins, et al., 2016, p.16).

Neste quadro, a operacionalização destes princípios e valores em contexto escolar requer a vinculação aos valores da inclusão por parte da comunidade educativa. Neste sentido, este paradigma escolar desafia os docentes, de uma forma geral, e os professores de educação física em particular, à necessidade de atuar em novos âmbitos e, consequentemente, a necessidade de desenvolver novas competências e skills de intervenção (Abegglen \& Hessels, 2018; Agência Europeia para o Desenvolvimento da Educação Especial - AEDEE, 2009, 2011; Celestino, 2019; Leite \& Fernandes, 2011; Nóvoa, 2009; Perrenoud, 2000; Rodrigues, \& Rodrigues, 2017; Van Mieghem, et al., 2020). Dito de outro modo, e numa disciplina predominantemente expressiva, em que o seu ensino se caracteriza pela complexidade e a incerteza, o êxito e sucesso da intervenção do professor de educação física, para a consecução da inclusão, exige o desenvolvimento de competências de resolução de problemas, de capacidade crítica e reflexiva sobre os fins, objetivos e resultados da sua intervenção, assim como, um domínio dos conhecimentos, habilidade e atitudes (Costa, 1996) positivas face à disciplina e os seus alunos em sintonia com a filosofia inclusiva.

Neste sentido, o profíssional de educação física para além de se nortear por valores inclusivos deverá também ter a capacidade e criatividade de incorporar, nas suas práticas pedagógicas, uma multiplicidade de metodologias, estratégias e recursos, que vão ao encontro da diferença e, consequentemente, promover a inclusão de todos os alunos (Celestino, et al., 2020; Rodrigues, \& Rodrigues, 2017; Van Mieghem et al., 2020).

Por conseguinte, o perfil do professor de educação física, no contexto da escola inclusiva, deve estimular nos docentes o desenvolvimento de competências críticas e reflexivas da sua prática, alicerceadas numa multiplicidade de conhecimentos e capacidades de intervenção para a consecução do sucesso educativo para todos os alunos.

Nesta assunção, o perfil do professor deve incluir, não só competências e habilidades relacionadas com o conhecimento das matérias de ensino, habilidades 
pedagógicas a desenvolver, capacidade de trabalhar e interagir com uma ampla diversidade de alunos e pares, como também capacidades que contribuam positivamente para o desenvolvimento da comunidade educativa e muito particularmente para o seu autodesenvolvimento pessoal e profissional ao longo do tempo (AEDEE, 2010).

Não obstante, à luz do novo enquadramento normativo que salvaguarda o direito de cada aluno a uma educação inclusiva que responda às suas potencialidades, expectativas e necessidades (Decreto-Lei n. ${ }^{\circ}$ 54/2018, de 6 de julho), quando pretendemos aprofundar o conhecimento sobre o perfil do professor de educação física, de um modo geral, e do professor de educação física inclusivo, de uma forma mais particular, que se encontra subjacente

à concretização deste desiderato social, confrontamonos com escassa evidência nesta área de estudo.

De facto, o incremento de investigação sobre o professor de educação física inclusivo, sob uma perspetiva construtivista e multidimensional de análise, tem sido diminuto. Com efeito, com base numa revisão realizada, entre 2010 e 2020, em algumas das principais bases de dados da área da educação física e desporto (PubMed, Web of Science, Scopus, EBSCO e SPORTDiscus) e em diversos repositórios de instituições do ensino superior de Portugal, verificamos que, na última década, existe uma carência de estudos desenvolvidos sobre esta temática.

Tomando como referência o quadro paradigmático que se vive na realidade escolar, assim como, o hiato de investigação neste campo de estudo específico urge a necessidade de refletir e estimular o debate sobre o eventual perfil do professor de educação física inclusivo no atual contexto da escola inclusiva. Neste sentido, com esta proposta de reflexão objetivamos, face à luz dos princípios e valores da escola inclusiva, alavancar algumas pistas para a compreensão dos valores, atitudes, competências e práticas subjacentes, que devem reger a conduta e a atuação profissional do professor de educação física face aos processos de inclusão de alunos com necessidades educativas específicas no contexto da educação física.

\section{Estado da arte}

Ainda existem importantes lacunas na formação inicial e contínua de professores de educação física no que concerne à sua capacitação para o desenvolvimento de processos inclusivos no contexto da educação física.

Com efeito, a literatura neste campo de estudo tem alertado para o facto de que muitos professores de educação física considerarem não estarem devidamente preparados para desenvolver processos de inclusão de alunos com incapacidade nas aulas de educação física (Lirgg, etal., 2017; Hersman \&
Hodge, 2010; Sato et al., 2007) revelando, inclusive, um baixo nível de competências de intervenção aquando a necessidade de adaptar os conteúdos à diversidade dos alunos (Gutiérrez-García, et al., 2011; Rekaa, et al., 2019).

Assim, denota-se que a educação física se encontra num processo de transformação paradigmática refletindo, ainda hoje, as influências e experiências desenvolvidas pelos seus profissionais enquanto alunos e praticantes desportivos. Com efetividade, a EF ainda se encontra radicada no paradigma desportivo (Cale, 2010), remetendo para uma ação docente do professor de educação física tendencialmente suportada em crenças, valores e atitudes do desporto, em detrimento dos valores e princípios da educação física escolar com reflexos consequentes no sucesso dos alunos (Nobre \& Silva, 2016) e, muito particularmente, nos processos de inclusão de alunos com necessidades educativas específicas.

Por outro lado, tendo em conta o perfil geral de desempenho profissional dos professores dos ensinos básico e secundário, aprovado pelo Decreto-lei, $\mathrm{n}^{\circ}$ 240/2001, de 30 de agosto, como também o perfil do professor de educação física que se alicerça, articuladamente, em quatro dimensões essenciais: (a) a dimensão profissional, social e ética, (b) a dimensão de desenvolvimento do ensino e da aprendizagem, (c) a dimensão de participação na escola e de relação com a comunidade, e (d) a dimensão de desenvolvimento profissional ao longo da vida.

Mais precisamente, o currículo instituído do professor de educação física exige destes profissionais um conhecimento científico específico, um domínio do currículo e ser dotado de um conjunto de competências pedagógicas, sobre a matéria de ensino dominando os modos de fazer aprender os alunos. Este deve munir-se também de um conjunto específico de características individuais e pautar o seu profissionalismo com base em valores de uma ética reflexiva sobre o ensino, as suas práticas letivas e analisar o impacto do seu desempenho numa perspetiva de melhoria contínua da sua atuação (Cale, 2010; Costa, 1996; Pascual, 2006).

Com efetividade, um docente de educação física deve ser um profissional especialista detentor de um conhecimento científico e pedagógico, que deve assumir uma postura crítica e reflexiva em resposta aos diferentes desafios e problemas que com que se depara no exercício das suas funções (Costa, 1996). Não obstante, ao longo do tempo, e face à necessidade de reajustamentos a nível da avaliação de desempenho docente, paulatinamente, este perfil anteriormente instituído, tendencialmente, tem vindo a sobrevalorizar as dimensões do exercício profissional mais relacionadas com a componente científica e pedagógica (Despacho 16034/2010; Decreto-Lei $n^{\circ}$ 41/2012; Decreto Regulamentar $n^{\circ}$ 26/2012, Despacho $n^{\circ} 13981 / 2012$ ). 
Neste sentido, no atual paradigma profissional, o perfil instituído do professor de educação física vem reafirmar a ênfase na dimensão do exercício profissional, designadamente na sua componente científica e pedagógica como eixos centrais do exercício da profissão docente (Nobre \& Silva, 2016). Isto é, maior valorização das dimensões mais técnicas, operativas relacionadas com a eficácia e eficiência do ensino, em detrimento da dimensão social, profissional e ética (dimensão humana de ser professor) importantes catalisadores para a consecução assertiva dos processos inclusão escolar. Face ao exposto, o forte impacto das componentes de realização, aliado ao carácter tecnicista da disciplina, muito enraizada na cultura desportiva e centrada nas dimensões do desempenho e da excelência desportiva, caracterizam fortemente o perfil de desempenho do professor de educação física. Consequentemente, tal facto tem-se configurado uma das grandes barreiras a uma maior participação e inclusão dos alunos com incapacidade e necessidades específicas face aos seus pares (Haycock \& Smith, 2011).

Sobre um outro ponto de vista, quando pretendemos abordar a temática do perfil do professor, indiscutivelmente, emergem na discussão as representações daquilo que se considera ser um professor competente de educação física em geral e aquilo que, eventualmente, poderá ser, ou não, um professor competente de educação física inclusivo de forma mais específica.

Efetivamente, um professor competente de educação física caracteriza-se acima de tudo por ser um profissional que: (a) domina os conhecimentos científicos específicos, (b) domina o conhecimento sobre o currículo e a avaliação, domina os conhecimentos pedagógicos, (c) fomenta a aprendizagem, (d) assume uma atitude crítica e reflexiva, (e) respeita princípios éticos e morais, (f) assume uma postura de aprendizagem contínua, individual e cooperativa, é capaz de estabelecer ligações entre os saberes, ( $g$ ) é um profissional amplo e cooperativo; assume o gosto pelo ensino, (h) tem disponibilidade, (i) aceita a diferença e procura ser imparcial, (j) sabe comunicar e promove a relação com o aluno; é organizado, (k) cuida dos alunos (Cale, 2010; Costa, 1996; Nobre \& Silva, 2016; Pascual, 2006).

\section{Uma representação do professor inclusivo}

Face ao exposto, e fruto das dificuldades sentidas ao nível da formação docente, materializadas nos constrangimentos e barreiras que os professores sentem na operacionalização dos processos inclusivos na escola, largamente documentados na literatura da especialidade, a AEDEE (2011) levou a cabo um estudo (Formação de Professores para a Inclusão) objetivando a identificação dos valores, competências, conhecimentos e atitudes e essenciais a todos os docentes que ingressam na profissão docente, independentemente da disciplina, especialidade ou faixa etária que irão lecionar ou do tipo de escola em que irão trabalhar e que procura dar resposta a duas questões prementes nesse contexto de estudo: i) Que tipo de professores é necessário para uma sociedade inclusiva numa Escola do século XXI? ii) Quais são as competências essenciais do professor para a educação inclusiva? Face aos resultados apurados, uma das recomendações chave identificada realça a necessidade de estabelecer um "Perfil de Professores Inclusivos" aquando da formação de professores, e desta forma procurar vincular os professores a uma estrutura axiológica e áreas de aptidão que são consideradas essenciais aos mesmos para o desenvolvimento de processos inclusivos eficazes em contexto de sala de aula (AEDEE, 2011).

Por conseguinte, o perfil do professor inclusivo materializa-se em torno do seguinte quadro de valores e de áreas de competência (atitudes, conhecimentos (saberes) e capacidades (saber fazer) consideradas fundamentais: (a) valorização da diversidade - a diferença é considerada um recurso e um valor para a educação, e neste sentido as áreas de competência a desenvolver devem relacionar-se com o fortalecer a conceção do que é realmente a educação inclusiva e consequentemente o desenvolver de uma visão holística do que é a diferença e um aluno diferente, (b) apoiar todos os alunos - os professores têm elevadas expectativas sobre os resultados de todos os alunos, e como competências desenvolver uma promoção da aprendizagem académica, prática, social e emocional de todos, promovendo metodologias de ensino eficazes em turmas heterogéneas, (c) trabalhar com outros - colaboração e trabalho em equipa são metodologias essenciais para todos os professores na sua intervenção, para tal devem desenvolver competências que lhes possibilite assertivamente trabalhar com os pais e famílias, assim como com um vasto leque de profissionais envolvidos nos processos educativos, (d) desenvolvimento profissional e pessoal - o ensino é uma atividade de aprendizagem e os professores são responsáveis pela aprendizagem ao longo da vida, para tal é essencial desenvolver competências que promovam a reflexão e processos de formação contínua de professores como base para o desenvolvimento profissional contínuo (AEDEE, 2012).

Numa outra perspetiva, e indo ao encontro da especificidade da educação física e da intencionalidade de efetivar respostas assertivas aos alunos com necessidades educativas específicas, emerge a figura do professor de educação física adaptada (Lytle, et al., 2010a; Lytle, et al., 2010b), cujas áreas de conhecimento e princípios orientadores de atuação aportam importantes diretrizes e referências daquilo que poderá ser o perfil do 
professor de educação física inclusivo na realidade em que nos situamos.

Este perfil requer um profissional altamente qualificado (Lytle, et al., 2010a; Lytle, et al., 2010b), caracterizado por ser um professor de educação física especialista em educação física inclusivo e cuja atuação se pauta pelos seguintes princípios orientadores que requerem uma permanente atualização e reforço ao longo do tempo (Lytle, et al., 2010a): (a) conhecimento do conteúdo de educação física - Dominar os saberes da educação física e da educação física adaptada e manter-se permanentemente atualizado por forma a seguir a melhores práticas de ensino, (b) princípio da Segurança - estar ciente e salvaguardar a integridade física e psicológica dos alunos, (c) estudo das deficiências - procurar ter um conhecimento e compreensão aprofundada sobre as diferentes deficiências, a variabilidade dos indivíduos, bem como, a variabilidade dentro de qualquer deficiência específica, (d) métodos de avaliação e comunicação adotar a avaliação como meio de promoção de um ensino eficaz, através ao recurso a ferramentas de aferição e avaliação ajustadas à diversidade de alunos, (e) dominar os normativos legais e os programas de educativos - ter um amplo conhecimento da legislação que rege a educação, a educação física e a educação especial, e conhecer a forma como a mesma se efetiva e operacionaliza na ação docente tendo em consideração a sua eficácia, (f) desenvolver um estilo de ensino eficaz - dominar os modelos, abordagens e planeamento curricular e estilos instrucionais, para um ensino eficaz, (g) promover a adaptações e modificações - possuir o conhecimento e a competência de tornar os conteúdos acessíveis a todos os alunos, (h) gestão de comportamentos - conhecer uma variedade de práticas de gestão de comportamentos e estratégias de ensino objetivando ajudar os alunos a assumir a responsabilidade do seu próprio comportamento e aumentar os comportamentos positivos e desejáveis, (i) colaborador e consultor - demonstrar conhecimentos e comportamentos que demonstrem e promovam o respeito, habilidades de comunicação e a capacidade de trabalhar, articular e aprender com outros profissionais e técnicos, (j) defensor da inclusão - promover práticas pro-inclusão e de defesa dos direitos dos alunos com incapacidade, assim como instituir-se como um recurso válido no apoio e coadjuvação dos seus pares e outros técnicos, (k) liderança Profissional - pautar-se por uma conduta profissional ímpar, sendo dinâmico e atualizado ora, participando em eventos e organizações profissionais da especialidade, ora interagindo e partilhando experiências com os seus pares e técnicos, (1) dominar a tecnologia assistida - recorrer a tecnologias que possibilitam o elevar os níveis de participação e aprendizagem dentro e fora da sala de aula.

Destarte, face à multidimensionalidade da educação física, da profissão docente, da incapacidade, da necessidade da efetivação da inclusão, e com base no Decreto-Lei n. ${ }^{\circ}$ 54/2018, de 6 de julho, quando destaca a necessidade da convocação de docentes especializados à implementação de medidas adicionais, fica patente que um professor de educação física inclusivo se pode repartir por três grandes dimensões essenciais que caracterizam a sua ação docente: (1) um professor Especialista em educação física, uma vez que apresenta como pré-requisito uma sólida formação e conhecimento das ciências do desporto/ motricidade humana enrobustecida por um interesse particular pelas atividades físico desportivas adaptadas. De igual modo, caracteriza-se por ser um docente detentor de um profundo conhecimento do conteúdo que ministra, planificando-o crítica e reflexivamente, de modo a torná-lo acessível e ir ao encontro da individualidade, especificidade $\mathrm{e}$ diversidade dos seus alunos. No mesmo sentido, deve ser um profissional que domina os múltiplos meios de motivação dos alunos, de representação das aprendizagens e das diferentes formas de avaliação, desse mesmo conteúdo, disponibilizando múltiplas formas de expressão; (2) um professor dinamizador da inclusão no sentido que, no âmbito da sua ação docente, demonstra uma conduta de ensino eficaz, consequente com o domínio das competências de gestão de comportamentos e atitudes, pela aplicação assertiva dos recursos instrucionais e modelos de ensino e competência de disponibilizar atividades significativas para todos, fruto da sua criatividade e capacidade de adaptabilidade face à diversidade e a diferença. Neste sentido, e pese embora o perfil de funcionalidade e constrangimentos apresentados pelos alunos com necessidades educativas especificas, o bom professor de educação física inclusivo consegue mobilizar e estimular as potencialidades de todos os alunos, articulá-las com os objetivos que pretende alcançar, e conseguir obter bons níveis de desempenho condicentes com as funcionalidades e capacidades dos discentes e deste modo elevar o seu desenvolvimento multidimensional; (3) um professor Articulador, na medida que nas relações interpessoais inerentes à sua ação docente, toda a sua postura de atuação, deve pautar-se pelo código ético e deontológico da profissão docente, agindo e sendo um exemplo de conduta profissional ímpar do seu contexto de atuação (escola) e um referencial moral para a diversidade de alunos que ensina. Do mesmo modo, deve ser um profissional que demonstra disponibilidade para assessorar e ser assessorado pelos seus pares, técnicos e agentes da comunidade educativa objetivando sempre a inclusão e o sucesso dos alunos de forma global e o seu melhor desempenho no contexto da educação física mais particularmente. 


\section{Implicações de natureza teórico-prática}

Face ao exposto, consideramos que a profissão docente se configura como uma atividade de interação humana, cujo desempenho competente transcende a matriz científico-pedagógica instituída e exige, de forma igual, qualidades das dimensões humanas associadas à excelência pessoal. Neste pressuposto, a educação inclusiva em educação física requer dos docentes uma forte consolidação de competências, aptidões, valores e princípios morais de ser e de estar, isto é, um propósito humano cuja objetividade transcende a matriz cientificopedagógica e técnica do ensinar.

Por conseguinte, pretende-se um profissionalismo de humanidade e de intencionalidade inabalável para a ação inclusiva de todos, enrobustecida pela busca constante do saber e do conhecimento científico para efetivar uma prática letiva de especificidade esclarecida, crítica e reflexiva (Celestino, 2019).

Neste sentido, e face ao exposto, é importante estarmos ciente que as dimensões operativas e normatizadas no perfil institucional procuram "teoricamente" responder, em última instância, à necessidade do desenvolvimento profissional e ao consequente sucesso educativo dos alunos. Este perfil, por outras palavras, rege-se por um quadro instituído normativamente, constituindo-se como um "farol" para todos promoverem o sucesso educativo. Porém, importa realçar que este perfil normatizado é influenciado por múltiplas experiências, realidades vividas e percecionadas pelos docentes que têm um impacto nas suas conceções, atitudes e comportamentos aquando da sua ação educativa e de forma muito particular nos processos inclusivos.

Assim, o sucesso da educação física inclusiva requer que o professor de educação física, para além de seguir e cumprir os normativos legais instituídos que regulam a sua prática docente, deva também enrobustecer a sua ação e conduta pessoal e profissional com um comportamento ético e deontológico ímpar.

\section{Considerações Finais}

Dadas as transformações ocorridas recentemente no contexto escolar, com a vinculação da escola aos valores inclusivos, perspetivando uma sociedade mais inclusiva, a reflexão em torno do perfil profissional do professor de educação física para a inclusão ainda carece de análise, reflexão e aprofundamento. Assim, com este intuito procurámos refletir acerca de alguns aspetos que poderão contribuir para a análise e desenvolvimento desta temática. Esta apreciação afigura-se pertinente devido às escassas reflexões que se têm desenvolvido neste campo de estudo nos últimos anos e também pelo facto do recente enquadramento legal e dos normativos orientadores assim o exigirem.
Por outro lado, e na persecução de "como fazer acontecer" o professor de educação física inclusivo no atual paradigma escolar, é pertinente refletir e compreender este perfil sob uma perspetiva multidimensional. Isto é, entender o desempenho docente sob uma perspetiva bio-psico-socioaxiológica, onde para lá das dimensões da realização, assumem igual pertinência as dimensões da formação humana, do saber ser e do saber estar, ou seja, da excelência pessoal como resposta à efetivação plena da inclusão escolar.

Neste sentido, o professor de educação física inclusivo deve pautar-se de uma intencionalidade no agir, no ser e pensar, consequente da confluência do desenvolvimento integrado de diversas áreas de atuação. Com efeito, tais dimensões, podem, porventura, configurar-se como importantes modeladores para o desenvolvimento de múltiplas respostas na materialização da inclusão no contexto escolar e da educação física em particular. Deste modo, da figura do professor de educação física inclusivo, emergem três operadores práticos que o caracterizam, como seja o domínio das competências especializadas em educação física, ser dinamizador da inclusão e assumir o papel de articulador entre os diferentes intervenientes no processo inclusivo. Por sua vez, tais competências de intervenção, podem, eventualmente, constituir um importante contributo para o robustecimento da equipa multidisciplinar de apoio à educação inclusiva na operacionalização e supervisão dos processos inclusivos na escola e, particularmente, no contexto da educação física e do desporto escolar.

Numa outra dimensão, a materialização deste perfil pressupõe uma sólida formação no âmbito da educação física adaptada. Neste sentido, e face às dificuldades evidenciadas nos processos de capacitação dos docentes para intervir neste contexto, impõe-se a restruturação de certas dinâmicas ao nível da formação docente, nomeadamente com o abandono de uma lógica vertical, caraterizada pela apreensão de conhecimentos sobre as necessidades educativas especiais em unidades curriculares isoladas e pontuais nos ciclos de estudos, para uma lógica de formação horizontal. Esta perspetiva defende a necessidade de uma transversalidade dos conteúdos e competências específicas nas necessidades educativas especiais pelas diferentes disciplinas ao longo dos processos formativos que habilitam para a docência em educação física.

A finalizar gostaríamos de salientar a insuficiência de reflexão e investigação em torno desta temática. Algo que nos deixa bastante inquietos face à pertinência do tema no contexto educativo em geral e no paradigma da escola inclusiva em particular face ao novo enquadramento normativo atualmente em vigor. Neste sentido, é conveniente reforçar a pesquisa nesta área de estudo por forma a identificar e caracterizar o perfil do professor de educação física no contexto da escola inclusiva com vista a tentar perceber o seu 
impacto no processo de inclusão de alunos com incapacidades e necessidades especiais nas aulas de educação física. Assim, é pertinente compreender quais os valores, práticas e representações são suscetíveis de serem associados ao perfil profissional do professor de EF inclusivo, ou mesmo como a formação inicial e contínua tem influenciado a efetivação de um perfil do professor de educação física inclusivo.

\section{Referências}

Abegglen, H. J., \& Hessels, M. G. (2018). Measures of individual, collaborative and environmental characteristics predict swiss school principals', teachers' and student teachers' attitudes towards inclusive education. Psychoeducational Assessment, Intervention and Rehabilitation, 1(1), 1-24. https://doi: 10.30436/PAIR18-01

Ainscow, M. (2005). Developing inclusive education systems: what are the levers for change? Journal of Educational Change, 6(2), 109-124. https://doi.org/10.1007/s10833-005-1298-4

Ainscow, M., Booth, T., \& Dyson, A. (2006). Improving schools, developing inclusion. Routledge.

Agência europeia para o desenvolvimento da Educação Especial - AEDEE. (2010). Formação de professores para a inclusão - Revisão da literatura [Teacher Education for Inclusion International Literature Review]. Agência Europeia para o Desenvolvimento da Educação Especial.

Agência europeia para o Desenvolvimento da Educação Especial - AEDEE. (2011). Formação de Professores para a Inclusão na Europa Desafios e Oportunidades [Teacher Education for Inclusion Across Europe - Challenges and Opportunities]. Agência Europeia para o Desenvolvimento da Educação Especial.

Agência Europeia para o Desenvolvimento da Educação Especial - AEDEE. (2012). Perfil de Professores Inclusivos [Profile of Inclusive Teachers]. Agência Europeia para o Desenvolvimento da Educação Especial.

Booth, T., \& Ainscow, (2002). Index for inclusion: Developing learning and participation in schools. Centre for Studies on Inclusive Education Bristol.

Cale, L. (2010). Becoming a Teacher. In R. Bailey (Ed.). Physical Education for Learning: A Guide for Secondary Schools (pp. 3-14). Continuum International Publishing Group.

Celestino, T. (2019). O Professor de Educação Especial: em busca de um perfil [Special Education Teacher: in search of a profile]. In $\mathrm{J}$. Rocha, L. Menezes, B. Rego, M. Figueiredo, A.
Ribeiro, A. I. Silva, S. Felizardo, A. P. Cardoso (Eds.) Livro de Atas: Olhares sobre a Educação 7 [Book of Minutes: Views on Education 7] (pp. 108-115). Viseu: Escola Superior de Educação Instituto Politécnico de Viseu. http://hdl.handle.net/10400.19/6082

Celestino, T., Pereira, A., \& Ribeiro, E. (2020). A Inclusão em Educação Física: uma revisão sistemática [Inclusion in Physical Education: a systematic review]. In J. Rocha, A. Ribeiro, L. Menezes, S. Felizardo, A. P. Cardoso, A. I. Silva, M. Figueiredo (Eds.), Livro de Atas: Olhares sobre a Educação 8 [Book of Minutes: Views on Education 8] (pp. 51-52). Viseu: Escola Superior de Educação Instituto Politécnico de Viseu. https://repositorio.ipv.pt/bitstream/10400.19/647 8/1/Livro_Resumos_Olhares_8_1.pdf

Costa, F.C. (1996). Formação de professores objetivos, conteúdos e estratégias [Teacher education: aims, contents and strategies]. In F.C. Costa, L. M. Carvalho, M. S. Onofre, J. A. Diniz \& C.Pestana, (Org.), Formação de Professores em Educação Física: concepções, investigação, prática [Teacher Training in Physical Education: concepts, research, practice] (pp. 9-36). Faculdade de Motricidade Humana.

Cunha, A. C. (2010). Representação do "bom" professor: o" bom professor em geral e o" bom" professor de educação física em particular [Representation of the "good" teacher: the "good teacher in general and the" good "physical education teacher in particular]. Educação em Revista, 11(2), 41-52. https://doi.org/10.36311/2236-

5192.2010.v11n2.2320

Coates, J., \& Vickerman, P. (2008). Let the children have their say: children with special educational needs and their experiences of physical education-a review. Support for Learning, 23(4), 168-175. https://doi.org/10.1111/j.14679604.2008.00390.x

De Boer, A., Pijl, S. J., \& Minnaert, A. (2010). Attitudes of parents towards inclusive education: A review of the literature. European Journal of Special Needs Education, 25(2), 165-181. https://doi.org/10.1080/08856251003658694

Decreto-Lei n. ${ }^{\circ}$ 41/2012, de 21 de fevereiro. Diário da República $n .^{\circ}$ 37, Série I. Ministério da Educação e Ciência.

Decreto-Lei n. ${ }^{o}$ 54/2018, de 6 de julho. Diário da República $n .^{\circ}$ 129, Série I. Presidência do Conselho de Ministros.

Decreto-Lei n. ${ }^{\circ}$ 240/2001, de 30 de Agosto. Diário da República $n .^{\circ}$ 201, Série I-A. Ministério da Educação. 
Decreto Regulamentar n. ${ }^{\circ}$ 26/2012, de 21 de fevereiro. Diário da República $n .^{\circ} 37$, Série I. Ministério da Educação e Ciência.

Despacho n. ${ }^{\circ} 16034 / 2010$, de 22 de outubro. Diário da República $n .^{\circ}$ 206, Série II. Ministério da Educação.

Despacho n. ${ }^{\circ} 13981 / 2012$, de 26 de outubro. Diário da República, 2. ${ }^{a}$ série $N .^{\circ}$ 208. Gabinete do Secretário de Estado do Ensino e da Administração Escolar.

Despacho n. ${ }^{\circ}$ 6478/2017, de 26 de julho. Diário da República $n .^{\circ}$ 143, Série II. Educação - Gabinete do Secretário de Estado da Educação.

Leite, C., \& Fernandes, P. (2011). Desafios aos professores na construção de mudanças educacionais e curriculares: Que possibilidades e que constrangimentos [Challenges for teachers in the construction of educational and curricular changes: what possibilities and what constraints]. Revista Educação, 33(3), 198-204.

Lirgg, C. D., Gorman, D. R., Merrie, M. D., \& Shewmake, C. (2017). Exploring challenges in teaching physical education to students with disabilities. Palaestra, 31(2).

Lytle R., Lavay, B. \& Rizzo, T. (2010a). What Is a highly qualified adapted physical education teacher? Journal of Physical Education, Recreation \& Dance, 81(2), 40-50. https://doi.org/10.1080/07303084.2010.1059843 3

Lytle, R., Miller, J., Grenier, M., Block, M., Davis, T., Lavay, B., \& Rizzo, T. (2010b). Position paper highly qualified adapted physical education teachers.

Flores, M. A. (2004). Dilemas e desafios na formação de professores [Dilemmas and challenges in teacher education]. In M. Célia Moraes, J. A. Pacheco \& M. Olinda Evangelista (Org.), Formação de professores. Perspetivas educacionais e curriculares [Teacher training. Educacional and curricular perspectives] (pp. 127-160). Porto Editora.

Gutiérrez-García, C., Pérez-Pueyo, Á., PérezGutiérrez, M. \& Palacios-Picos, A. (2011). Percepciones de profesores y alumnos sobre la enseñanza, evaluación y desarrollo de competencias en estudios universitarios de formación de profesorado [Perceptions of teachers and students about the teaching, evaluation and development of competences in university studies of teacher training]. Cultura $y$ Educación, 23(4), 499-514. https://doi.org/10.1174/113564011798392451

Hersman, B. L., \& Hodge, S. R. (2010). High school physical educators' beliefs about teaching differently abled students in an urban public school district. Education and Urban Society, 42(6), 730-757.

https://doi.org/10.1177/0013124510371038

Haycock, D., \& Smith, A. (2011). Still 'more of the same for the more able?' Including young disabled people and pupils with special educational needs in extra-curricular physical education. Sport Education and Society, 16(4), 507-526.

https://doi.org/10.1080/13573322.2011.589647

Inspeção-Geral da Educação e Ciência - IGEC. (2016). A escola inclusiva: desafios [The inclusive school: challenges]. Lisboa: InspeçãoGeral da Educação e Ciência.

Martins, G., Gomes, C. A., Brocardo, J. M., Pedroso, J. V., Carrillo, J., Silva, L., Encarnação, M. M., Horta, M. J., Calçada, M., Nery, R., \& Rodrigues, S. (2017). Perfil dos alunos à saída da escolaridade obrigatória [Profile of Students Leaving Compulsory Education]. Ministério da Educação/Direção-Geral da Educação.

Nobre, B., \& Silva, F. (2016). O perfil do professor de educação física na perspetiva dos alunos em formação inicial [The profile of the physical education teacher from the perspective of students in Initial formation]. Agora for pe and Sport, 18(2), 151-166.

Nóvoa, A. (2009). Para una formación de professores construída dentro de la profesión [For a teacher training built within the profession]. Revista de Educación, 350, 203-218.

Pascual, C. (2006). The initial training of physical education teachers, in search of the lost meaning of professionalism. Physical Education and Sport Pedagogy, 11(1), 69-82. https://doi.org/10.1080/17408980500471110

Perrenoud, P. (2000). Dez novas competências para ensinar [Ten new skills to teach]. Artmed Editora.

Rekaa, H., Hanisch, H., \& Ytterhus, B. (2019). Inclusion in physical education: Teacher attitudes and student experiences. A systematic review. International Journal of Disability, Development and Education, 66(1), 36-55. https://doi.org/10.1080/1034912X.2018.1435852

Rodrigues, D. (2007). Desenvolver a educação inclusiva: Dimensões do desenvolvimento profissional [Developing inclusive education: dimensions of professional development]. In D. Rodrigues (Org.), Investigação em educação inclusiva [Research in Inclusive Education]. Fórum de Estudos de Educação Inclusiva.

Rodrigues, D., \& Rodrigues, L. L. (2017). Educação física: Formação de professores e inclusão 
[Physical Education: teacher training and inclusion]. Práxis Educativa, 12(2), 317-333.

Sato, T., Hodge, S. R., Murata, N. M., \& Maeda, J. K. (2007). Japanese physical education teachers' beliefs about teaching students with disabilities. Sport Education and Society, 12(2), 211-230. https://doi.org/10.1080/13573320701287536

Van Mieghem, A., Verschueren, K., Petry, K., \& Struyf, E. (2020). An analysis of research on inclusive education: A systematic search and meta review. International Journal of Inclusive Education, 24(6), 675-689. https://doi.org/10.1080/13603116.2018.1482012 


\title{
Importância dada às Competências Profissionais
}

\section{entre Treinadores Experientes e Treinadores Jovens do Futebol Distrital}

\author{
José C. Araújo \\ Escola Superior de Desporto de Rio Maior - Instituto Politécnico de Santarém
}

\begin{abstract}
Palavras-chave Competências Profissionais; Futebol, Formação, Treinadores

\section{RESUMO:}

A formação de treinadores de futebol é um tema de bastante análise e constante desenvolvimento. Cada vez mais o futebol apresenta uma heterogeneidade nos treinadores, seja em termos de experiência como treinador, da idade, do contexto de intervenção e, até da prática passada como jogador. Essa heterogeneidade poderá ser mais evidente no futebol distrital, uma vez que é a base deste desporto, onde a maioria dos jogadores e treinadores começam as suas carreiras. Assim, o futebol distrital pode apresentar um grande "choque" entre idade e experiência dos treinadores, o que leva a diferentes visões e intervenções por parte dos mesmos. Portanto, é pertinente analisar a importância que os treinadores (experientes e jovens) deste contexto dão às diferentes competências profissionais, para perceber quais as suas convergências e divergências. Foram realizadas 40 entrevistas ( 20 treinadores experientes e 20 treinadores jovens) com média de idades de 35.6 anos e desvio padrão de 8.6 anos, seguindo um guião composto por cinco partes: a Caracterização pessoal e socioprofissional, a Importância dada pelos entrevistados às Competências: "Saberes-Saber", "Saberes-Fazer" e Saberes-Ser". Observamos que ambos os grupos dão relativa importância aos diversos "saberes", porém, são os Treinadores Jovens que apresentam melhores resultados, com (51\%) dos itens do (PNFT-RCFG).
\end{abstract}

Importance given to Professional Skills between Expert Coaches and Youth Coaches in Regional football

\section{Keywords \\ Professional Skills;} Football, Formation, Coaches.

\section{ABSTRACT:}

The football coaches formation is a topic of considerable analysis and constant development. Today football coaches are very heterogeneous, whether in terms of experience as a coach, age, context of intervention and even past practice as a player. This heterogeneity may be more evident in regional football, since it is the basis of this sport, where most players and coaches begin their careers. Thus, regional football can present a big difference between the age and experience of the coaches, which leads to different views and interventions on the part of the coaches. So it is relevant to analyze the importance that coaches (expert and young) in this context give to different professional skills to understand what their convergences and divergences, 40 interviews were conducted (20 expert coaches and 20 young coaches) with an average age of 35.6 years and standard deviation of 8.6 years, following a script composed of five parts: a Personal and socio-professional characterization, the importance given by the interviewees to the Competencies: "Knowledge-Knowledge "," Knowledge-Do "and Knowledge-Be". We observed that both groups give relative importance to the different "knowledges", however it is the Young Coaches who present the best results, with (51\%) of items of (PNFT-RCFG). 


\section{Importância dada às Competências Profissionais entre Treinadores Experientes e Treinadores Jovens do Futebol Distrital}

A legislação atual permite a que jovens com 18 anos possam ser treinadores de Futebol. Para tal é necessário estudar e concluir com sucesso o Grau I UEFA C, nas diversas associações (Regulamento Curso de Treinador Grau I-UEFA C, AFL, 2018). Com apenas 20 anos, esse mesmo jovem poderá possuir o grau II-UEFA B, se cumprir com os critérios necessários para se inscrever e, concluir com sucesso o respetivo curso (Regulamento Curso de Treinador Grau II-UEFA B, AFL, 2018). Isto poderá levar a que, no mesmo contexto possam existir grandes diferenças em termos de idade e experiência entre treinadores, sendo pertinente estudar a diferença entre o Treinador Jovem e o Treinador Experiente, em relação à importância dada por estes às diferentes Competências Profissionais.

Segundo Resende, Gomes, Silva, Fernández, e Castelo (2009), os treinadores têm oportunidades sublimes de influenciar positivamente $\mathrm{o}$ desenvolvimento de atitudes e comportamentos dos jovens, proporcionando assim a sua integração social e a promoção de estilos de vida conducentes de uma vida saudável.

Os treinadores que entendem diferentes estilos de aprendizagem e preferências tendem a ser mais eficazes, o que tem implicações para o conteúdo da educação dos atletas (Cassidy, Potrac, \& McKenzie, 2006), respeitando patamares evolutivos independentemente de a modalidade ser coletiva ou individual (Duffy, 2008).

Segundo Buceta (2009), o treinador é o responsável máximo pelo funcionamento dos aspetos associados à equipa assim como, com o rendimento dos seus atletas razão pela qual as suas decisões e ações têm uma grande influência. Dos acertos e erros do treinador dependem em grande medida o êxito desportivo e a satisfação dos que trabalham com ele. Mesquita, Isidro, e Rosado (2010), para analisarem a perceção e preferências dos Treinadores portugueses para procurarem conhecimento, inquiriram 336 Treinadores de 22 desportos diferentes. Os autores concluíram que para a maioria dos treinadores em Portugal é indispensável desenvolver conhecimento e, atribuem muita importância à experiência, como por exemplo, trabalhar com experts. Isto motiva os treinadores a procurar o terreno com o objetivo de trabalhar com pessoas diferenciadas para ganhar experiência.

No estudo de Santos, Mesquita, Graça, e Rosado (2010), foram inquiridos 343 treinadores de diferentes modalidades com o objetivo de examinar a perceção das competências e no que os treinadores necessitam formar-se, relacionando isso com as competências profissionais. Os resultados do estudo apontam que as respostas aos questionários são influenciadas pela experiência dos treinadores. Os treinadores com menos experiência consideram ter menos competências e mais formação. Os com maior grau académico consideram-se mais competentes que os outros em todos os aspetos. No geral, os treinadores consideram-se competentes, mas sentem que necessitam de mais formação. Nestas competências e formações destacam-se as competências para a execução de planos anuais, de orientação da prática/treino e da competição e, por fim, a relação pessoal e grupal.

As conceções do desporto têm-se alterado ao longo dos tempos, como também, a denominação de treinador de desporto e o seu processo de profissionalização (Almeida, 2001). Segundo Stoszkowski e Collins (2012), os programas de formação de treinadores têm sido desenvolvidos em muitos países e são apresentados como um papel fundamental no desenvolvimento dos treinadores, para a promoção de elevados padrões de intervenção. Para Figueiredo (1997), a formação de treinadores deve conseguir, em algumas modalidades, dar o salto da cientificidade dos seus cursos de qualificação (formação inicial). Perrenoud (1995) define formação como uma intervenção visando uma modificação nos domínios dos saberes, dos saberes-fazer e dos saberes-ser do sujeito em formação.

Segundo Resende, Sequeira, e Sarmento (2016), as competências que o treinador deve manusear agrupam-se nas dimensões dos "saberes", o "saberfazer", "saber-ser" e "saber-estar", do referencial de formação geral de Grau I, II e III de treinador.

A bibliografia não é consensual em torno da idade para se considerar um treinador experiente. No entanto, estudos efetuados por vários autores com treinadores experts (Côté, Salmela, Trudel, Baria, \& Russel, 1995; Horton, Baker, \& Deakin, 2005; Saury \& Durand, 1998) apontam 10 anos de atividade na função de treinador como critério balizador de experiência profissional. Bruden (1990), por seu lado, aponta três fases caracterizadoras da experiência profissional: fase de iniciação entre dois a quatro anos de experiência, fase de ajustamento, entre três a quatro anos de experiência e fase de estabilização, entre cinco ou mais anos de experiência. A experiência efetiva como treinador é referenciada como fator determinante de conhecimento e, consequentemente, de sucesso estando presente nos treinadores experts (Bloom, Bush, Schinke, e Salmela, 1998; Salmela, 1996; Salmela, Draper, Laplante, 1993). Também Gould, Giannini, Krane, e Hodge, (1990) numa questão a 130 treinadores experts americanos sobre os fatores que mais influenciam a sua atividade os inquiridos, referiram a experiência como o fator mais importante. No entanto, Fleurence e Cotteaux (1999) e Gilbert e Trudel (1999) realçam que a investigação ainda tem de estudar como é que a experiência é transformada em conhecimento, pois para se ser expert é necessário ter experiência; contudo, o inverso pode não ser verdadeiro. 
Para Neves (2013), os treinadores de futebol distrital são usualmente amadores (obtêm os seus rendimentos principais em profissões fora do futebol). Este demonstra ainda que o futebol distrital tem vários problemas associados, tais como, pouca capacidade financeira, incapacidade de manter os bons jogadores nos clubes, instabilidade enquanto aos recursos humanos, poucas e fracas infraestruturas (sendo muitas vezes partilhadas por diferentes modalidades), poucos patrocínios, baixa lotação dos seus estádios, o que leva a que o futebol distrital gera pouco dinheiro. Para o autor deste estudo, sendo o futebol distrital a base do futebol português, é aqui que encontramos grandes diferenças entre a experiência e a idade do treinador. Ou seja, podemos encontrar, por exemplo, um treinador com 21 anos de idade, sendo treinador há três anos, assim como um treinador de 60 anos de idade, sendo treinador há mais de 20 anos. $\mathrm{O}$ autor acredita que esta grande diferença é mais usual nas competições e treinadores distritais, do que nas competições nacionais, devido à maior exigência e uma maior procura dos clubes, por treinadores já com provas dadas e com experiência passada relevante. Assim sendo, este estudo é pertinente, devido a analisar a importância dada às diferenças competências profissionais, por dois grupos de treinadores (experientes e jovens) tão diferentes, seja em termos de visão, de experiência de treinador, da experiência própria da vida, mas do mesmo contexto de intervenção, o contexto distrital. $O$ objetivo principal deste estudo e perceber as divergências e convergências entre os treinadores experientes e os treinadores jovens sobre a importância que estes dão às diferentes competências profissionais. Espera-se que os resultados consigam responder às seguintes hipóteses:

Hipotese 1- Os treinadores distritais dão importância às Competências Profissionais?

Hipótese 2 - São os treinadores jovens que dão mais importância às Competências Profissionais do que os treinadores experientes ou vice-versa?

Hipótese 3 - São os treinadores jovens que dão mais importância as competências relacionadas com o "Saber-Saber" do que os treinadores experientes ou vice-versa?

Hipótese 4 - São os treinadores jovens que dão mais importância as competências relacionadas com o "Saber-Fazer" do que os treinadores experientes ou vice-versa?

Hipótese 5- São os treinadores jovens que dão mais importâncias as competências relacionadas com o "Saber-Ser" do que os treinadores experientes ou vice-versa.

\section{Método}

\section{Participantes}

Os participantes foram divididos em dois grupos, de modo que a análise e interpretação dos resultados fosse ao encontro com o objetivo pretendido. Esta divisão teve como base a experiência e a idade dos treinadores, dividindo então em treinadores experientes $(n=20)$ e treinadores jovens $(n=20)$, sendo apresentados na tabela 1 .

Dos 40 treinadores, $n=34$ do sexo Masculino (85\%) e $\mathrm{n}=6$ do sexo feminino $(15 \%)$ As idades dos indivíduos caracterizam-se por uma média de 33.5 sendo o valor mínimo de 24 anos e o máximo de 60 anos. Relativamente às suas habitações literárias (55\%) dos participantes detêm o Ensino Superior na área do Desporto, dos quais $(22.5 \%)$ detêm o Grau de Mestre na área do Desporto, (12.5\%) possuem graduação a nível do Ensino Superior fora da área desportiva e, os restantes $(32.5 \%)$ não possuem qualquer graduação ao nível do Ensino Superior. Todos os treinadores possuem o Grau II de Treinadores de Futebol.

A localização Geográfica dos 40 treinadores varia entre as Associações de Futebol de Santarém, Lisboa, Porto, Viseu, Guarda, Castelo Branco, Portalegre, Madeira, Aveiro, Leiria e Vila Real. O processo de recrutamento dos participantes foi através da rede de contactos pessoal do autor, e de alguns colegas de profissão que providenciaram algum apoio, para que o autor tenha tido a possibilidade de chegar a mais, e diferenciados treinadores. Os critérios de elegibilidade considerados foram os seguintes: o treinador entrevistado teria que possuir o Grau 2 de Treinador de Futebol, estar no ativo, ser treinador em contexto de competições distritais.

Para se definir o que era um treinador experiente e um treinador jovem houve os seguintes critérios de inclusão:

Treinador Experiente: 10 ou mais anos de experiência (Côté, Salmela, Trudel, Baria, \& Russel, 1995; Horton, Baker, \& Deakin, 2005; Saury \& Durand, 1998) com idades igual ou superior a 35 anos (decidido pelo autor de forma a salientar uma diferença tanto de experiência como de idade entre o treinador experiente e jovem)

Treinador Jovem: menos de 10 anos de experiência (Côté et al., 1995; Horton, et al., 2005; Saury \& Durand, 1998), com idade igual ou inferior a 30 anos. 
Tabela1. Caracterização dos Treinadores

\begin{tabular}{|c|c|c|c|c|c|c|c|c|c|c|}
\hline $\begin{array}{c}\text { Variável } \\
\text { Treinador }\end{array}$ & $\mathbf{N}=$ & $\%$ & G.M & $\%$ & $\mathbf{G . F}$ & $\%$ & $\begin{array}{l}\text { Idade } \\
\text { Média }\end{array}$ & DP & $\operatorname{Exp}$ & DP \\
\hline Experiente & 20 & $50 \%$ & 18 & $90 \%$ & 2 & $10 \%$ & 40.6 & 7.51 & 14.9 & 4.18 \\
\hline Jovem & 20 & $50 \%$ & 16 & $80 \%$ & 4 & $20 \%$ & 26.4 & 1,88 & 5.8 & 1.54 \\
\hline Total & 20 & $100 \%$ & 34 & $85 \%$ & 6 & $15 \%$ & 33.5 & 8.62 & -- & -- \\
\hline
\end{tabular}

Legenda: N - Número de Treinadores; G.M - Género

Masculino; G.F - Género Feminino.

\section{Instrumento}

$\mathrm{O}$ instrumento utlizado foi um guião de entrevista semi-estruturada experimental, criado para este estudo, não tendo sido previamente validado. O guião é composto por cinco partes: a caracterização pessoal e socioprofissional, em que o entrevistado tinha de responder às seguintes questões: sexo, idade, profisssão principal, habilitações literárias, Grau do TPTD, número de anos de experiência como treinador(em Portugal e no estrangeiro) e, por último, os níveis etários com quem trabalhava predominantemente (crianças - dos 11 para baixo, Jovens - entre os 12 e os 17 anos, Adultos I - entre os 19 e 39 anos, Adultos II - entre os 39 e 63 anos e Seniores - acima de 63). Depois da caracterização pessoal e socioprofissional foram realizadas as seguintes questões, com o intuito de saber a opinião dos entrevistados sobre as Competências Profissionais: "Quais os Conhecimentos (SaberesSaber) mais importantes que um treinador deve possuir?", "Quais as competências práticas (Saber Fazer) mais relevantes que um treinador deve possuir?" e, por último, "Quais são as atitudes e os comportamentos (saber ser) que mais valoriza num treinador?". As entrevistas asseguraram as condições de anonimato e confidencialidade exigíveis no perfil ético que subjaz a este tipo de metodologia.

\section{Procedimentos}

Foi realizado um contacto com os treinadores informando-os e explicando-lhes acerca da finalidade do estudo e de todas as suas condições (através da apresentação do TCLE - Termo de Consentimento Livre e Esclarecido). Nos casos em que o consentimento livre e esclarecido não foi registado por escrito (entrevistas via online) o participante pode ter acesso ao TCLE sempre que solicitado. Nos casos em que o consentimento livre e esclarecido foi registado por escrito (entrevistas presenciais), foi assinado pelo treinador entrevistado e pelo autor do estudo, sendo entregue ao entrevistado. Após a sua aceitação, tornando claro que a participação era voluntária e que as respostas seriam confidenciais, iniciou-se as entrevistas. As entrevistas do tipo semiestruturadas, com uma duração média de 25 minutos, foram efetuadas por duas vias: por via informática através dos softwares Skype e Zoom, e utilizado o recurso do gravador áudio dos mesmos softwares e por via presencial, em que o entrevistador estava na mesma sala que o entrevistado, utilizando o recurso a gravador áudio do seu telemóvel. O investigador seguiu um guião experimental, criado para o efeito, não tendo sido previamente validado, dividido em cinco partes: a caracterização pessoal e socioprofissional do entrevistado, a importância dada pelos treinadores às competências: "Saberes-Saber", "Saberes-Fazer" e "Saberes-Ser".

A recolha de dados foi mista, inicialmente foi qualitativa, uma vez que foi analisado o que o treinador disse ao ser entrevistado. Porém, posteriormente, as entrevistas foram transcritas para texto word, foram identificadas e enumeradas as frases chave. As respostas dadas pelos treinadores foram analisadas, de acordo a se os treinadores experientes e jovens mencionavam ou não os Referenciais da Componente da Formação Geral. Sendo esta uma medida de tendência central, indicanos o modo como se distribuem os dados de um estudo. Para evitar o risco de viés e, desta forma, garantir a credibilidade dos dados, o autor avaliou o conteúdo das entrevistas por duas vezes, com diferença temporal de um mês, para perceber se em ambas as vezes identificou e enumerou as mesmas frases. Em caso de diferenças existentes na primeira para a segunda leitura, o autor solicitou a um investigador externo, que analisasse as mesmas entrevistas. $\mathrm{O}$ autor aceitou como válida a sua leitura que ia ao encontro da leitura do investigador externo. No que diz respeito aos procedimentos estatísticos, foram utilizados parâmetros descritivos, com representação de valores mínimos, máximos, média, desvio padrão (na caraterização dos treinadores, tabela 1) e frequências (competências profissionais dos treinadores jovens e experientes) com recurso ao software Microsoft Excel.

\section{Variáveis}

\section{Variáveis Dependentes}

Correspondem às competências do Referencial de Formação Geral do Programa Nacional da Formação de Treinadores, do Instituto Português da Juventude e do Desporto, que estão agrupadas em três dimensões associadas aos "Saberes", "Saberes- Fazer" e "Saberes-Ser".

\section{Variáveis Independentes}

Corresponde ao tipo de Treinador, se é Treinador Experiente ou Treinador Jovem. 


\section{Resultados}

Os gráficos seguintes permitem apresentar um conjunto de resultados, onde é possível identificar as diferenças entre treinadores experientes e os treinadores jovens em relação aos três "saberes" e destacar as competências em que dão maior importância, ou aquelas que referiram menos. Os resultados foram analisados, seja em termos globais dos dois grupos, seja em termos mais específicos nas diversas dimensões das competências profissionais.

Figura 1. Resultados percentuais Treinadores Distritais.

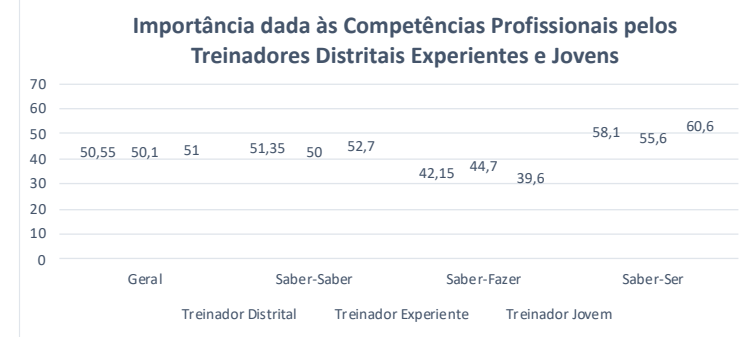

Tabela 2. Competências mais citadas pelos dois grupos (Saber-Saber)

\begin{tabular}{lcc}
\hline "Saber - Conhecimento", & $\begin{array}{c}\text { Treinadores } \\
\text { Experientes }\end{array}$ & $\begin{array}{c}\text { Treinadores } \\
\text { Jovens }\end{array}$ \\
\hline $\begin{array}{l}\text { Da modalidade desportiva } \\
\text { adequado ao nível de }\end{array}$ & $80 \%$ & $85 \%$ \\
$\begin{array}{l}\text { intervenção. } \\
\begin{array}{l}\text { Acerca da formulação de } \\
\text { objetivos de preparação e de } \\
\text { competição. }\end{array}\end{array}$ & $75 \%$ & $60 \%$ \\
$\begin{array}{l}\text { Acerca dos diferentes Estilos } \\
\text { de Ensino }\end{array}$ & $55 \%$ & $65 \%$ \\
$\begin{array}{l}\text { Sobre os procedimentos de } \\
\text { organização, gestão } \\
\text { avaliação do treino. }\end{array}$ & $75 \%$ & $70 \%$ \\
\hline
\end{tabular}

Tabela 3. Competências menos citadas pelos dois grupos (Saber-Saber)

\begin{tabular}{lccc}
\multicolumn{1}{c}{ "Saber - Conhecimento" } & $\begin{array}{c}\text { Treinadores } \\
\text { Experientes }\end{array}$ & $\begin{array}{c}\text { Treinadores } \\
\text { Jovens }\end{array}$ \\
\hline $\begin{array}{l}\text { Sobre nutrição aplicável à } \\
\text { otimização do processo de } \\
\text { treino e de competição. }\end{array}$ & $20 \%$ & $30 \%$ \\
$\begin{array}{l}\text { Que lhe permitem participar } \\
\text { na análise e avaliação dos }\end{array}$ & & \\
$\begin{array}{l}\text { adversários e demais } \\
\text { participantes na sua } \\
\text { modalidade desportiva. }\end{array}$ & $30 \%$ & $40 \%$ \\
\hline
\end{tabular}

Tabela 4. Maiores Diferenças entre os dois grupos (Saber-Saber)

\begin{tabular}{lcc}
\hline "Saber - Conhecimento" & $\begin{array}{c}\text { Treinadores } \\
\text { Experientes }\end{array}$ & $\begin{array}{c}\text { Treinadores } \\
\text { Jovens }\end{array}$ \\
\hline $\begin{array}{l}\text { Acerca das determinantes do } \\
\text { processo de desenvolvimento }\end{array}$ & & \\
desportivo do praticante a \\
$\begin{array}{l}\text { longo prazo } \\
\text { Diferentes modelos de } \\
\text { planeamento anual do treino e }\end{array}$ & & \\
as suas diferentes & $55 \%$ & $70 \%$ \\
componentes & & \\
\hline
\end{tabular}

Tabela 5. Competências mais citadas por ambos os grupos (Saber-Fazer).

\begin{tabular}{lcc}
\hline \multicolumn{1}{c}{ “Saber - Fazer" } & $\begin{array}{c}\text { Treinadores } \\
\text { Experientes }\end{array}$ & $\begin{array}{c}\text { Treinadores } \\
\text { Jovens }\end{array}$ \\
\hline $\begin{array}{l}\text { Utilizar técnicas e estratégias } \\
\text { de comunicação adequadas às } \\
\text { circunstâncias }\end{array}$ & $85 \%$ & $70 \%$ \\
$\begin{array}{l}\text { Dirigir os praticantes na } \\
\text { sessão de treino, assegurando }\end{array}$ & & \\
$\begin{array}{l}\text { oxercício das competências } \\
\text { de ensino fundamentais } \\
\text { (explicação, demonstração, }\end{array}$ & $70 \%$ & $65 \%$ \\
observação e correção). & & \\
$\begin{array}{l}\text { Participar na conceção do } \\
\text { planeamento da atividade de } \\
\text { treino e de competição }\end{array}$ & $70 \%$ & $55 \%$ \\
\hline
\end{tabular}

Tabela 6. Competências menos citadas por ambos os grupos (Saber-Fazer).

\begin{tabular}{lcc}
\hline \multicolumn{1}{c}{ "Saber - Fazer" } & $\begin{array}{c}\text { Treinadores } \\
\text { Experientes }\end{array}$ & $\begin{array}{c}\text { Treinadores } \\
\text { Jovens }\end{array}$ \\
\hline $\begin{array}{l}\text { Aplicar técnicas elementares } \\
\text { dos primeiros socorros e }\end{array}$ & $25 \%$ & $20 \%$ \\
suporte básico de vida & & \\
$\begin{array}{l}\text { Promover o registo de toda a } \\
\text { informação da unidade de }\end{array}$ & & \\
treino e da competição & $20 \%$ & $30 \%$ \\
pertinente a \\
monitorização da carreira \\
desportiva do praticante
\end{tabular}

Tabela 7. Competências mais citadas por ambos os grupos (Saber-Ser)

\begin{tabular}{lcc}
\multicolumn{1}{c}{ "Saber-Ser" } & $\begin{array}{c}\text { Treinadores } \\
\text { Experientes }\end{array}$ & $\begin{array}{c}\text { Treinadores } \\
\text { Jovens }\end{array}$ \\
\hline $\begin{array}{l}\text { Adapta-se a diferentes } \\
\text { culturas e contextos sociais } \\
\text { desportivos. }\end{array}$ & $70 \%$ & $80 \%$ \\
$\begin{array}{l}\text { Promove o espírito } \\
\text { desportivo. }\end{array}$ & $70 \%$ & $80 \%$ \\
$\begin{array}{l}\text { Promove atitudes e } \\
\text { comportamentos } \\
\text { consentâneos com a função } \\
\text { social que desempenha }\end{array}$ & $75 \%$ & $75 \%$ \\
$\begin{array}{l}\text { Valoriza estilos de } \\
\text { comunicação adaptáveis às } \\
\text { circunstâncias. }\end{array}$ & $70 \%$ & $75 \%$ \\
\hline
\end{tabular}


Tabela 8. Maiores diferenças entre os dois grupos (Saber-Ser)

\begin{tabular}{|c|c|c|}
\hline "Saber-Ser" & $\begin{array}{l}\text { Treinadores } \\
\text { Experientes }\end{array}$ & $\begin{array}{c}\text { Treinadores } \\
\text { Jovens }\end{array}$ \\
\hline $\begin{array}{l}\text { Promove o comprometimento } \\
\text { individual do praticante } \\
\text { perante a equipa e o clube, } \\
\text { bem como a fidelização à } \\
\text { modalidade e à prática } \\
\text { desportiva }\end{array}$ & $65 \%$ & $50 \%$ \\
\hline $\begin{array}{l}\text { Promove o relacionamento } \\
\text { interpessoal na prática } \\
\text { desportiva, com vista ao } \\
\text { desenvolvimento de um bom } \\
\text { nível de colaboração, } \\
\text { especialmente no que se refere } \\
\text { ao suporte parental }\end{array}$ & $35 \%$ & $45 \%$ \\
\hline
\end{tabular}

\section{Discussão}

Com base nos resultados apresentados na figura 1 verifica-se, que os treinadores distritais, independentemente de serem treinadores experientes ou jovens, atribuem relativa importância às competências, já que referiram nas entrevistas mais de $50 \%$ dos diferentes itens do (PNFT-RCFG). Estes resultados poderão ser explicados, devido a tanto o treinador experiente, como o treinador jovem procurarem potenciar a sua qualidade enquanto treinador, procurando adquirir conhecimentos nos diferentes "saberes."

Passando para um olhar mais específico dos resultados, em termos das dimensões das competências associadas ao "SaberSaber/Conhecimento", os dois grupos apresentam resultados médios positivos e similares, (é o saber em que os resultados entre ambos são mais próximos). $\mathrm{O}$ resultado mais elevado apresentado pelos treinadores jovens poderá ser devido ao facto de terem tirado o curso de treinador há menos tempo que os treinadores experientes.

A tabela 2 que apresenta as competências profissionais mais citadas por ambos os grupos relativos ao "saber-saber", demonstra que tanto os treinadores experientes como os jovens dão relativa importância ao nível de intervenção e aos diferentes estilos de ensino, pode-se ver nisso, através deste excerto de uma entrevista “ É importante também adequares a tua intervenção de acordo com quem tens a tua frente, epah, imagina, o meu estilo de ensino, é muito autocrata nas equipas de rendimento, a partir dos sub15, até por exemplo uso muito a força da voz, e quando as coisas não estão do meu agrado, aquele vernáculo, mas as vezes quando treino equipas muito jovens, tenho de perceber que não só o meu estilo de ensino, deverá ser mais democrata como também a minha intervenção, deverá ser mais simples, concisa e acima de tudo limpa"

Para Vallée e Bloom (2005), os treinadores demonstram a capacidade de alternar entre estilos de lideranças conforme as circunstâncias, procuram que os seus atletas alcancem o alto nível, criando um ambiente seguro e positivo para ensinar as habilidades, bem como procuram valorizar cada jogador de igual forma e o seu staff técnico com respeito.

Jones (2006) diz que o treino é uma das profissões que exigem habilidades críticas e conhecimentos das visões do mundo, direcionando a prática do treino ao ensino.

Para se conseguir ter êxito, num âmbito geral, o treinador tem de ser um líder instruído que direciona as pessoas para que trabalhem todas em prol desse mesmo objetivo de maneira inteligente. As habilidades de liderança dos treinadores são cruciais para obter resultados bem-sucedidos. Treinadores de sucesso "soltam" o potencial dos jogadores, permitindo que eles se realizem e apreciem aquilo que fazem (Acet, Gumusgul, \& Isik, 2017).

$\mathrm{Na}$ tabela 3 podemos ver as competências profissionais do "saber-saber" na qual tanto os treinadores experientes como os jovens apresentaram resultados bastante negativos. Estes resultados são contraditórios ao que defende Veríssimo (1999) pois, este demonstra que uma correta nutrição leva a que os mecanismos de recuperação ocorram com maior eficácia. Esta nutrição é um dos fatores que pode maximizar o desempenho dos atletas, bem como melhorar a sua saúde a longo prazo e reduzir a fadiga, o que permite ao atleta treinar por períodos mais longos ou recuperar mais rapidamente entre sessões de treino. Um dos entrevistados defendeu a importância do conhecimento da nutrição"...e depois também temos que perceber o impacto da nutrição nos nossos atletas. Como raio é que eu quero ter sucesso, se tenho jogadores que chegam ao jogo e não tomaram o pequeno-almoço, ou não saberem como certo tipo de bebidas e de nutrientes são capazes de potenciar ou prejudicar o seu rendimento desportivo? Isso é inadmissível, e faz parte da nossa função, incentivar, sensibilizar, e ensinar os nossos jogadores acerca desta parte do futebol. Se um treinador não souber, temos que contratar quem saiba, se não temos dinheiro para contratar, o treinador tem que ganhar formação nesse especto, simples. Os jogos também se ganham aqui!" Por sua vez, Garcia (2000) defende que a melhoria do desempenho passa pela obtenção de informação pontual e objetiva sobre as atuações dos jogadores em competição. Francks, Mcgarry e, Hanvey (1999) defendem que os treinadores têm procurado obter informações sobre o desempenho individual ou coletivo dos seus jogadores e equipas. Porém, tanto os treinadores distritais jovens como os experientes não deram grande importância a esta competência profissional.

$\mathrm{Na}$ tabela 4 podemos analisar onde existiram maiores diferenças entre os treinadores experientes e jovens, no que concerne ao "Saber-Saber". No primeiro caso, poderá ser explicado devido a que os treinadores jovens normalmente estão em escalões mais baixos, com claro objetivo formativo e de potenciar os jogadores para os escalões superiores, enquanto os treinadores experientes usualmente já estão em 
escalões mais de rendimento, seja em termos da formação ou seniores, em que é mais importante o curto prazo do atleta. Porém Para Baker e Horton (2004) o treinador tem responsabilidade ao nível da qualidade do treino, da resposta às exigências da competição e do desenvolvimento dos atletas, enquanto desportistas e pessoas.

Já no segundo caso, ambos dão importância, contudo é o treinador jovem que apresenta maiores resultados, que coincidem com os dados recolhidos por Costa (2005), pois este demonstra que o treinador deverá possuir "conhecimentos técnico táticos da modalidade" e os "conhecimentos de planeamento do treino".

No que diz respeito ao "Saber-Fazer", ambos apresentaram resultados negativos, em especial os treinadores jovens com apenas 39.6\% comparativamente ao também negativos, $42.7 \%$ dos treinadores experientes. Estes dados podem ser explicados devido à pouca experiência do treinador jovem, em que apesar de demonstrar bons resultados no "Saber-Saber" poderá não conseguir fazer o transfere da teoria para a prática.

$\mathrm{Na}$ tabela 5, tanto os treinadores jovens como os experientes deram importância à comunicação em diferentes circunstâncias, à forma de dirigir os praticantes na sessão de treino, assegurando o exercício das competências de ensino fundamentais (explicação, demonstração, observação e correção) e ainda a participar na conceção do planeamento da atividade de treino e de competição, como podemos ver em “...Acho que é importante ter a capacidade de definição de objetivos e etapas de conteúdos a serem transmitidos o grupo é importantíssimo ter essa capacidade... previsão do futuro, que será o trabalho? aquilo que eu quero...Eu quero trabalhar, e o que eu quero transmitir, mas também acima de tudo a capacidade de ajustamento, porque nem sempre o que planeamos é $100 \%$ adequado, e temos que ajustar, mas nunca fugindo da planear, de planificar os altos e baixos próprios da época.

Araújo (1994) refere que a profissão de treinador deve obedecer a uma certa organização, em diferentes aspetos, como o estilo e as formas de comunicação (com os jogadores, treinadores, dirigentes, árbitros, comunicação social). Costa (2005) demonstrou que os treinadores do seu estudo deram importância à capacidade de organizar e planear a prática do treino, à capacidade de identificar os erros e fornecer informação de correção. No mesmo estudo, os treinadores também demonstraram grande preocupação em questões relacionadas com o planeamento.

$\mathrm{Na}$ tabela 6 é apresentado as competências profissionais menos referidas por ambos os grupos. Carvalhinho, Rodrigues, Nunes e Rosa (2014) aludem que é fundamental o domínio dos aspetos de segurança e o saber intervir ao nível do socorrismo, tendo em conta as diferentes etapas de desenvolvimento das crianças e dos jovens praticantes.

No que respeita ao "Saber-Ser" ambos os casos apresentam os seus melhores resultados, com maior pendor para os treinadores jovens (60.6\%) em comparação aos $(55.6 \%)$ dos treinadores experientes. Na tabela 7 é evidenciado que, ambos os grupos de treinadores dão, praticamente na sua totalidade, importância na forma como se adaptam aos contextos, e de procurarem promover comportamentos seus dignos em frente a toda a estrutura da sociedade. Côté, Young, Duffy, e North (2007) afirmaram que o conceito de excelência (nos treinadores) deve ser julgada pela forma como os treinadores usam o seu conhecimento, demonstram o seu comportamento e competências sociais durante as suas interações com os atletas em vários contextos desportivos. No entender de Côté e Gilbert (2009), a excelência nos treinadores é evidente quando a sua eficácia, que consiste na aplicação de conhecimento profissional, interpessoal e intrapessoal para melhorar a competência dos atletas, confiança, ligação emocional e caráter em contextos desportivos específicos. Esta visão é evidenciada através do seguinte excerto: “...Um treinador tem que tentar ser o mais justo e honesto possíveis com todos do grupo, quanto mais transparente e imparcial mais fácil é ganhar o respeito do grupo de trabalho. Parece a história da carrocinha, mas é verdade, todos os valores que os nossos pais nos ensinam quando somos crianças e nós não ligamos, são todos os valores que um treinador deve possuir, porque afinal o treinador é muitas vezes um pai, pois a sua forma de estar será sempre o exemplo, se nós formos um mau exemplo não vamos querer ou conseguir que os nossos jogadores tenham bons valores, porque nós recebemos dos jogadores aquilo que lhes mostramos."

Os resultados da tabela 8 podem ser explicados devido, a que no primeiro caso, os treinadores experientes já estão há mais tempo no clube e até possuem funções coordenativas, o que leva a procurarem "fixar" os jogadores ao seu clube, do que o treinador jovem que muitas vezes transita de clube em cada final de época. No segundo caso, os resultados poderão ser explicados devido a que normalmente os treinadores jovens estão em escalões mais baixos, o que poderá significar precisarem da ajuda dos pais dos seus jogadores em algumas matérias do futebol (transportes, delegados, apoio técnico, etc.) ao contrário dos treinadores experientes que já não precisam tanto do apoio parental dos jogadores devido a todo um contexto mais elaborado e estruturado.

Por fim, e segundo Sullivan, Paquette, Holt, e Bloom, (2012) todos os resultados apresentados neste estudo podem ser explicados na medida em que os treinadores ainda não dominam toda a complexidade ao nível das competências profissionais impostas para a função de treinador, porém Curado (1982) defende 
que o treinador necessita de possuir uma grande competência, alicerçada numa sólida formação, a qual terá de ser, por um lado multilateral e, por outro, especializada, afirmando, ainda, que os treinadores têm de saber tudo da sua modalidade.

Limitações: Uma limitação deste estudo foi a metodologia utlizada. Ao utilizar um guião de entrevistas experimental, não previamente avaliado e aceite por um grupo de especialistas é uma lacuna do presente estudo. Também e, como referido anteriormente, o número de treinadores entrevistados é uma limitação, pois apenas existe dados de 20 treinadores de cada grupo (jovem e experiente), sendo importante aumentar consideravelmente os números de entrevistados para podermos generalizar os dados.

Linhas de Orientação Futura: Utilizar um guião previamente validado por especialistas e, analisar o contexto nacional, amador e profissional e perceber quais as suas diferenças em relação as competências Profissionais dos Treinadores de Futebol.

\section{Conclusões}

Através dos resultados obtidos com este estudo podemos concluir sobre a importância dada pelos treinadores distritais jovens e experientes em relação às diferentes competências profissionais, as suas divergências e as suas convergências. Devido ao número reduzido de entrevistados (40, sendo 20 de cada grupo), não podemos generalizar os dados obtidos, porém foi possível observar que ambos os grupos atribuíram relativa importância aos diversos "Saberes", já que ambos referiram mais de 50\% das competências profissionais. Não existe grandes diferenças entre os treinadores distritais jovens e experientes, contudo, foram os treinadores distritais jovens que apresentaram resultados mais elevados, referindo (51\%) dos itens do (PNFT).

Em relação ao "Saber-Saber" os treinadores jovens apresentaram melhores resultados, referindo (52.7\%) dos itens do (PNFT). Por sua vez, em relação ao "Saber-Fazer" foram os treinadores experientes que apresentaram melhores resultados, referindo (44.7\%) dos Itens do (PNFT). Por fim, no "Saber-Ser" foi de novo os treinadores jovens a apresentarem melhores resultados, referindo $(60.6 \%)$ dos itens do (PNFT). Conclui-se ainda que é o "Saber Fazer" em que tanto os treinadores experientes como os jovens apresentam os piores resultados, não conseguindo referir metade dos tópicos deste saber.

Acrescentar ainda que os resultados apresentados responderam às hipóteses lançadas na introdução, uma vez que se conseguiram concluir qual dos grupos de treinadores dão mais importância aos diferentes "saberes" (saber-saber, saber-fazer, saber-ser) e em quais competências específicas de cada saber que estes dão mais importância.

\section{Referências}

Acet, M., Gumusgul, O., \& Isik, U. (2017). Leadership characteristics of football coaches. Sports Si Societate Revistă de Educaţie Fizică, Sport şi Ştiinţe Conexe.

Almeida, C. (2001). O Treinador em Portugal Perfil social, caracterização da atividade $e$ formação. Instituto Nacional de Formação e Estudos do Desporto.

Araújo, J. (1994). Ser treinador. Editorial Caminho, S.A.

Baker, J., \& Horton, S. (2004). A review of primary and secondary influences on sport expertise. High Ability Studies, 15(2), 211-228.

Bloom, G. A., Bush, N., Schinke, R., \& Salmela, J. (1998). The importance of mentoring in the development of coaches and athletes. International Journal of Sport Psychology, 29(3), 267-289.

Bruden, P. (1990) Teacher development. In W. Robert Houston (ed.), Handbook of research on teacher education (pp. 311-328). MacMillan.

Buceta, J. M. (2009). Psicologia dos treinadores esportivos: Conceitos fundamentais e áreas de intervenção. In M. R. Brandão \& A. A. Machado (Eds.), Coletânea psicologia do esporte e do exercício: O treinador e a psicologia do esporte, (Vol. 4, pp. 17-40). Editora Atheneu.

Cassidy, T., Potrac, P., \& McKenzie, A. (2006). Evaluating and reflecting upon a coach education initiative: The code of rugby. The Sport Psychologist, 20, 145-161.

Carvalhinho, L., Rodrigues, L., Nunes, G., \& Rosa, P. (2014). Formação de técnicos (Treinadores) de grau I de Desportos de Natureza. Estudo das competências profissionais. Em, $2^{\circ}$ Congresso da UIIPS, Santarém, 6 e 7 fevereiro.

Costa, J. P. (2005). A formação do treinador de futebol-análise de competências, modelos e necessidades de formação (Mestrado). Faculdade de Motricidade Humana - Universidade Técnica de Lisboa, Lisboa.

Côté, J., \& Gilbert, W. (2009). An integrative definition of coaching effectiveness and expertise. International Journal of Sports Science \& Coaching, 4(3), 307-323

Côté, J., Salmela, J., Trudel, P., Baria, A., \& Russel, S. (1995). The coaching model: A grounded assessment of expert gymnastic coaches' knowledge. Journal of Sport and Exercise Psychology, 17, 1-17.

Côté, J., Young, B. W., Duffy, P., \& North, J. (2007). Towards a definition of excellence in sport 
coaching. International Journal of Coaching Science, 1, 3-17.

Curado, J. (1982). Planeamento do treino e preparação do treinador. Editora Caminho.

Duffy, P. (2008). Implementation of the Bologna Process and model curriculum development in coaching. In K. Petry, K. Froberg, A. Madella, \& W. Tokarsky, (Eds). Higher education in sport in Europe: From labour market demand to training supply (pp. 80-108). Meyer \& Meyer Sport.

Figueiredo, A. (1997). A formação de treinadores no desporto federado - $\mathrm{O}$ treinador no segundo milénio (pp. 113-121). II Congresso de Gestão do Desporto - Comunicações, APOGESD, Lisboa.

Fleurence, P., \& Cotteaux, V. (1999). Construction de l'expertise chez les entraineurs sportifs d'athlètes de haut niveau français. Avante, (5), 54-68.

Franks, I., McGarry, T., Hanvey, T. (1999). From notation to training: Analysis of the penalty kick. Insight, 3, 24-25.

Garcia, J. (2000). Balonmano: Perfeccionamiento e investigación. INDE.

Gilbert, W., \& Trudel, P. (1999). Framing the construction of coaching knowledge in experiential learning theory. Sosol sociology of sport online, 2(1), 5 .

Gould, D., Giannini, J., Krane, V., \& Hodge, K. (1990). Educational needs of elite U.S. National teams pan American, and olympic coaches. Journal of Teaching in Physical Education, 9(4), 332-344.

Horton, S., Baker, J., \& Deakin, J. (2005). Experts in action: A systematic observation of 5 national team coaches. International Journal Sport Psychology, 36, 299-319.

Jones, R. L. (Ed.). (2006). The sports coach as educator: Re-conceptualising sports coaching. Routtledge.

Mesquita, I., Isidro, S., \&; Rosado, A. (2010). Portuguese coaches' perceptions and preferences for knowledge sources related to their professional background. Journal of Sports Science and Medicine, 9, 480-489.

Neves, A, J. (2016). O Fenómeno do futebol em Portugal. Estudo de caso Concelho da Guarda. (Mestrado). Universidade da Beira Interior.

Perrenoud, Ph. (1995). La fabrication de d' excellence scolaire: Du curriculum aux pratiques d' evaluation. Droz

Programa nacional de formação de treinadores Referenciais de formação (2020). Geral.https://ipdj.gov.pt/documents/20123/11782
3/PNFT2020_05032020.pdf/fd3b3b3e-56140b89-d2b1-c3e79947c99f?t=1585671093558.

Regulamento curso de treinador grau I- UEFA C (2020).

https://afl.pt/_docs/documentacao/notasinformati vas/2019/Regulamento do Curso de Treinador es_de_Futebol_UEFA_C_2018_2020_pdf.

Regulamento curso de treinador grau II - UEFA B (2020).

https://afl.pt/ docs/documentacao/regulamentos/ 2018/Regulamento do Curso de Treinadores d e Futebol UEFA B 2018 2020 .pdf.

Resende, R., Sequeira, P., \& Sarmento, H. (2016). Coaching and coach education in Portugal. International Sport Coaching Journal, 3, 178183

Resende, R., Gomes, J., Silva, A., Fernández, J., \& Castelo, J. (2009). O bom treinador: Um estudo realizado com treinadores experts de Voleibol Portugueses. II Congresso Internacional de Deportes de Equipo, Coruña, Espanha.

Salmela, J. (1996). Great job coach! Getting the edge from proven winners. Ed. Potentiun.

Salmela, J., Draper, S., \& Laplante, D. (1993). Development of expert coaches of team sports. VIII World Congress of Sport Psychology, Lisbon.

Santos, S., Mesquita, I., Graça, A., \& Rosado, A. (2010). Coaches' perceptions of competence and acknowledgement of training needs related to professional competences. Journal of Sports Science and Medicine, 9, 62-70.

Saury, J., \& Durand, M. (1998). Practical knowledge in expert coaches: On-site study of coaching in sailing. Research Quarterly for Exercise and Sport, 69(3), 254-266.

Stoszkowski, J., \& Collins, D. (2012). Communities of practice, social learning, and networks: Exploiting the social side of coach development. Sport, Education and Society, 1(16), 773-788.

Sullivan, P., Paquette, K., Holt, N., \& Bloom, G. (2012). The relation of coaching context and coach education to coaching efficacy and perceived leadership behaviors in youth sport. The Sport Psychologist, 26, 122-134.

Vallée, C., \& Bloom, G. (2005). Building a successful university program: Key and common elements of expert coaches. Journal of Applied Sport Psychology, (17), 179-196.

Veríssimo, M. (1999). Alimentação do desportista. In H. Saldanha (Ed), Nutrição clínica (pp. 113 143). Lidel, Edições Técnicas. 


\title{
Understandings and uses of assessment: case study with Spanish teacher educators
}

\author{
André Moura, Amândio Graça, Paula Batista. \\ University of Porto, Faculty of Sport.
}

\begin{abstract}
Keywords Palavras-chave Formative and shared assessment; teacher education programmes; student-centred teaching; learning

\section{ABSTRACT:}

Assessment can serve different purposes. In Spain there has been an increase of research in assessment processes that intends to enhance students' learning. Attending to this scenario, this study intends to explore the understandings of four teachers from one Spanish university, known as one of the most active in developing formative and shared assessment processes, about i) the process of implementing formative and shared assessment processes and ii) the impact of these assessments on students and on the teaching-learning process. Four teachers were purposively selected to be interviewed, according to their availability, use of assessment to promote students' learning, work in a teacher education programme and have more than 15 years of experience as teacher. Analysis of data collected from semi-structured individual interviews resulted in the following themes i) formative and shared assessment - advantages vs. disadvantages, ii) vision about teacher education programmes, iii) teachers' changes throughout their career, iv) students' participation in assessment, and v) negotiating the teaching-learning process with students. These teachers consider that formative and shared assessment can be laborious, but worth the effort, mainly in teacher education programmes, where the focus is not only on student-person, but also on future teacher-person.
\end{abstract}

Palavras-chave Avaliação formativa e partilhada; programas de formação de professores; ensino centrado nos alunos; aprendizagem
Entendimentos e usos da avaliação: estudo de caso com educadores de professores de espanhol

\section{RESUMO:}

A avaliação pode servir diferentes propósitos. Em Espanha tem havido um aumento de investigação em processos de avaliação que procuram melhorar a aprendizagem dos alunos. Neste sentido, este estudo pretende explorar os entendimentos de quatro professores de uma universidade espanhola, conhecida como uma das mais ativas no desenvolvimento de processos de avaliação formativa e partilhada, sobre i) o processo de implementação de processos de avaliação formativa e partilhada e ii) o impacto dessas avaliações nos alunos e no processo ensino-aprendizagem. Os quatro professores entrevistados foram selecionados intencionalmente, tendo em conta a sua disponibilidade, o uso de avaliação para promover a aprendizagem dos alunos, trabalhar num programa de formação de professores e ter mais do que 15 anos de experiência como professor. A análise dos dados recolhidos, através das entrevistas individuais semiestruturadas resultou nos seguintes temas: i) avaliação formativa e partilhada - vantagens e desvantagens, ii) visão sobre os programas de formação de professores, iii) mudanças dos professores ao longo da carreira, iv) participação dos alunos na avaliação, e v) negociação do processo ensino-aprendizagem com os alunos. Estes professores admitem que a avaliação formativa e partilhada pode ser exaustiva, mas compensa o esforço, principalmente nos programas de formação de professores onde o foco é desenvolver o estudante não só como aluno, mas também como futuro professor. 


\section{Understandings and uses of assessment: case study with Spanish teacher educators}

Assessment is a central aspect in education and one of the key components to a quality Education (Graça et al., 2019; Hay et al., 2015). Although considered as having a huge impact on teaching and learning, assessment has been mostly used as a means of classifying and ranking students (Batista, 2019; Black \& Wiliam, 1998; López-Pastor, Kirk, et al., 2013; MacPhail \& Murphy, 2017). Assessment can only have a positive impact when intended to promote students' learning and teachers reducing assessment only to grading purposes will fail to reach the whole potential of assessment (AIESEP, 2020; Baird et al., 2017; Batista et al., 2019; Black \& Wiliam, 1998; Leirhaug \& Annerstedt, 2016; MacPhail et al., 2018; Wiliam, 2011).

In the last twenty years, there was an increase of literature advocating for a formative use of assessment (Baird et al., 2017; Broadfoot et al., 1999; MacPhail et al., 2018; Salom, 2019). This concern reached teachers and researchers in Spain where a network of formative and shared assessment in higher education was created some years ago (López-Pastor, Castejón, et al., 2011c). The intention behind this network was to allow teachers and researchers from different universities developing their knowledge in assessment: methods/strategies, students' participation, improve the quality of teaching and learning. It also allowed them to easily interact and support each other when implementing formative and shared assessment practices in their contexts. Hence, several studies in formative and shared assessment processes in higher education were conducted across the different universities in the country with the purpose of increasing students' learning (e.g., Castejón Oliva et al., 2011; Córdoba-Jiménez et al., 2018; Hortigüela-Alcalá \& Pérez-Pueyo, 2016; López-Pastor, 2009, 2011a; López-Pastor et al., 2008; López-Pastor, Pintor, et al., 2013; López-Pastor \& Sicilia-Camacho, 2016; Pueyo et al., 2008; RomeroMartín et al., 2017). Furthermore, there was also an interest in increasing students' participation in assessment process which occurred through self, peer and co assessment (Barrientos-Hernán et al., 2019; Hamodi et al., 2017; Lorente-Catalán \& Kirk, 2014; Molina \& López-Pastor, 2019). These techniques can increase students' autonomy, motivation, and responsibility (AIESEP, 2020; Boud \& Falchikov, 2007; Fletcher, 2018).

In teacher education programmes, future teachers must learn contents but also how to use assessment in a formative and shared way. These skills can be developed during their training while using self, peer and co assessment. Student teachers seem to value having these experiences during their training (Hamodi et al., 2017; Molina \& López-Pastor, 2019), because implementing assessment that intends to promote students' learning is complex and difficult.
The challenges to apply formative and shared assessment mentioned in literature tend to be: (a) lack of training and knowledge (Leirhaug \& Annerstedt, 2016; Lund, 1993); (b) increase of workload (Chng \& Lund, 2018; López-Pastor, Pintor, et al., 2013); and (c) lack of practical examples in literature (Borghouts et al., 2017; López-Pastor, Kirk, et al., 2013). Despite these challenges, some studies showed teachers putting formative and shared assessment in practice (e.g., Córdoba-Jiménez et al., 2018; HortigüelaAlcalá \& Pérez-Pueyo, 2016; López-Pastor, Pintor, et al., 2013; López-Pastor \& Sicilia-Camacho, 2016). Attending to this scenario, this study intends to explore the understandings of four Physical Education teacher educators from one Spanish university, known as one of the most active developing formative and shared assessment processes, about (a) the process of implementing formative and shared assessment processes and, (b) the impact of these assessments on students and the teaching-learning process.

\section{Method}

A case study (Yin, 2009) was used to get a deep understanding of the phenomenon under study. This method contributed to improve the knowledge of the main researcher while in the study context, and so when doing interviews with teachers.

The study took place in one university in Spain that has been one of the most actively involved in developing formative and shared assessment processes in higher education, making this a good example to (a case) study.

\section{Participants and settings}

A researcher developed an internship in a Spanish university very well known for all the work that has been developed throughout the years in terms of formative and shared assessment. This university with four campuses in one region of Spain, is one of the oldest universities in Spain and in the world, with more than 20.000 students and more than 2.000 teachers. The specific faculty in which these teacher educators work offer several courses among undergraduate, master and $\mathrm{PhD}$ degrees.

Although there is a huge tradition with the use of formative and shared assessment not all teacher educators in that university follow these assessment processes. Some teachers and researchers from this university belong to a network that intend to use assessment to improve students' learning and participations. Teachers and researchers on that network belong to different teaching contexts (school and university) and are from different regions of Spain and, in some cases, Portugal. There are also some meetings with teachers from different teaching levels who attend and share ideas, practices and difficulties while trying to implement formative and shared assessment practices. These meetings are 
optional and intend to support teachers who want to use these assessment practices. The teacher educators who teach in this teacher education programme not only advocate for the use of formative and shared assessment to their students (teachers) but they also use it throughout the units they teach. These teachers follow the motto teach by example, i.e., use their students as active participants in their learning and assessment process, negotiate with their students what and how they are assessed and providing practical examples of how to implement these assessment practices to improve their students' learning.

From the eight teachers' educators purposively selected (Patton, 2002) by the researcher, it was only possible to interview four of them due to external constraints to the researcher. To be considered eligible to the study teachers' educators would have to i) be available and interested in being interviewed, ii) use assessment to promote students' learning, iii) work in a teacher education programme and iv) have more than 15 years of experience as a teacher. All the four teacher educators belong to the same faculty and teach in the same teacher education programme. Three teach physical education and one teaches subjects as management and qualitative research. One of the teachers from physical education only teach theoretical units while the other two teach theoretical and practical units. These four teachers have been teaching for many years in higher education (more than 22 years), they also had experiences in schools in their first years as teachers (for three years). Three from the four teachers revealed that they used assessment only to grading purposes during their first years as teachers as consequence of their initial teacher education programmes. All teachers accepted having the interview recorded. The researcher ensured confidentiality and anonymity to all participants in all phases of the study.

\section{Data collection and analysis}

The four teachers were individually interviewed through semi-structured interviews in a quiet room at the university. Each interview lasted 30 minutes on average. Examples of questions posed in the interview consist of "What kind of assessment have you been using throughout your career? what changed?", "what is your and your students' role in assessment?", and "how do you teach assessment to your students and what kind of assessment?". Interviews were recorded and transcribed verbatim to a Word document before being returned to teachers who read and approved their respective transcripts. The study took a deductive-inductive analysis triangulating data from the interviews with the study aims about: i) the process of implementing formative and shared assessment and ii) the impact of these assessments on students and the teaching-learning process.
Interview's transcripts were first read and examined incident by incident (Braun \& Clarke, 2012), highlighting possible meaningful extracts on the text. The text on highlighted extracts was re-read by the author, before starting the coding process (Resende, 2016). A second author read the codes, approving, or rejecting them. Codes were then refined, being aggregated by proximity. The following themes emerged from the analysis: i) formative and shared assessment - advantages vs. disadvantages, ii) vision about teacher education programmes, iii) teachers' changes throughout their career, iv) students' participation in assessment, and v) negotiating the teaching-learning process with students.

\section{Results}

\section{Formative and shared assessment - advantages vs. disadvantages}

According to teachers, using formative and shared assessment can be challenging due to the time needed to assess students' work throughout the process:

One of the drawbacks of assessing throughout the process to improve students' learning is the time we need to this. Assessing my students' works means a time in each week just for that 'task'. Sometimes can be challenging (Teacher3).

Although teachers consider using formative and shared assessment can bring more work to teachers, they advocate that this is more meaningful to students. The teaching-learning process is oriented to improve students' learning:

I do not see it as harder. Could mean more work but is much more enriching. Instead of preparing what I want to say, I prepare what I want them to work on. All the things are done in a way that is more meaningful to students, focused to improve their learning and not only to teach some contents that they maybe will never use it (Teacher2).

Teachers consider the advantages of formative and shared assessment surpass the disadvantages. Working in this way allows students to learn better, improve as a teacher and so their subject:

I work the way I do, because students can learn more, I can improve as a teacher and the subject is corrected and adapted during the process which makes the discipline work better (Teacher4).

Students complain sometimes throughout the teaching-learning process about the work they have, but tend to appreciate after the process:

Students tend to criticize and say that they have too many tasks, but this happens to give them chances to learn throughout the process. For example, when in group work, what matters is not only the contents, but also how they do, prepare, and the group works. It is necessary tutoring, follow-up, feedback. In the end of the process, students mention that all the work paid off, allowed them to learn more, see their weaknesses and potentialities. Education should be about helping students be better rather than only approve/disapprove students (teacher2). 
Vision about teacher education programmes These teachers consider teacher education programmes should help students making the transition from students to teachers and this means prepare their students to be teachers, e.g., teach them how to assess:

Assessment needs to help students understand their teaching-learning process and change their mindset start thinking as teachers. Students will have to assess in the future, so it is important they start having some experiences, getting used to assess. As students they are usually used to wait for the teacher to take the next step and the idea is to change that. Teacher education programmes have to prepare students to be teachers, and this demand, even more, change the traditional passive role of students (Teacher3).

These teachers consider then, teacher education has a double purpose - teach contents (students) and teach how to teach and assess (future teachers). These teachers advocate those students need to have practical experiences, assuming the role of teachers, e.g., prepare classes, teach, assess, reflect.

I believe teacher education programmes have a double purpose. Is about teaching the contents and teaching students how to teach, how to assess. They are future teachers, so they must learn how to assess. Only assessing them and talking about assessment is not going to help them to develop their assessment skills. I really believe the way I work - having them acting as teachers, teaching, assessing, reflecting, being teachers, promote more learning on their current situation as students, but also, prepare them better to their future as teachers (Teacher4)

I give students the opportunity to prepare classes, reflect and be critical about the work they receive and the work they do. What I do and think, every teacher in initial teacher training should do, it is thinking that we are teaching future teachers. Giving them only contents, is not enough, because everyone can take a planning and use it. They need to learn how difficult it is to be a teacher, because we are responsible for taking the best from each student, to help them become better people, capable of assuming challenges and overcome problems and failures while teaching our contents (Teacher2).

\section{Teachers' changes throughout their career}

Three from the four teachers reported that on their first years as teachers, assessment served just the purpose of grading students on exams. They changed throughout their career from summative to more formative approaches of assessment for considering it would benefit their students:

"This change on the way I understand and use assessment came with my training. The formative process demanded that I understood assessment in a more formative way. Previously, I had seen assessment only as a means of giving grades and then, started seeing it as a process of dialogue, understanding and improvement" (Teacher3)

In the beginning of my career, assessment was using exams to grade students. Then, when I came to university, I saw other ways to assess, more formative, more shared. I thought that would be beneficial to students, so I changed a lot. Now I almost do not use summative assessment (Teacher2).
Teacher mentioned they felt they had to change their assessment to be able to support students' learning. Changing to assessment as a support of the teachinglearning process implied changing the way they used to teach, mainly students' role:

I changed my assessment and teaching. I noticed that I did not like what I did, because I could not identify students' problems, interest, learning and knowledge. I decided to change the way I assessed, and this is only possible if we also change the way we teach. What we want with these types of assessment is to have students also participating in their learning process (Teacher2).

Students tend to be surprised in the beginning of the semester, as they are not expecting, when teachers leave comments with feedbacks about what students need to improve rather than marks on their work:

Initially, students get lost and confused with my amendments on their works, because they expect to receive a mark. They think that I send these works to evaluate them. However, when I assess these tasks, I do not give grades, only comments, because my intention is to explain them what I want them to improve (Teacher2).

Teachers highlighted that the purpose of formative assessment - improve students' learning, must be ahead of everything else. Teacher admitted that sometimes there is a tendency to put assessment before learning, however, they advocate teachers should use what supports their students' learning:

What we call formative assessment is a tyranny. My concern is how students are learning, I see the things more globally. That is why I reduced the number of instruments used in classes, because I do not believe that this is the essence of assessment. We cannot use instruments just because others use. We must use what helps our students' learning (Teacher1)

Sometimes I think assessment is overvalued. Assessment is crucial, but the emphasis needs to be on students' learning. There is a concern to assess everything through objective instruments as rubrics or checklists. I advocate that assessment is used to support learning, not the other way around. Assessment has to fit learning, and this does not occur if assessment is scheduled first (Teacher1)

\section{Students' participation in assessment}

One of the teachers' teaching is based on dialogic learning which is the reason why that teacher uses both formative and shared assessment:

The way I work and understand education since I started to work is founded on a learning approach deeply dialogic. For me, formative and shared assessment matches very well with the dialogic learning model, because they are very consistent among them (make the learning process clear to students) and that is why I always use them jointly (Teacher4)

Teachers agree that students must be able to assess their learning and teachers want them to reflect about it. For this reason, students' work is followed by a self-assessment form. Teachers believe this also allow them to provide quicker feedback to students:

I consider self-assessment paramount because students have to diagnose themselves. I ask them how they think they are in their learning, and I am really interested in 
what they tell me. I want to understand what they think they learned and what they did not. For me, it is crucial that they reflect about their learning (Teacher1).

We use self-assessment on a 'work base'. Each time students deliver a work they must complete a selfassessment form about the work they developed. These sheets allow me to give faster and clear feedback. These are assessment processes without grades and focused on the quality of students' work and what they have to improve (Teacher4).

Teachers consider students appreciate receiving feedbacks, but simultaneously fail to accept their flaws. Doing this work of assessing themselves and their peers can help them to be more critical about their own work and learn to accept criticism from teachers and peers:

Sometimes when students see a comment in their work, they appreciate the comments, but at the same time, they do not accept it very well. Many students think that they did everything right because there is a lack of selfcriticism. They are not used to do these processes, and we are very proud of ourselves, we feel so much selflove and it is hard for us to accept that we have difficulties. This is a learning process which I consider extremely important. I think assessing their own and peers can help students lose that lack of self-criticism and learn how to accept criticism from teachers and peers (Teacher2).

One teacher revealed that peer assessment is mostly used when students assume the role of teachers in the practical experiences they have during the course. Students who acted as teachers must assess peers from their group and students who acted as students must assess students who acted as teachers:

We use peer assessment when we simulate a teachinglearning process with some students assuming a role as teachers and others as students. At this moment, students who act like teachers must assess how their group worked, how they solved problems. On other hand, students who act like students must assess 'teachers', providing feedback on how they felt as students on this class, if they think it can be applied in school with students. They also assess their colleagues every time a group exposes their work. In both cases, students receive assessment criteria and must fulfill a peer assessment form to assess their colleagues. They highly value what their colleagues say, because they know it is real. This is how they saw it, how they felt it, this is not only a teacher's perception and so, but they also take it into consideration (Teacher2).

Other two teachers use peer assessment as a way of students reflecting about peers' work, but do not use it in a systematic way neither use specific tasks to apply it:

I use peer assessment, but it is like a process of collective reflection in analyse of sessions. Students do not have to fulfill documents (Teacher4)

We have an online platform where students can give feedback to each other. Some students share their work in the common area to receive feedback from others, some do not (Teacher1)

\section{Negotiating the teaching-learning process with students}

One teacher mentioned that teacher and students sign a contract at the beginning of the semester so they both know their obligations and duties. This contract contains learning goals and assessment criteria:

This year every student signed a contract in which I take on my duties and students theirs. Subject goals and assessment criteria are shared when we sign this contract at the beginning of the semester (Teacher1).

One teacher revealed that every year there are some adjustments in terms of instruments or criteria, but the purpose behind assessment remains the same. These adjustments result from students' suggestions when the teacher announce the goals, contents, and criteria at the first class of the semester:

Every year I make some minor changes when I detect errors or problems in some aspect of assessment. The way and the purpose behind assessment is always the same, but I change some technical aspects as for example, instruments or assessment criteria. Learning goals, contents and assessment criteria are shared with students on the first class. I give a detailed program and explain in detail how the subject will work. After this moment, they are placed in groups of two-three students, and I give them time to discuss to see if they want to propose something different than what I proposed. Then, we make an assembly with everyone in the classroom and if someone present a proposal that make sense and sounds good to all of us, we use it (Teacher4).

One teacher mentioned that, especially first year students who usually have never had the opportunity to negotiate what they are going to learn, tend to find difficult to suggest learning goals:

There are some problems in the moment I share learning goals and assessment criteria with students who are not used to it, especially first year students who never had the 'power' to negotiate what they are going to learn. This is especially evident with learning goals because they do not understand very well where I want them to go and how much they can achieve. So, when I ask them, they struggle to participate (Teacher2).

One teacher considers more relevant in only taking decisions about assessment criteria at the end of the teaching-learning process. At that point both teacher and students decide how to value each work conducted by students:

Within formative assessment there are a lot of people who thinks that is necessary a previous agreement about the instruments used on assessment, however, I work in a different way. I consider it more relevant that students know and understand the teaching-learning process, and when it came to the last class, we decide together how to value each instrument used during the process. In the last years, I have been allowing students to select different criteria from their colleagues, since it is one of the proposed options accepted by everyone (Teacher3). 


\section{Discussion}

In their first years as teachers, they used assessment only to provide marks to students as consequence of their education. Even nowadays, the unique use of summative assessment remains as the most common among teachers (López-Pastor, Kirk, et al., 2013; MacPhail \& Murphy, 2017), despite the increasing literature reporting the advantages of formative practices on improving students' learning (Graça et al., 2019; Salom, 2019; Silva et al., 2019). These teachers' interest in improving their students' learning helped them to change their use of assessment to more formative and shared approaches. This change could be also influence of the work developed among the network of teachers and researchers in Spain (López-Pastor, Castejón, et al., 2011c).

Although assessment is recognized as a means to promote students' learning (Leirhaug \& Annerstedt, 2016; López-Pastor, Kirk, et al., 2013; MacPhail et al., 2018), one of the teachers of this study consider that sometimes there is a tendency to overemphasize assessment (strategies and instruments), forgetting about the impact of these on learning. That teacher described that as a paradox, reinforcing the idea that assessment should serve learning and not the other way around. This idea is aligned with literature reporting the need to teachers being critical about the use of assessment (Hay et al., 2015; Lorente-Catalán \& Kirk, 2013; Tolgfors, 2018). Rather than the amount or the type of instrument, it is the way the instrument is used that makes assessment formative or summative. For this reason, these teachers mentioned that the use and instruments can vary every year according to what can be more effective and easier to implement on their classes. This critical stance against instruments and strategies available can be 'a solution' to solve one of the disadvantages commonly indicated on literature about formative assessment (Baird et al., 2017; López-Pastor, 2011b; López-Pastor, Kirk, et al., 2013; Molina \& LópezPastor, 2019) that is the increase of workload on teachers (many times unworkable in practice). LópezPastor, Pintor, et al. (2013) showed on their work that the workload increases with formative and shared assessment, but not in the way many times teachers and students perceive it. Teachers interviewed on this study agree that using formative and shared assessment brings more work to teachers compared to summative assessment, but worth the effort, considering it results in more students' learning, improve their teaching and their subject.

According to these teachers, changing to an assessment oriented to students' learning forced them to change the way they taught to a more studentcentred approach. A formative and shared assessment classroom tends to rely on socio constructivist learning theories which implies having students as active participants in the teaching-learning process
(Allal, 2020; Batista et al., 2019; Coombs et al., 2018; Fletcher, 2018). Interviewed teachers consider important share learning outcomes and assessment criteria with students, because it allows students to be an active part of their teaching-learning process. When students know and understand decisions in the teaching-learning process they have higher possibilities to learn, because they know what is expected from them (Chng \& Lund, 2018; Chróinin \& Cosgrave, 2013). Furthermore, students can participate and regulate their own learning through self and peer assessment (Barrientos-Hernán et al., 2019; López-Pastor \& Sicilia-Camacho, 2016; Lorente-Catalán \& Kirk, 2013) which develop students' autonomy and self-regulation in their learning (Boud \& Falchikov, 2007; López-Pastor \& Sicilia-Camacho, 2016; Wiliam, 2011). Interviewed teachers agree that self and peer assessment are important to students who find difficult to self-, peers-, and teachers-critique, encouraging students to become critical about their work. This idea is aligned with literature that reports that peer assessment allows students to learn from other and to learn how to accept criticism from their colleagues (Boud \& Falchikov, 2007; López-Pastor \& Sicilia-Camacho, 2016).

Formative and shared assessment as well as assessment techniques as self and peer assessment became even more important in teacher education programmes if we want teachers to use it in their professional future (Barrientos-Hernán et al., 2019; Hamodi et al., 2017; Lorente-Catalán \& Kirk, 2014; Molina \& López-Pastor, 2019). Teachers of this study reported that their work take into consideration the fact of working with students that are going to be future teachers, highlighting the importance of preparing them for that. These teachers believe they must enhance their learning as students at the same time they develop students' skills to be teachers in future. Then, narrowing the gap between learning and assessment (Baird et al., 2017; Black \& Wiliam, 1998; Chng \& Lund, 2018; Hay et al., 2015; Leirhaug \& Annerstedt, 2016; Wiliam, 2011) will be crucial. According to teachers of this study, this occurs providing opportunities to students to teach, assess, negotiate the curriculum with their teachers, and actively participate on the teaching-learning and assessment processes. These teachers admit that might be challenging, especially to students in their first year of teacher education programmes, to be a co-constructer and co-responsible for their learning process, because students tend to be passive learners throughout their entire education. Although this may be difficult, these teachers believe it is necessary to develop agency on their students (future teachers), and a critical and reflective stance against what they learn and do. These teachers' ideas are aligned with literature which advocates for practice-based teaching (learning by doing) (Brevik et al., 2017; Darling-Hammond, 2006), teaching-learning process 
based on socio-constructivist learning theories (active learners) (Allal, 2020; Batista et al., 2019), and teaching by example (teacher educators using what they advocate for their student teachers' future practices) (MacPhail et al., 2019; Moura et., 2021).

\section{Final Remarks}

Three of the four teachers in their first years of career used assessment only to grade students. Throughout their career they found necessary to start using assessment as a support to their students' learning. Within a more formative use of assessment, teachers revealed that every year they adapt the instruments and criteria, also according to what their students think and agree. This process of bringing students into decisions, allowing them to negotiate the criteria in which their assessment is based is not always easy for students who are not used to participate in this process. However, negotiate their curriculum and participate in assessment (through self or peer assessment) is crucial to students who are future teachers. These teachers consider that teacher education programmes must teach contents and also to teach students how to teach and assess.

These teachers agree that formative and shared assessment can bring challenges in terms of workload to teachers and that changing their assessment practices forced them to change their teaching. However, on the other hand, they believe that the fact of improving students' learning, teachers' teaching and the subject worth that effort. These teachers also reinforced the need for teachers to be critical about the instruments used, reporting that more than the amount or the instruments used, what really matters is what supports their students' learning.

\section{References}

AIESEP. (2020). AIESEP position statement on physical education assessment. https://aiesep.org/scientific-meetings/positionstatements/.

Allal, L. (2020). Assessment and the co-regulation of learning in the classroom. Assessment in Education: Principles, Policy \& Practice, 27(4), 332-349.

Baird, J.-A., Andrich, D., Hopfenbeck, T. N., \& Stobart, G. (2017). Assessment and learning: Fields apart? Assessment in Education: Principles, Policy \& Practice, 24(3), 317-350. https://doi.org/10.1080/0969594X.2017.1319337

Barrientos-Hernán, E., López-Pastor, V. M., \& PérezBrunicardi, D. (2019). Why do I do formative and share assessment and/or assessment for learning in physical education? The influence of teacher education. Retos, 36, 37-43.

Batista, P. (2019). Assessment in physical education: What we know? Where we are? Where do we want to go? Journal of Sport Pedagogy and Research, 5(3), 46-52. https://doi.org/10.47863/XMLT9281

Batista, P., Moura, A., \& Graça, A. (2019). Assessment as a bridge between teaching and learning: Strategies and examples to restructure assessment in physical education. In Sociedade Portuguesa de Educação Física (Ed.), Assessment in physical education - Perspectives and development. SPEF (Omniserviços).

Black, P., \& Wiliam, D. (1998). Assessment and classroom learning. Assessment in Education: Principles, Policy \& Practice, 5(1). https://doi.org/10.1080/0969595980050102

Borghouts, L., Slingerland, M., \& Haerens, L. (2017). Assessment quality and practices in secondary PE in the Netherlands. Physical education and sport pedagogy, 22(5), 473-489. https://doi.org/10.1080/17408989.2016.1241226

Boud, D., \& Falchikov, N. (2007). Rethinking assessment in higher education: Learning for the long term. Routledge.

Braun, V., \& Clarke, V. (2012). Thematic analysis. In H. Cooper (Ed.), APA handbook of research methods in psychology (Vol. 2). American Psychological Association.

Brevik, L., Blikstad-Balas, M., \& Engelien, K. (2017). Integrating assessment for learning in the teacher education programme at the University of Oslo. Assessment in Education: Principles, Policy \& Practice, 24(2), 164-184.

Broadfoot, P., Daugherty, R., Gardner, J., Gipps, C., Harlen, W., James, M., \& Stobart, G. (1999). Assessment for learning: Beyond the black box: University of Cambridge School of Education.

Castejón Oliva, F. J., López-Pastor, V. M., Julián Clemente, J. A., \& Zaragoza Casterad, J. (2011). Formative assessment and academic performance in pre-service physical education teacher education. Revista Internacional de Medicina y Ciencias de la Actividad Física y el Deporte, 11(42), 328-346.

Chng, L. S., \& Lund, J. (2018). Assessment for learning in physical education: The what, why and how. Journal of Physical Education, Recreation \& Dance, 89(8), 29-34. https://doi.org/10.1080/07303084.2018.1503119

Chróinin, D. N., \& Cosgrave, C. (2013). Implementing formative assessment in primary physical education: Teacher perspectives and experiences. Physical Education and Sport Pedagogy, 18(2), 219-233. https://doi.org/10.1080/17408989.2012.666787

Coombs, A., DeLuca, C., LaPointe-McEwan, D., \& Chalas, A. (2018). Changing approaches to 
classroom assessment: An empirical study across teacher career stages. Teaching and Teacher Education, 71, 134-144.

Córdoba-Jiménez, T., López-Pastor, V. M., \& Sebastiani-Obrador, E. (2018). Why do I use formative assessment in physical education? A teacher's autobiographical account. Estudios Pedagógicos, XLIV(2), 21-38.

Darling-Hammond, L. (2006b). Constructing 21stcentury teacher education. Journal of Teacher Education, 57(3), 300-314.

Fletcher, A. (2018). Classroom assessment as a reciprocal practice to develop students' agency: A social cognitive perspective. Assessment Matters, 12, 34-57. https://doi.org/10.18296/am.0032

Graça, A., Batista, P., \& Moura, A. (2019). Consider assessment in physical education oriented to learning. In Sociedade Portuguesa de Educação Física (Ed.), Assessment in physical education Perspectives and development. SPEF (Omniserviços).

Hamodi, C., López-Pastor, V. M., \& López-Pastor, A. T. (2017). If I experience formative assessment whilst studying at university, will I put it into practice later as a teacher? Formative and shared assessment in Initial Teacher Education (ITE). European Journal of Teacher Education, 40(2), 171-190.

Hay, P., Tinning, R., \& Engstrom, C. (2015). Assessment as pedagogy: A consideration of pedagogical work and the preparation of kinesiology professionals. Physical Education and Sport Pedagogy, 20(1), 31-44. https://doi.org/10.1080/17408989.2013.788145

Hortigüela-Alcalá, D., \& Pérez-Pueyo, Á. (2016). Perception of students in physical education classes in connection with other subjects. Apunts, $123,44-52$.

Leirhaug, P. E., \& Annerstedt, C. (2016). Assessing with new eyes? Assessment for learning in Norwegian physical education. Physical Education and Sport Pedagogy, 21(6), 616-631. https://doi.org/10.1080/17408989.2015.1095871

López-Pastor, V. M. (2009). Formative and shared assessment in higher education: Proposals, techniques, instruments and experiences. Narcea.

López-Pastor, V. M. (2011a). Best practices in academic assessment in higher education: A case in formative and shared assessment. Journal of Technology and Science Education, 1(2), 25-39. https://doi.org/10.3926/jotse.2011.20

López-Pastor, V. M. (2011b). The role of formative assessment in competency assessment: contributions from the formative and shared assessment in higher education network. Revista de Docencia Universitaria, 9(1), 159-173.

López-Pastor, V. M., Castejón, J., Sicilia-Camacho, A., Navarro-Adelantado, V., \& Webb, G. (2011c). The process of creating a cross-university network for formative and shared assessment in higher education in Spain and its potential applications. Innovations in Education and Teaching International, 48(1), 79-90.

López-Pastor, V. M., Kirk, D., Lorente-Catalán, E., Macphail, A., \& Macdonald, D. (2013). Alternative assessment in physical education: A review of international literature. Sport Education and Society, 18(1), 57-76. https://doi.org/10.1080/13573322.2012.713860

López-Pastor, V. M., Monjas, R., Manrique, J.-C., Barba, J. J., \& González, M. (2008). Assessment implications in cooperative physical education approaches: The role of formative and shared assessment in the necessary search for coherence. Cultura y Educación, 20(4), 457-477.

López-Pastor, V. M., Pintor, P., Muros, B., \& Webb, G. (2013). Formative assessment strategies and their effect on student performance and on student and tutor workload: the results of research projects undertaken in preparation for greater convergence of universities in Spain within the European Higher Education Area (EHEA). Journal of Further and Higher Education, 37(2), 163-180.

López-Pastor, V. M., \& Sicilia-Camacho, A. (2016). Formative and shared assessment in higher education. Lessons learned and challenges for the future. Assessment \& Evaluation in Higher Education, 42(1), 77-97. https://doi.org/10.1080/02602938.2015.1083535

Lorente-Catalán, E., \& Kirk, D. (2013). Alternative democratic assessment in PETE: An actionresearch study exploring risks, challenges and solutions. Sport, Education and Society, 18(1), 77-96.

https://doi.org/10.1080/13573322.2012.713859

Lorente-Catalán, E., \& Kirk, D. (2014). Making the case for democratic assessment practices within a critical pedagogy of physical education teacher education. European Physical Education Review, 20(1), 104-119.

Lund, J. (1993). The role of accountability and assessment in physical education: A pedagogical view. In J. Rink (Ed.), Critical crossroads: Middle and secondary school physical education (pp. 102-112). National Association for Sport and Physical Education.

MacPhail, A., Halbert, J., \& O’Neill, H. (2018). The development of assessment policy in Ireland: The story of the junior cycle reform. Assessment in 
Education: Principles, Policy \& Practice, 25(3), 310-326.

https://doi.org/10.1080/0969594X.2018.1441125

MacPhail, A., \& Murphy, F. (2017). Too much freedom and autonomy in the enactment of assessment? Assessment in physical education in Ireland. Irish Educational Studies, 36(2), 237252.

https://doi.org/10.1080/03323315.2017.1327365

MacPhail, A., Ulvik, M., Guberman, A., Czerniawski, G., Oolbekkink-Marchand, H., \& Bain, Y. (2019). The professional development of higher education-based teacher educators: Needs and realities. Professional Development in Education, 45(5), 848-861.

Molina, M., \& López-Pastor, V. M. (2019). Do I evaluate as I was at the faculty? Transfer of the formative and shared evaluation lived during the initial teacher training to teaching practice. Revista Iberoamericana de Evaluación Educativa, 12(1), 85-101.

Moura, A., Graça, A., MacPhail, A., \& Batista, P. (2021). Aligning the principles of assessment for learning to learning in physical education: A review of literature. Physical Education and Sport Pedagogy, 26(4), 388-401.

Patton, M. Q. (2002). Qualitative research and evaluation methods ( $3^{\text {rd }}$ ed.). Sage Publications.

Pueyo, Á. P., Sánchez, B. T., López-Pastor, V. M., Ortín, N. U., Lara, E. R., Bujosa, M. C., . . Oliva, F. J. C. (2008). Formative and shared assessment in higher education and european area of higher education: Key cuestions for their implementation. Revista de Educación, 347, 435451.

Resende, R, (2016). Qualitative research technique: ETCI. Journal of Sport Pedagogy \& Research, 2(1), 50-57.

Romero-Martín, M. R., Castejón-Oliva, F.-J., LópezPastor, V. M., \& Fraile-Aranda, A. (2017). Formative assessment, communication skills and ICT in initial teacher training. Comunicar, 25(52), 73-82. https://doi.org/10.3916/C52-2017-07

Salom, M. (2019). An opportunity to advance towards authentic assessment in Physical Education. Retos, 36, 259-265.

Silva, A. M., Moura, A., \& Batista, P. (2019). Assessment for learning in the teaching of acrobatic gymnastics during school placement. Journal of Sport Pedagogy and Research, 5(3), 36-45. https://doi.org/10.47863/XJTT5025

Tolgfors, B. (2018). Transformative assessment in physical education. European Physical Education Review, 25(4),

1211-1225. https://doi.org/10.1177/1356336X18814863
Wiliam, D. (2011). What is assessment for learning? Studies in Educational Evaluation, 37, 2-14.

Yin, R. K. (2009). Case study research: Design and methods (4th ed). SAGE Publications. 


\title{
Attentional Style and Pace Monitoring on Rate of Perceived Exertion and Run Performance
}

\author{
Todd Christensen $^{1}$, Frances Cacho ${ }^{2}$, Timothy Baghurst ${ }^{3}$ \\ ${ }^{1}$ Department of Wellness, Oklahoma State \\ ${ }^{2}$ Sport Psychology, Florida State University \\ ${ }^{3} \mathrm{FSU}$ COACH, Florida State University
}

\begin{abstract}
Keywords
RPE, association, dissociation, running, runners, attention, attentional control, TAIS

\section{RPE, associação, dissociação, corrida, atenção dos corredores, controle de atenção, TAIS}

Palavras-Chave

ABSTRACT:

Run-tracking devices are used by athletes and exercisers to monitor various metrics of human locomotion such as pace and distance. This study sought to determine the effects of pace monitoring on run performance and rate of perceived exertion (RPE). Participants were 41 (17 male, 24 female) recreationally fit runners, age $19-40$ years $(M=22.4, S D=4.4)$, who completed the Test of Attentional and Interpersonal Style (TAIS) to determine individual attentional focus. They then completed an associative condition (AC) 1-mile time trial and a dissociative condition (DC) 1-mile time trial 24-36 hours apart. Individual, independent $t$-tests compared completion time means between conditions. The internalizers group (AC) performed significantly faster in the associative condition $(M=496.10, S D=105.05$ seconds $)$ than in the dissociative condition $(M=525.00, S D$ $=109.67$ seconds), $t(20)=5.79, p<.001$. The externalizers group (DC) performed significantly faster in the dissociative condition $(M=522.70, S D=97.37$ seconds $)$ than in the associative condition $(M=556.90, S D=116.62), t(19)=-4.92, p<.001$. Results support the value of identifying an individual's preferred attentional focus to place them in the optimal environment for success. While the study showed no significant difference in RPE scores between conditions, there may be practical implications of similar RPE scores when accompanied by significant changes in performance.

Estilo de atenção e ritmo de monitorização da taxa de esforço percebida e desempenho de corrida RESUMO:

Os dispositivos de rastreamento de corrida são usados por atletas e treinadores para monitorar várias métricas de locomoção humana, como ritmo e distância. O objetivo deste estudo foi determinar os efeitos do monitoramento de ritmo no desempenho da corrida e na taxa de esforço percebido (RPE). Os participantes foram 41 ( 17 corredores masculinos, 24 femininos) de corrida recreativa com idade entre os 19 e $40 \operatorname{anos}(M=22.4, S D=4.4)$, que completaram o Teste de Estilo Atenção e Interpessoal (TAIS) para determinar o foco de atenção individual. Posteriormente completaram uma condição associativa (AC) o teste de tempo de $1.6 \mathrm{~km}$ (1 milha) e uma condição dissociativa (DC) de $1.6 \mathrm{~km}$ (1 milha) de duração com 24-36 horas de intervalo. T-testes individuais e independentes foram executados comparando médias de conclusão entre as condições. $\mathrm{O}$ grupo internalizador $(\mathrm{AC})$ teve um desempenho significativamente mais rápido na condição associativa $(M=496.10, D P=105.05$ segundos $)$ do que na condição dissociativa $(\mathrm{M}=525,00, \mathrm{DP}=109,67$ segundos), $\mathrm{t}(20)=5.79, \mathrm{p}<.001$. O grupo externalizador (DC) teve um desempenho significativamente mais rápido na condição dissociativa $(M=522.70, \mathrm{DP}=97.37$ segundos $)$ do que na condição associativa $(M=556.90, D P=116.62), \mathrm{t}(19)=-4.92, \mathrm{p}<.001$. Os resultados suportam o valor de medir o foco de atenção preferido de um indivíduo para colocá-lo no ambiente ideal para o sucesso. Embora o estudo não tenha mostrado diferença significativa nos escores de RPE entre as condições, pode haver implicações práticas de escores semelhantes de RPE quando acompanhados por mudanças significativas no desempenho.
\end{abstract}




\section{Attentional Style and Pace Monitoring on Rate of Perceived Exertion and Run Performance}

For decades, running has been at the forefront of the sports community (Jacobson, 2015). Between 1990 to 2013 , there was a $300 \%$ growth in the number of road race finishers totaling over 19 million in the United States alone. The ease of participation and the minimal financial investment of running makes it a popular option for individuals seeking to improve their physical condition or compete at an elite level. For competitive runners, some are willing to invest in the best training aids available: shoes, clothes, energy supplements, and run trackers (LaMagna, 2016). Run trackers have grown in popularity in recent years with the development of smartphone applications and wearable devices (Fritz, Huang, Murphy, \& Zimmerman, 2014; Whitehead, 2016). They rely on a global positioning system (GPS) to give real-time feedback of distance, pace, elevation change, split times, and much more (Smith, Moran, \& Foley, 2013). Whether using a smartphone app or a wearable device, runners can monitor everything from energy expenditure to distance traveled. However, the effect of usage and the degree of those effects is still somewhat unknown, as there are several factors to consider such as pacing, perceived exertion, attentional focus, and GPS.

\section{Run Tracking and Pacing}

Understanding the importance of pace control is vital to any runner, beginner or experienced (Young, 2007; Smyth, 2021). It is defined as the capability to produce a certain speeded variation of a continuous motor behavior from memory, accurately and/or consistently over time (Young, 2007). This is crucial to athletes racing to win, as it helps dictate maximum performance without hitting "the wall," or lactate threshold, too early in a race (Silva \& Applebaum, 1989; Smyth, 2021). A pace that is off by even a few seconds can have detrimental implications (Smith, Moran, \& Foley, 2013). Pacing is equally vital to the runner on a recovery run or recreational run, as it is related to rate of perceived exertion (RPE; Masters \& Ogles, 1998). Therefore, it is important to understand how the skilled of pacing is developed.

Most experienced runners know the maximum pace that they can run for a given distance (Young, 2007). However, novice runners may only have an idea of their limits. To train the pacing skill, repetitive runs at specified paces are required (Young, 2007; Moore, Jones, \& Dixon, 2012). Before run tracking devices, pace monitoring or "pacing" was accomplished by sense of feel (Young, 2007). Feel is developed through increased awareness of factors such as heart rate, respiration, knee-drive, and effort while running over time, and it can become an automated skill (Fitzgerald, 2014; Whitehead, 2016; Young, 2007). While there are still runners who rely on feel to determine pace rather than computer programs, even the most seasoned runners can make errors when it comes to pace-control (Rodriquez, 2015).

With so many run-tracking options available, it is unclear if monitoring pace so closely is beneficial to novice performers or whether it might hinder their understanding of pace. In theory, it could lead to focusing too much on the device than on internal awareness (Smith, Moran, \& Foley, 2013). Additionally, very few studies have researched run trackers and how they impact run. For example, it is unknown if constant knowledge of speed improves or hinders running performance, if feedback on distance covered/remaining helps or harm effort levels, or if knowledge of run progress encourages complacency or challenges. Therefore, if pacing is a necessary skill for a runner, then it is important to determine whether using a run tracker enhances or degrades this skill.

\section{Run Tracking and Perceived Exertion}

As it relates to this study, perceived exertion is closely linked to attentional focus and pacing. Therefore, an understanding of how to measure Rate of Perceived Exertion (RPE) is vital to the discussion of pace monitoring for maximum run performance. RPE is known as the "single best indicator of physical strain," and "integrates various information, including many signals elicited from the peripheral working muscles and joints, from the central cardiovascular and respiratory functions, and from the central nervous system" (Tucker, 2009, p. 396). Borg's scales are among the most recognized and used to measure RPE, and its reliability has been confirmed by multiple studies (e.g., Baden et al., 2004 Borg \& Kaijser, 2005; Ceci \& Hassmen, 1990; Tucker, 2009). Furthermore, the link between subjective feelings of effort and the discrete physiological changes that occur during work is important, as RPE has been found to directly affect the level of performance in exercise (Tucker, 2009). As it pertains to attentional focus, dissociation (i.e., focusing on task irrelevant cues) and RPE have a negative relationship (Baden et al., 2004). Therefore, as an individual focuses on things not relevant to the task at hand, RPE increases.

\section{Run Tracking and Attentional Focus}

When deciding the effects of run tracking on an individual's run performance, identifying their preferred attentional focus is also important. Attention can be measured through its breadth of focus and direction; the ability to control these dimensions and direct them it is considered central to performance (Nideffer, 1976). Breadth of focus is measured on a scale from narrow to broad, whereby a broader focus suggests an individual can focus on a greater number of stimuli at one time. Direction is measured on a scale between external (a focus on things outside of oneself) and internal (a focus on things within oneself). 
One way of internally and externally directing one's focus is by using associative or dissociative focus (A/D). Association traditionally referred to the way runners monitored sensory input, and adjusted their pace accordingly, with the goal of avoiding pain (Morgan \& Pollock, 1977). This definition has since evolved to be synonymous with general internal focus and faster speeds (Brick, MacIntyre, \& Campbell, 2014; Schucker et al., 2009).

Similarly, dissociation has developed a much broader meaning than its original definition. Dissociation often refers to focusing on "task irrelevant cues including problem-solving, or listening to music, and distracting from the sensory information stemming from the body" and is linked with lower exertion levels (Garcia et al., 2015, p. 302). The common thread lies in the use of some external stimuli to distract an individual from the body's mechanics and corresponding sensory feedback. Broadly speaking, internalizers prefer an internal or associative focus while externalizers prefer an external or dissociative focus (Baghurst et al., 2004).

There are different advantages and disadvantages of both types of attentional focus while running (Laasch, 1995). Previous studies suggested association is beneficial for greater performance and dissociation is beneficial if the goal is a more relaxed experience (Fillingim \& Fine, 1986; Morgan \& Pollock, 1977). Others found that regardless of skill level, runners generally prefer dissociation during training runs and association during competitive runs (Masters \& Ogles, 1998). However, it has been suggested that different attentional foci are less experience-driven and more situation-dependent, and a runner should be able to move seamlessly in and out of association to dissociate when the need arises to serve different purposes (Laasch, 1995). For example, during longer distance runs, such as marathons, internal dissociation tends to be the more common and useful attentional focus strategy, as it can help runner stave off "hitting the wall" and is related to lower levels of perceived and physiological exertion (Johnson \& Siegel, 2008; Schucker et al., 2009; Stevinson \& Biddle, 1998). However, training runs are typically performed at a slower pace that allows the athlete to dissociate easier (Masters \& Ogles, 1998). Due to the dynamic and fluid nature of thought processes combined with fluctuations of exercise intensity, runners need to use both associative and dissociative strategies (Garcia et al., 2015). Silva and Applebaum (1989) concluded that an attentional focus strategy that hinges on flexibility to the situation is the best practice for maximum pace and performance.

In terms of performance, research has concluded that association and dissociation play a large role in performance (Schücker \& Parrington, 2019). According to Nideffer's work (1976), certain individuals are more likely to perform well in an associative condition while others will more likely succeed in a dissociative condition. Therefore, it was proposed that association was most beneficial for elite athletes but not novice athletes; conversely, dissociation was best for novice athletes and did not benefit elite athletes striving for maximum performance (Stevinson \& Biddle, 1998). Furthermore, association was linked to higher levels of performance while dissociation was linked to lower exertion levels (Schucker et al., 2009).

A recent shift in thinking has proposed a more dynamic relationship between association and dissociation to performance levels. This relationship allows an individual to move seamlessly between an associative and a dissociative focus of attention. When an individual can perform within their preferred attentional style, they maintain a faster pace over the same amount of time (Baghurst et al., 2004). Pace monitoring is a function of association, as the runner is constantly receiving real-time feedback of pace and distance. However, an individual who thrives in a dissociative condition may not perform as well when they have the constant feedback available. The constant feedback may distract them from their preferred dissociate condition. Thus, research still needs to clarify the which attentional style is best for internalizers and externalizers where pace monitoring would be beneficial.

\section{Run Tracking and GPS}

In recent years, GPS has been used in many studies to measure human motion. GPS-guided devices have become increasingly cost effective and accurate (Terrier et al., 2000). Some studies have used them to measure movements of human locomotion as small as stride frequency and length (Terrier et al., 2005). Others have used GPS technology to measure factors such as training intensity, volume, and speed (Karboviak, 2005). These studies support their reliability and accuracy when measuring pace and progress in sub-maximal intensities. The primary sources of any errors came from high-velocity running or rapid changes in direction (Terrier et al., 2000). However, when it comes to running at slower speeds than maximum sprinting, GPS run-tracking devices can be relied on to monitor pace and progress with great precision.

There is limited research on the effectiveness of runtracker use on pace-setting as it relates to maximum run performance. Research that has been conducted focuses mainly on the accuracy of GPS-guided run tracking systems, the use of GPS systems to coach pace, and the use of GPS systems to monitor training loads (Karboviak, 2005; Terrier et al., 2000; Terrier et al., 2005). However, these were descriptive studies, so no empirical conclusions can be drawn. There are also narratives on the difference between running with a GPS system and with running by feel (Fitzgerald, 2014; Rodriquez, 2015; Whitehead, 2016), but there is no research that directly measures the effects of visual pace and distance feedback on running performance. 


\section{Study Purpose}

Running is a popular sport and a major part of training for other sports. The use of run-tracking devices is becoming more common in many sports, especially running. Previous research suggested that run trackers are accurate in measuring factors such as pace and distance. However, the effectiveness of using trackers to improve performance remains unknown. It is possible that people wear a run tracker under a false assumption that it is benefiting their performance. Additionally, using a run tracker may be more beneficial for an individual who prefers an internal focus (i.e., association) while being detrimental for an individual who prefers an external focus (i.e., dissociation). Thus, further investigation is warranted to aid our understanding of the situations where pace monitoring is beneficial and when it is detrimental, especially with maximal performance (Karahanoğlu et al., 2021; Mopas \& Huybregts, 2020; Morgan \& Pollock, 1977). This could help an individual achieve greater success in or enjoyment of the sport of running.

Therefore, the purpose of this study was to determine the effects of pace monitoring on run performance and rate of perceived exertion (RPE). It was hypothesized that: (a) there would be no difference between the completion times of internalizers and externalizers by condition, (b) there would be no difference between the average RPE of internalizers and externalizers by condition, (c) internalizers' completion time would be significantly faster in the associative condition, (d) externalizers' completion time would be significantly faster in the dissociative condition, (e) internalizers' average RPE would be significantly lower in the associative condition, and (f) externalizers' average RPE would be significantly lower in the dissociative condition.

\section{Method}

\section{Participants}

Upon IRB approval, 59 individuals were recruited via flyers, announcements in Health and Human Performance classes, and word of mouth at a major university in the mid-south of the United States. Of those participants, 18 did not meet the inclusion criteria and were eliminated from the study. Participants included were 41 recreationally fit runners (17 men, 24 women) between the ages of 19 and 40 years $(M=22.4, S D=4.4)$. Participants were on average 1.72 meters tall $( \pm .11)$ and weighed 71.3 $\mathrm{kg}( \pm 14.29)$. To ensure participants would be able to successfully complete the one-mile trials, recreationally fit was defined as the ability to complete a two-mile run without stopping. Participants were split into two groups, internalizers and externalizers, based on scores on the Test of Attentional and Interpersonal Style (TAIS, Nideffer, 1976).

\section{Instruments}

Prior to the experimental trials being conducted, participants completed a Physical Activity Readiness Questionnaire (PAR-Q) as well as an Informed Consent. The PAR-Q served as an opportunity to determine the participant's readiness for physical activity and to disclose any injuries or conditions that may have limited their ability to complete the testing protocol.

Additionally, participants completed the Test of Attentional and Interpersonal Style (TAIS) to determine their preferred attentional focus: association or dissociation. Grading of the questionnaire generated scores in four separate categories: broad external (BET), overload external (OET), broad internal (BIT), and overload internal (OIT). Results of individual TAIS questions were compiled to determine means and standard deviations. Each participant's scores were compared to the standardized means established by Nideffer (1976) to identify which group they would be assigned to. Table 1 shows the breakdown of means for each of the four TAIS categories.

Table 1. Means and standard deviations of TAIS scores for internalizers and externalizers

\begin{tabular}{ccccc}
\hline Group & BET & OET & BIT & OIT \\
\hline \multirow{2}{*}{ Externalizers } & 18.9 & $12.6 \pm$ & $16.05 \pm$ & $12.9 \pm$ \\
& \pm 2.2 & 3.5 & 2.1 & 5.1 \\
Internalizers & 14.0 & $17.7 \pm$ & $20.7 \pm$ & $12.7 \pm$ \\
& \pm 3.3 & 4.6 & 2.3 & 3.9 \\
\hline
\end{tabular}

Note: BET: Broad External Test Score, OET: Overload External Test Score, BIT: Broad Internal Test Score, OIT: Overload Internal Test Score

The criteria for inclusion in either the internalizer group or the externalizer group was based on multiple criteria. For inclusion in the internalizer group, an individual had to score above the standardized mean $(\mathrm{BIT}=18)$ in the BIT category. Additionally, their BIT score had to be greater than their BET score and OIT score (Nideffer, 1976). Likewise, for inclusion in the externalizers group, an individual had to score above the standardized mean $(\mathrm{BET}=14)$ in the BET category, and their BET score had to be greater than their BIT score and OET score (Nideffer, 1980).

The warm-up, experimental trials, and cool-down were conducted on a Trackmaster (Full Vision Inc, Newton, KS) treadmill in a university lab setting. The on-board time and distance functions on the treadmill were used to monitor pace and progress. Rate of Perceived Exertion (RPE) was measured using the Borg CR10 scale of perceived exertion (Borg, 1998).

\section{Procedure}

Upon arrival, participants completed the PAR-Q, Informed Consent, and Test of Attentional and Interpersonal Style. Participants were assigned a deidentified number for record keeping and were not told which group they belonged to until after the completion of the second time trial. Groups were split 
into 21 internalizers (10 men, 11 women) and 20 externalizers ( 7 men, 13 women). The experimental trials were conducted as a randomized, repeatedmeasures design. A minimum of two days and no more than three days was required between the participant's first and second trials. Order of testing with pace monitoring (associative condition) or without pace monitoring (dissociative condition) was randomized for each participant.

For the warm-up, participants walked at a selfselected comfortable pace for three to five minutes to allow for gradual warm-up and familiarization with the treadmill. Then they slowly increased the speed of the treadmill until they were running at an easy jog for three to five minutes. They could manipulate the speed controls of the treadmill during the full time of the warm-up to familiarize themselves with the operational controls. At the completion of the tenminute warm-up period, they were given the opportunity to go through their normal pre-run stretching routine for three minutes. They were not, however, required to complete a stretching routine if that was not their normal practice. All participants were instructed to use the same pre-run stretching or no stretching routine before both time trials.

Upon completion of the warm-up and stretching, participants returned to the treadmill to begin the time trial. Prior to both treatments, they were given the goal of running one mile as fast as possible. For the associative condition (AC), the speed display was left uncovered to enable pace monitoring. For the dissociative condition (DC), the speed display was covered to prevent them from being able to view their pace. During both conditions, they maintained full responsibility of manipulating their pace with the onboard speed controls. Also, during both treatments, the time display was covered so that they were unaware of the elapsed time or completion times of each trial until after completion of the study.

Participants were instructed to start the trial with the following prompt. "When you are ready, start the treadmill by pressing the up arrow. As soon as you press the button, the band on the treadmill will begin moving, and I will start the stopwatch. Increase the speed of the treadmill as fast as you feel comfortable with to reach your desired running pace. You will have full control of the speed for the duration of the trial to increase or decrease your speed as you desire. Try to run at the highest intensity possible without hitting the wall too early causing you to slow down. You will be able to monitor the distance display for the duration of the test. I will ask you every quarter of a mile how hard you feel like you are working on a scale of 1-10, with one being easiest and ten being hardest. Your goal is to run one mile as fast as you are able to."

During both trials, the distance display was visible. At each quarter of a mile interval, the participants were asked to report their RPE on a scale of 1-10 and their cumulative elapsed time was recorded.
Immediately upon completion of one mile, participants were asked their final RPE and instructed to press the Cool Down button on the treadmill. Participants were instructed to follow the programmed cool down protocol of the treadmill which progressively decreases the speed of the belt over three minutes.

\section{Data Analysis}

Statistical analysis was conducted using Microsoft Excel and JMP Pro 13. Rate of perceived exertion scores were examined using a 2 × 2 × 4 (Group [internalizer vs externalizer] $x$ Condition [AC vs DC] $\mathrm{x}$ Time [.25 miles, .5 miles, .75 miles, and 1 mile]) analysis of variance (ANOVA). Post hoc Bonferroni pairwise comparisons were used to identify differences between time points for RPE scores. Mean change in completion time between conditions for each group was examined using an independent $t$ test. Completion times were compared between conditions for each group using dependent $t$-tests. The alpha level for statistical analysis was set at $p<$ .05 .

\section{Results}

Rate of perceived exertion (RPE) scores were examined using a $2 \times 2 \times 4$ (Group [internalizer vs externalizer] $\mathrm{x}$ Condition [AC vs DC] $\mathrm{x}$ Time [.25 miles, .5 miles, .75 miles, and 1 mile]) analysis of variance (ANOVA). There was no significant effect between groups and visits across times. Likewise, no significant effect was found between time and group or visit and time. There was a significant effect in RPE scores across time $(p<.001)$. Table 2 presents the means and standard deviations for each group according to condition across times. Post hoc Bonferroni pairwise comparisons revealed that each time point was significantly different $(p<.001)$ compared with all other time points.

Table 2. Internalizer and externalizer RPE means and standard deviations across conditions and times.

\begin{tabular}{|c|c|c|c|c|c|}
\hline Group & Cond. & .25 & .5 & .75 & 1 \\
\hline \multirow{6}{*}{ Internalizers } & \multirow{3}{*}{$\mathrm{DC}$} & 5.2 & 6.5 & 7.3 & 8.3 \\
\hline & & \pm & \pm & \pm & \pm \\
\hline & & 1.3 & 1.1 & 1.1 & 1.1 \\
\hline & \multirow{4}{*}{$\mathrm{AC}$} & 5.0 & 6.2 & 7.3 & 8.4 \\
\hline & & \pm & \pm & \pm & \pm \\
\hline & & 1.4 & 1.3 & 1.5 & 1.5 \\
\hline \multirow{6}{*}{ Externalizers } & & 5.5 & 6.5 & 7.3 & 8.4 \\
\hline & \multirow[t]{3}{*}{$\mathrm{DC}$} & \pm & \pm & \pm & \pm \\
\hline & & 1.3 & 1.4 & 1.2 & 0.9 \\
\hline & & 5.6 & 6.6 & 7.5 & 8.6 \\
\hline & \multirow[t]{2}{*}{$\mathrm{AC}$} & \pm & \pm & \pm & \pm \\
\hline & & 1.6 & 0.8 & 0.8 & 0.9 \\
\hline
\end{tabular}

Rate of perceived exertion (RPE) scores were examined using a $2 \times 2 \times 4$ (Group [internalizer vs externalizer] $\mathrm{x}$ Condition [AC vs DC] $\mathrm{x}$ Time [.25 miles, .5 miles, .75 miles, and 1 mile]) analysis of 
variance (ANOVA). There was no significant effect between groups and visits across times. Likewise, no significant effect was found between time and group or visit and time. There was a significant effect in RPE scores across time $(p<.001)$. Table 2 presents the means and standard deviations for each group according to condition across times. Post hoc Bonferroni pairwise comparisons revealed that each time point was significantly different $(p<.001)$ compared with all other time points.

Data were divided according to attentional focus group classification: internalizers or externalizers. Completion times were compared between conditions for each group using dependent $t$-tests. The internalizers group performed significantly faster in the associative condition $(M=496.10, S D=105.05$ seconds) than in the dissociative condition $(M=$ $525.00, S D=109.67$ seconds), $t(20)=5.79, p<.001$. The externalizers group performed significantly faster in the dissociative condition $(M=522.70, S D=$ 97.37 seconds) than in the associative condition $(M=$ $556.90, S D=116.62), t(19)=-4.92, p<.001$. Table 3 presents the completion times for both groups in both conditions, which is also represented in Figure 1.

Table 3. Internalizers and externalizers completion time (in seconds) means and standard deviations (SD) in the associative and dissociative conditions.

\begin{tabular}{cccc}
\hline Condition & Group & Mean & SD \\
\hline \multirow{2}{*}{ Associative } & Internalizers & 496.1 & \pm 105.05 \\
& Externalizers & 556.9 & \pm 116.92 \\
\hline \multirow{2}{*}{ Dissociative } & Internalizers & 525.0 & \pm 109.67 \\
& Externalizers & 522.7 & \pm 97.37 \\
\hline
\end{tabular}

Figure 1. Completion Time in Seconds of Internalizers (Int) and Externalizers (Ext) Across the Associative Condition (AC) and Dissociative Condition (DC)

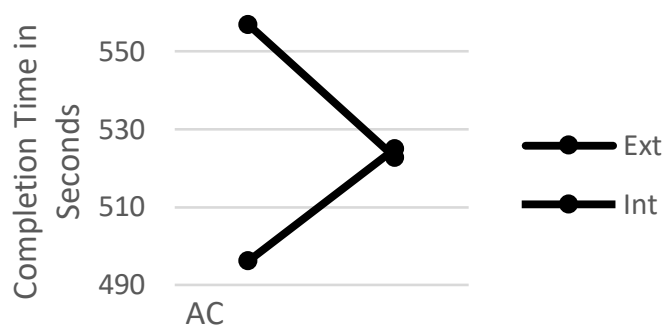

Based on the results of the $t$-tests, the following null hypotheses were accepted: 1) Internalizers' average RPE would not differ between conditions, and 2) Externalizers' average RPE would not differ between conditions. Based on the results of the $t$-tests, the following null hypotheses were rejected: 1) Internalizers' completion time would not differ between conditions, and 2) Externalizers' completion time would not differ between conditions.

\section{Discussion}

The purpose of this study was to determine how pace monitoring via a run tracking device might affect run performance. The two variables of run performance that were investigated were completion time of a 1 mile run and rate of perceived exertion (RPE) during the run. For this purpose, 41 recreationally fit runners ran one-mile time trials in two conditions. A pace monitoring (associative) condition was achieved by having the pace visible on the treadmill display. The no-monitoring (dissociative) condition was achieved by covering the pace display on the treadmill to block visual feedback from the participant. It was found that internalizers performed significantly better in the associative condition $(M=496.10, S D=105.05$ seconds) than in the dissociative condition $(M=$ 525.00, $S D=109.67$ seconds), $t(20)=5.79, p<.001$. Likewise, externalizers performed significantly better in the dissociative condition $(M=522.70, S D=97.37$ seconds) than in the associative condition $(M=$ $556.90, S D=116.62), t(19)=-4.92, p<.001$.

Participants classified as externalizers prefer a dissociative attentional focus (Morgan \& Pollock, 1977). Dissociation can be described as focusing on external stimuli to distract from sensory cues while running. Baghurst et al. (2004) showed increased performance when participants were engaged in their preferred attentional style, and it was hypothesized that participants in this study would perform better in their preferred condition. Not having their pace to focus on, participants were forced to focus on any number of external stimuli. For individuals who scored highly in externalization on Nideffer's (1976) Test of Attentional and Interpersonal Style (TAIS), this condition was better suited for them to succeed. Many studies over the past 35 years have suggested that dissociation is more commonly associated with lower RPE levels and decreased performance (Brick et al., 2014; Fillingim \& Fine, 1986; Laasch, 1995; Stevinson \& Biddle, 1998). However, our findings suggest that if an individual prefers to dissociate, they will perform better in a dissociative rather than associative condition. Participants classified as internalizers performed significantly better in the associative condition than in the dissociative, which is supported by past research that found a positive relationship between association and increased performance (Baghurst et al., 2004; Mopas \& Huybregts, 2020; Young, 2007). Overall, the findings of this study suggest that personal preference for association or dissociation likely influences performance.

\section{Rate of Perceived Exertion (RPE)}

According to previous research, the dissociative condition (DC) was expected to yield significantly lower RPE scores (Baden et al., 2004; Ceci \& Hassmen, 1990; Tucker, 2009). However, our 
findings found no significant difference in average RPE between conditions. Even the externalizers group reported a minimal difference in perceived exertion between conditions. This may be due to the maximal effort goal of both time trials.

Similar RPE scores across conditions contribute to the practical significance of the completion time results. The results showed significantly faster completion times within groups when participants could perform in their preferred attentional style. The implication of being able to run a mile significantly faster with similar effort levels is profound. After all, a common goal among runners is to run a given distance as fast as possible with minimal perceived or actual exertion (Tucker, 2009). If simply shifting attentional focus can produce such significant differences in completion times, then the use of the TAIS to determine preferred style, and the application of the test's results, is a method of performance enhancement (Nideffer, 1990).

\section{Limitations and Future Research}

This study is not without limitations, which lend opportunities for future research. First, the maximum speed of the treadmill appeared to limit one participant's top speed for a brief time. It is possible that the participant could have completed the time trial faster had they been able to continue to increase speed. Another limitation of the current study was the use of RPE as a measure of exertion. The RPE score is subjective in nature between individuals and between trials for each individual. Therefore, there is no way to standardize individual perceptions. However, despite its subjectivity, past research supports the use of an RPE scale as a valid measure of exertion (Borg, 2005).

Despite the significant results of the current study, sample size and generalizability of the findings could be another limitation, as results may not be an accurate representation of the larger running community. Future studies should consider testing larger sample sizes with the same protocol. Similarly, while an effort was made to address the age-related limitation of previous research, few participants over the age of 25 were willing to volunteer. The addition of a system of analysis to quantify some of the trends noted during post-test discussions could be a valuable modification to future study as well.

Additionally, conducting the same testing protocol on a more homogenous sample regarding experience level may be beneficial, as the current study did not differentiate between participants with extensive or minimal running experience or their fitness levels. Lastly, changing from an indoor treadmill to an outdoor running trail, with established distance markers, may provide different results but would increase real-world applicability. To conduct a similar study that focuses on the effects of pacemonitoring on RPE exclusively, changing the goal of each time trial could suffice. Instructing participants to run at a pre-determined pace rather than as fast as possible would help isolate RPE.

\section{Conclusion}

Our findings showed significant differences in completion times of a one-mile time trial between two attentional focus conditions. Results confirm the use of pace monitoring as a means of performance enhancement. Simply shifting to/away from or restricting a runner's ability to focus on their pace while running may be a viable method of manipulating performance. While the study showed no significant difference in RPE scores between conditions, there may be practical implications of similar RPE scores when accompanied by significant changes in performance. One conclusion that agrees with most research is the dynamic nature of attentional focus of runners (Brewer et al., 1996; Brick et al., 2014; Garcia et al., 2015). Certain situations may call for an associative focus while others may benefit from a dissociative focus. Viewing pace-monitoring during a run as a function of attentional focus can significantly benefit performance.

\section{References}

Baden, D. A., Warwick-Evans, L., \& Lakomy, J. (2004). Am I nearly there? The effect of anticipated running distance on perceived exertion and attentional focus. Journal of Sport \& Exercise Psychology, 26(2), 215-231.

Baghurst, T. (2012). The psychological components of elite cycling. Athletic Insight, 4(1), 13-29.

Baghurst, T., Thierry, G., \& Holder, T. (2004). Evidence for a relationship between attentional styles and effective cognitive strategies during performance. Athletic Insight, 6(1), 36-51.

Borg, G. (1998). Borg's perceived exertion and pain scales. Human Kinetics.

Brewer, B.W., \& Karoly, P. (1989). Effects of attentional focusing on pain perception. Motivation and Emotion, 13(3), 193-203.

Brewer, B. W., Van Raalte, J. L., \& Linder, D. (1996). Attentional focus and endurance performance. Applied Research in Coaching and Athletics Annual, 1-14.

Brick, N., MacIntyre, T., \& Campbell, M. (2014). Attentional focus in endurance activity: new paradigms and future directions. International Review of Sport and Exercise Psychology, 7(1), 106-134.

Ceci, R., \& Hassmén, P. (1991). Self-monitored exercise at three different RPE intensities in treadmill vs field running. Medicine \& Science in Sports \& Exercise, 23(6), 732-738. 
Ferstle, J. (2012). Diversity in sports: Can road races match their communities? Road Race Management, 345, 1-8.

Fillingim, R. B., \& Fine, M. A. (1986). The effects of internal versus external information processing on symptom perception in an exercise setting. Health Psychology, 5(2), 115-123.

Fritz, T., Huang, E. M., Murphy, G. C., \& Zimmermann, T. (2014). Persuasive technology in the real world: A study of long-term use of activity sensing devices for fitness. Proceedings of the SIGCHI Conference on Human Factors in Computing Systems (pp. 487-496).

García, S., Razon, S., Hristovski, R., Balagué, N., \& Tenenbaum, G. (2015). Dynamic stability of taskrelated thoughts in trained runners. Sport Psychologist, 29(4), 302-309.

Jacobson, J. (2015, May 6). State of the sport: US race trends. Running USA. www.runningusa.org.

Johnson, J. H., \& Siegel, D. S. (1992). Effects of association and dissociation on effort perception. Journal of Sport Behavior, 15(2), 119-130.

Karahanoğlu, A., Gouveia, R., Reenalda, J., \& Ludden, G. (2021). How are sports trackers used by runners? running-related data, personal goals, and self-tracking in running. Sensors, 21(11), 3687 .

Karboviak, R. J. (2005). Using GPS technology to monitor intensity, speed, and training volume in outdoor athletes. Strength \& Conditioning Journal, 27(2), 24-25.

Laasch, C. (1995). Cognitive strategies and longdistance running. Imagination, Cognition and Personality, 14(4), 317-332.

LaMagna, M. (2016, January 28). Have we reached peak Fitbit? Market Watch. www.marketwatch.com

Moore, I. S., Jones, A. M., \& Dixon, S. J. (2012). Mechanisms for improved running economy in beginner runners. Medicine Science Sports Exercise, 44(9), 156-163.

Mopas, M. S., \& Huybregts, E. (2020). Training by feel: Wearable fitness-trackers, endurance athletes, and the sensing of data. The Senses and Society, 15(1), 25-40.

Nideffer, R. M. (1976). Test of attentional and interpersonal style. Journal of Personality and Social Psychology, 34(3), 394-404.

Nideffer, R. M. (1990). Use of the Test of Attentional and Interpersonal Style (TAIS) in sport. The Sport Psychologist, 4(3), 285-300.

Schücker, L., Hagemann, N., Strauss, B., \& Völker, K. (2009). The effect of attentional focus on running economy. Journal of Sports Sciences, 27(12), 1241-1248.

Schücker, L., \& Parrington, L. (2019). Thinking about your running movement makes you less efficient: Attentional focus effects on running economy and kinematics. Journal of sports sciences, 37(6), 638-646.

Smith, J. W., Moran, M. F., \& Foley, J. T. (2013). Effect of GPS feedback on lactate threshold pacing in intercollegiate distance runners. International Journal of Exercise Science, 74-80.

Smyth, B. (2021). How recreational marathon runners hit the wall: A large-scale data analysis of late-race pacing collapse in the marathon. PloS one, 16(5), e0251513.

Stevinson, C. D., \& Biddle, S. (1998). Cognitive orientations in marathon running and "hitting the wall". British Journal of Sports Medicine, 32(3), 229-234.

Terrier, P., Ladetto, Q., Merminod, B., \& Schutz, Y. (2000). High-precision satellite positioning system as a new tool to study the biomechanics of human locomotion. Journal of Biomechanics, 33(12), 1717-1722.

Terrier, P., Turner, V., \& Schutz, Y. (2005). GPS analysis of human locomotion: Further evidence for long-range correlations in stride-to-stride fluctuations of gait parameters. Human Movement Science, 24(1), 97-115.

Tucker, R. (2009). The anticipatory regulation of performance: The physiological basis for pacing strategies and the development of a perceptionbased model for exercise performance. British Journal of Sports Medicine, 43(6), 392-400.

Whitehead, P. M. (2016, June 17). On ditching the watch while training: Re-examining the pacebased approach to training long-distance runners. Sport Journal. http://thesportjournal.org

Young, B. W. (2007). Perspectives on coaching pace skill in distance running. International Journal of Sports Science \& Coaching, 2(3), 211-216. 